\title{
Article \\ Global-Local Heat Demand Development for the Energy Transition Time Frame Up to 2050
}

\author{
Dominik Keiner ${ }^{1, *}\left(\mathbb{D}\right.$, Larissa D.S.N.S. Barbosa ${ }^{2}$, Dmitrii Bogdanov ${ }^{1} \oplus$, Arman Aghahosseini ${ }^{1}{ }^{1}$,

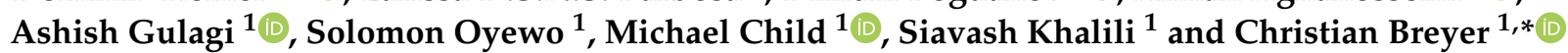 \\ 1 School of Energy Systems, LUT University, Yliopistonkatu 34, 53850 Lappeenranta, Finland; \\ dmitrii.bogdanov@lut.fi (D.B.); arman.aghahosseini@lut.fi (A.A.); ashish.gulagi@lut.fi (A.G.); \\ solomon.oyewo@lut.fi (S.O.); michael.child@lut.fi (M.C.); siavash.khalili.maybodi@lut.fi (S.K.) \\ 2 Luiz De Queiroz College of Agriculture, University of São Paulo, Piracicaba 13418-900, Brazil; \\ larissa.snsb@gmail.com \\ * Correspondence: dominik.keiner@lut.fi (D.K.); christian.breyer@lut.fi (C.B.)
}

check for

updates

Citation: Keiner, D.; Barbosa,

L.D.S.N.S.; Bogdanov, D.;

Aghahosseini, A.; Gulagi, A.; Oyewo,

S.; Child, M.; Khalili, S.; Breyer, C.

Global-Local Heat Demand

Development for the Energy Transition Time Frame Up to 2050. Energies 2021, 14, 3814. https://doi.org/10.3390/ en14133814

Academic Editor: Alessia Arteconi

Received: 29 May 2021

Accepted: 21 June 2021

Published: 24 June 2021

Publisher's Note: MDPI stays neutral with regard to jurisdictional claims in published maps and institutional affiliations.

Copyright: (c) 2021 by the authors. Licensee MDPI, Basel, Switzerland. This article is an open access article distributed under the terms and conditions of the Creative Commons Attribution (CC BY) license (https:/ / creativecommons.org/licenses/by/ $4.0 /)$.

\begin{abstract}
Globally, the heat sector has a major share in energy consumption and carbon emission footprint. To provide reliable mitigation options for space heating, domestic hot water, industrial process heat and biomass for cooking for the energy transition time frame up to the year 2050, energy system modeling relies on a comprehensive and detailed heat demand database in high spatial resolution, which is not available. This study overcomes this hurdle and provides a global heat demand database for the mentioned heat demand types and in a resolution of 145 mesoscale regions up to the year 2050 based on the current heat demand and detailed elaboration of parameters influencing the future heat demand. Additionally, heat demand profiles for 145 mesoscale regions are provided. This research finds the total global heat demand will increase from about $45,400 \mathrm{TWh}_{\text {th }}$ in 2012 up to about 56,600 $\mathrm{TWh}_{\text {th }}$ in 2050. The efficiency measures in buildings lead to a peak of space heating demand in around 2035, strong growth in standards of living leads to a steady rise of domestic hot water consumption, and a positive trend for the worldwide economic development induces a growing demand for industrial process heat, counterbalanced by the efficiency gain in already industrialised countries. For the case of biomass for cooking, a phase-out path until 2050 is presented. Literature research revealed a lack of consensus on future heat demand. This research intends to facilitate a more differentiated discussion on heat demand projections.
\end{abstract}

Keywords: heat; energy demand; industrial process heat; space heating; domestic hot water; energy system modeling; biomass; profiles; energy transition

\section{Introduction}

The global energy system is in a major transition. By signing the Paris Agreement in 2015, almost 200 countries accorded to limit global warming to far below $2.0^{\circ} \mathrm{C}$ and to make efforts for limiting global warming to $1.5^{\circ} \mathrm{C}$ by the end of the 21st century [1]. To achieve this precious goal, all energy sectors have to contribute and finally reach zero greenhouse gas (GHG) emissions. Besides power supply, the use of transportation services, specific industries and seawater desalination, the heat sector plays an important role in the energy consumption of human societies. Space heating, cooling and water heating can, on average, contribute to around $60-70 \%$ of a buildings' total energy consumption [2]. With the ongoing development of emerging countries and the expansion of industrial activities in already industrialised nations, industrial process heat gains relevance in the global energy/heat supply [3]. The transition of the heat sector until 2050, in particular an extensive use of modern and efficient heating technologies, as well as phasing out biomass for cooking, will play a major role in reducing carbon emissions in industry and buildings [4]. 
Heat is the largest end-use energy sector, accounting for $40 \%$ of the global final energy consumption in 2015 [5] and 50\% in 2018 compared to transport (29\%) and power (21\%) [6]. Heat consumption was responsible for $40 \%$ or $13.2 \mathrm{Gt}$ of the global carbon dioxide $\left(\mathrm{CO}_{2}\right)$ emissions in 2018 [6]. While the industrial processes make up half of the total heat consumption, the majority of the other half comes from space heating, as well as water heating, cooking and agriculture [6]. A more detailed breakdown of the heat end-use is available for the European Union (EU), which can be used as a benchmark for industrialised countries with a mild climate. In 2015, the heat and cooling sector represented almost half of the total final energy consumption within the EU $[7,8]$, while space and process cooling contributed on a minor level, while almost all of the heat sector's energy demand is represented by heating processes itself. About three-quarters of this heat demand was still supplied by fossil fuels. Within the heat sector, more than half of the energy demand can be assigned to residential heat consumption, with a major share from space heating, followed by hot water and cooking. About a fifth $(21 \%)$ of the final heat (and cooling) energy consumption can be assigned to industrial activities, meaning the supply of process heat. In the tertiary sector (commercial and public services), mainly space heating is needed besides some hot water and cooking demand.

The share of heat supplied by renewable sources is still not very promising. Globally, about $75 \%$ of almost 160,000 PJ (about 44,450 TWh) in 2015's heat supply was based on fossil fuels [5]. Until 2018, the share of fossil fuels even increased. Only 10.2\% were supplied by renewable energy sources (RES), $12.5 \%$ by the traditional use of biomass, whereas the lion's share of $77 \%$ came from fossil fuels [6]. Therefore, the interest in mitigating the impact of the heat sector on climate change rose the interest in developing new approaches for a sustainable heat supply. On the one hand side, technological solutions are developed, such as high-temperature heat pumps [9] or broader use of solar energy for industrial systems $[10,11]$. On the other hand, using existing technologies in a smarter way, e.g., in smart grids [12], by extensive use of district heating [13,14], or on-site micro sector coupling in residential dwellings [15]. These are just a few examples of pushing the sustainable energy transition in the heat sector. Moreover, pushing towards sustainable cooking does not only increase efficiency but also brings major health benefits and advantages for households in developing countries [16,17].

For comprehensive research on heat sector mitigation options, a comprehensive database of heat demands is needed. A global structuring of the heat demand in both, a high spatial resolution and by types of heat end-use is not yet available. The flagship report of the International Energy Agency (IEA), the World Energy Outlook (WEO), published annually, includes heat in the final consumption of energy carriers such as coal, oil, natural gas, bioenergy and other renewables $[18,19]$. The share of heat by end-use types cannot be obtained from the given data. IEA's online energy balance statistics lack in completeness and comprehensiveness [20]. As an example, for Spain, no heat data are available, even though Spain has a developed industry sector and residents in mountainous regions will have to heat their homes at certain times of the year. The Greenpeace Energy [R]evolution report [21,22] already makes a distinction between the industrial energy sector, other energy sectors and non-energetic use of fossil fuels and specifically excludes electricity. However, the results are represented on a low spatial resolution for 10 major regions globally. Other studies set the course for a high spatial resolution $[23,24]$, but fail to provide comprehensive datasets for further use in techno-economic energy system modeling.

These gaps in the availability of heat demand data show the importance of a comprehensive heat demand database. The present study has the purpose to provide the very same:

- In a high spatial resolution, for 145 regions globally;

- For the whole energy transition time frame from 2020 to 2050 in 5-year steps;

- For different heat demand types, such as industrial heat demand (IHD), domestic hot water demand (DHW), biomass for cooking demand $(\mathrm{BCH})$ and space heat demand (SHD); 
- Including heat demand profiles for IHD, DHW and SHD for 145 mesoscale regions.

Mesoscale regions are defined as the spatial level between major regions spanning several countries and specific local areas. As a novelty, this paper aims to be the first study to describe the global heat demand with respect to the gaps in the availability of a comprehensive heat demand database. The emphasis of this study lies in heating demand. Cooling is not considered in the context of the present paper (cf. Section 5.2). The following sections will deal with a literature review of existing energy system studies and additional major reports and how they handle heat demands. After the literature reviews, the data and methods of the present approach, a visualisation of the results, as well as a discussion and conclusion of the outcome of this study.

\section{Literature Review}

In this section, a short review of the available literature on final energy demand in the global heat sector is provided. Available global $100 \%$ renewable energy studies are covered in full, as well all major global scenarios, covering a broad range of energy transition approaches, as long as minimum criteria for transparency and data resolution were fulfilled. The reporting styles vary across different articles and reports. Some of them focus and differentiate the heat sector by space heating, domestic hot water, industrial process heat and biomass for cooking, while others mix final end-use types and report as residential and industrial sectors, but with not sufficient transparency. Therefore, the final energy demand for electricity and heat cannot be separated anymore. Due to violation of minimum transparency and data resolution, reports of the following institutions had to be excluded: International Renewable Energy Agency, World Energy Council, Exxon Mobil, and BP. It is strongly recommended for the excluded institutions to improve their reporting quality for consideration in research and benchmark studies. Shell [25] is the only fossil fuel company whose reports were detailed enough to be included in the review, while BP and Exxon Mobil did not fulfill the minimum criteria in transparency and data resolution. All scenarios which fulfilled the minimum criteria are listed in Table 1.

Some studies and reports list low temperature and high temperature demand, which were used as an indication for space heating and industrial process heat. Jacobson et al. [26] use an outlier method in reporting annual averaged constant power flows with capacity factors for various demand types and a final mix of direct electricity use and heat pumps. Jacobson et al. [26] is the only considered overnight scenario not describing an energy transition pathway and thus neglecting the most important aspects of steps to be taken while transitioning from the present status to the target status in 2050. Similarly, IEA does not describe transition pathways until 2050 in its flagship report World Energy Outlook [19] for the two main scenario lines and stops reporting in 2040 as the final year. Long-term investments require longer scenario horizons, which is not yet acknowledged by IEA for the two main scenario lines, while all other institutions have overcome such limitations in the recent past and report until 2050. In 2021, the IEA has published a new scenario for netzero emissions in 2050 (NZE2050) [27], which sets more ambitious transition measures as the Sustainable Development Scenario (SDS), that reflects high-efficiency progress leading to less heat demand and a higher overall renewable electricity share in energy supply, which forms the basis for the electricity-based heat supply, which can be estimated for this scenario. In general, the heat pump reporting has to be improved in several scenarios, as it remains partly unclear what is the finally provided heat, what is the required input electricity, or what is the coefficient of performance averaged for the installed heat pump capacity. DNV [28] was included, while the reporting for industrial process heat had been below minimum transparency standards so that its contribution could not be figured out and thus, is not included in the reported numbers. Biomass for cooking demand had been included in all studies except Löffler et al. [29] and Jacobson et al. [26]. Non-energetic energy demand, such as for chemicals, was excluded from all scenarios. The used energy units vary, but all were converted to watt-hours, as the most likely leading metric in this century, due to the perceived strong role of electricity. 


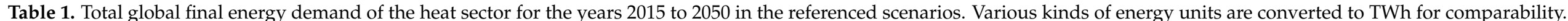

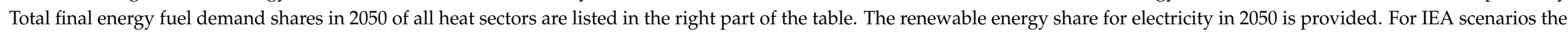
fuel-share values for 2040 are considered.

\begin{tabular}{|c|c|c|c|c|c|c|c|c|c|c|c|c|c|c|c|c|}
\hline $\begin{array}{l}\text { Global Heat } \\
\text { Sector Scenarios }\end{array}$ & & \multicolumn{9}{|c|}{ Final Energy Demand of Heat Sector in TWh/a } & \multicolumn{5}{|c|}{ Final Energy Fuel Shares of Heat Sector in 2050 [\%] } & \multirow[t]{2}{*}{$\begin{array}{c}\text { RE Share in } \\
2050[\%]\end{array}$} \\
\hline Source & Publ. Year & 2015 & 2020 & 2025 & 2030 & 2035 & 2040 & 2045 & 2050 & $\begin{array}{l}\text { Fossil } \\
\text { Fuels }\end{array}$ & Bioenergy & $\begin{array}{c}\text { Synthetic } \\
\text { Fuels }\end{array}$ & Electricity & $\begin{array}{c}\text { Solar } \\
\text { Thermal }\end{array}$ & Geothermal & \\
\hline WWF [32]/Deng et al. [33] & 2011,2012 & 33,452 & 36,140 & 34,286 & 30,561 & 26,410 & 23,074 & 18,684 & 17,848 & 15.0 & 46.0 & 0 & 10.0 & 26.0 & 3.0 & 100 \\
\hline Teske- $2.0^{\circ} \mathrm{C}[34]$ & 2019 & 41,667 & - & 44,444 & 45,556 & - & 43,889 & - & 42,222 & 0 & 22.6 & 8.8 & 24.1 & 18.2 & 26.3 & 100 \\
\hline Teske- $-1.5^{\circ} \mathrm{C}[34]$ & 2019 & 41,667 & & 41,944 & 40,556 & - & 39,722 & - & 40,000 & 0 & 21.1 & 12.5 & 27.5 & 18.3 & 20.6 & 100 \\
\hline Löffler et al. [29] & 2017 & 51,944 & 49,167 & 49,167 & 49,444 & 49,444 & 48,889 & 48,889 & 50,278 & 0 & 46.0 & 13.0 & 39.0 & 2.0 & 0 & 100 \\
\hline Jacobson et al. [26] & 2019 & - & - & - & - & - & - & - & 73,519 & 0 & 0 & 0 & 100 & 0 & 0 & 100 \\
\hline $\begin{array}{l}\text { Bogdanov et al. } \\
\text { [35]/Ram et al }\end{array}$ & 2019,2021 & 38,620 & 40,559 & 42,070 & 44,215 & 46,202 & 48,329 & 50,389 & 52,502 & 0 & 12.0 & 12.0 & 70.0 & 5.0 & 1.0 & 100 \\
\hline DNV [28] & 2019 & 19,097 & 20,139 & 20,658 & 20,833 & 20,936 & 20,556 & 20,139 & 19,444 & 52.5 & 5.5 & 4.0 & 35.8 & 2.2 & 0 & 78.0 \\
\hline IEA-WEO-SDS [19] & 2020 & 47,764 & & 45,380 & 39,682 & - & 35,611 & - & - & 71.6 & 19.3 & 0 & $\mathrm{n} / \mathrm{a}$ & 3.00 & 6.1 & 71.5 \\
\hline IEA-WEO—StPS [19] & 2020 & 47,764 & - & 49,742 & 51,207 & - & 53,731 & - & - & 74.2 & 22.3 & 0 & $\mathrm{n} / \mathrm{a}$ & 1.1 & 2.3 & 46.9 \\
\hline IEA-WEO-NZE2050 [27] & 2021 & - & 264 & - & 758 & - & 642 & - & 360 & 37.9 & 24.5 & 5.2 & 21.3 & 3.7 & 7.5 & 87.6 \\
\hline $\begin{array}{l}\text { IPCC-SR1.5-MESSAGE } \\
\text { v.3-GEA_Eff_1p5C [30] }\end{array}$ & 2018 & - & 50,673 & - & 43,779 & - & 40,775 & - & 37,484 & 60.3 & 39.7 & 0 & $\mathrm{n} / \mathrm{a}$ & $\mathrm{n} / \mathrm{a}$ & $\mathrm{n} / \mathrm{a}$ & 91.6 \\
\hline $\begin{array}{l}\text { IPCC-SR1.5-IMAGE } \\
\text { 3.0.1-IMA15-RenElec [30] } \\
\text { IPCC-SR1.5-REMIND- }\end{array}$ & 2018 & 53,071 & 47,391 & 42,442 & 40,598 & 38,397 & 36,392 & 33,932 & 30,763 & 63.5 & 36 & 0.5 & $\mathrm{n} / \mathrm{a}$ & $\mathrm{n} / \mathrm{a}$ & $\mathrm{n} / \mathrm{a}$ & 71.6 \\
\hline MAgPIE & 2018 & 64,532 & 66,986 & 66,583 & 65,663 & 60,238 & 54,789 & 50,515 & 47,611 & 76.2 & 14.6 & 9.2 & $\mathrm{n} / \mathrm{a}$ & $\mathrm{n} / \mathrm{a}$ & $\mathrm{n} / \mathrm{a}$ & 88.4 \\
\hline $\begin{array}{c}\text { 1.7-3.0-PEP_1p5C_FNZ [30] } \\
\text { Shell-Sky [25] }\end{array}$ & 2018 & 49,656 & 51,272 & 52,278 & 51,061 & 49,308 & 47,228 & 45,444 & 43,656 & 48.6 & 19.5 & 3.4 & 23.8 & 4.6 & 0 & 77.0 \\
\hline
\end{tabular}


The findings are summarised in Table 1 and displayed for the total final energy demand of all global heat demand, summing up space heating, domestic hot water, industrial process heat and biomass for cooking for the projected period from 2015 to 2050. In addition, the fuel shares projected for the heat supply in 2050 are provided as are the renewable energy share of electricity in the year 2050. The limited data resolution of scenarios used in IPCC [30] reports does not allow to differentiate in electricity demand for heat, which may not be that complicated as heat pumps seem to be not activated in the used models, but also solar thermal heat and geothermal heat use is not reported. The same deficit was found in the International Energy Outlook of the US Department of Energy (DoE) [31]. The IEA [19] is also not reporting the role of electricity for heating. Reporting on heat pumps should be improved in scenarios from IEA [19], IPCC [30], and US DoE [31]. Interestingly, IPCC, US DoE and IEA are also the institutions with the highest fossil energy share, which may explain the lower reporting standards for electricity-based and renewable energy-based solutions.

The variation in final energy demand across all studies reported in Table 1 is substantial, ranging from slightly less than 18,000 $\mathrm{TWh}_{\text {th }}$ to slightly more than 73,000 $\mathrm{TWh}_{\text {th }}$ in 2050. More discussion on this aspect is provided in Section 4. There is no structural difference in final energy demand between 100\% renewable energy studies and studies with high fossil fuel shares in 2050, as there are low and high final energy demand cases among the $100 \%$ renewable energy studies, and a comparable range is found for scenarios with higher fossil fuel shares. Interestingly, the relative compound annual growth rates (CAGR) of final energy demand in the global heat sector are almost all negative with values between $-0.1 \%$ and $-1.8 \%$. Only three scenarios show a positive CAGR between $0.1 \%$ and $0.9 \%$, projected by DNV [28], US DoE [31] and Bogdanov et al. [35], which documents that 100\% renewable energy supply and growing heat demand does not have to be in contradiction.

Only four teams were identified who have reported detailed studies for the heat sector without fossil fuels demand in 2050: Löffler et al. [29], Teske et al. [21,22,34], Jacobson et al. [26], and the team of this research [35,36]. Three scenarios, Jacobson et al. [26], DNV [28] and US DoE [31], report bioenergy fuel shares below 10\%, but only Jacobson et al. avoids fossil fuel use. Close to the $10 \%$ bioenergy limit is the scenario of Bogdanov et al. [35] with $12 \%$ and also zero fossil fuels, while they only allow biomass waste, residues and by-products for sustainability reasons. Synthetic fuels, converting renewable electricity to hydrogen or methane is considered in several scenarios, with contribution shares higher than 10\% in Löffler et al. [29], Teske et al. [21,22,34], and Bogdanov et al. [35], which all belong to the group of $100 \%$ renewable energy scenarios. Electricity as an energy carrier is used for heat supply in all scenarios, while IEA [19], IPCC [30] and US DoE [31] do not match minimum reporting standards, so that the electricity shares in these scenarios remain unknown. Only two teams report substantial electricity supply shares of more than $50 \%$, Bogdanov et al. [35] with 70\% and Jacobson et al. [26] with $100 \%$. Using no geothermal heat, no solar thermal heat and no bioenergy for heat is technically possible but may be rather unrealistic for the global heat supply. Two teams, WWF [32]/Deng et al. [33] and Teske et al. [21,22,34], project solar thermal heat supply of around $20 \%$ of total final energy demand. Geothermal heat supply is only considered by Teske et al. [21,22,34] as a considerable resource with values between $13 \%$ and $26 \%$, depending on scenarios. Electricity-based heat supply, either via heat pumps or direct electricity use, is projected to be mainly based on renewable electricity. Only two scenarios, IEA [19] and US DoE [31], project renewable electricity of less than $50 \%$, while about half of all scenarios assume a fully renewable electricity supply in 2050.

The deficits in heat pump inclusion and reporting were mentioned for IEA [19], IPCC [30], and US DoE [31], while WWF [32]/Deng et al. [33] seemed to be the only scenario without district heating consideration. Combined heat and power, however, is not considered/reported in Jacobson et al. [26], DNV [28], and Shell [25].

Summing up, the projected final energy demand in the heat sector deviates strongly across scenarios, while the low CAGR values indicate a rather flat development, indepen- 
dent of the present demand assumptions. Practically all scenarios show methodological deficits in the full inclusion of all relevant technologies, or surprisingly large shares of rather high-cost options indicating improvement potential for cost optimisation. Several scenarios still rely massively on fossil fuels by 2050, which documents a strong violation of the targets of the Paris Agreement.

\section{Data and Methods}

\subsection{General Heat and Input Data}

Reliable, complete and most comprehensive data on heat demands are not easily accessible. The heat statistics of the IEA lacks completeness and comprehensiveness for most of the non-OECD countries and even for a few OECD countries [20]. The most comprehensive database with reliable data is the Greenpeace Energy [R]evolution report [22], published in 2015. This report divides the world into 10 major regions, as is visualised in Figure 1. All data in the report are available in this resolution.

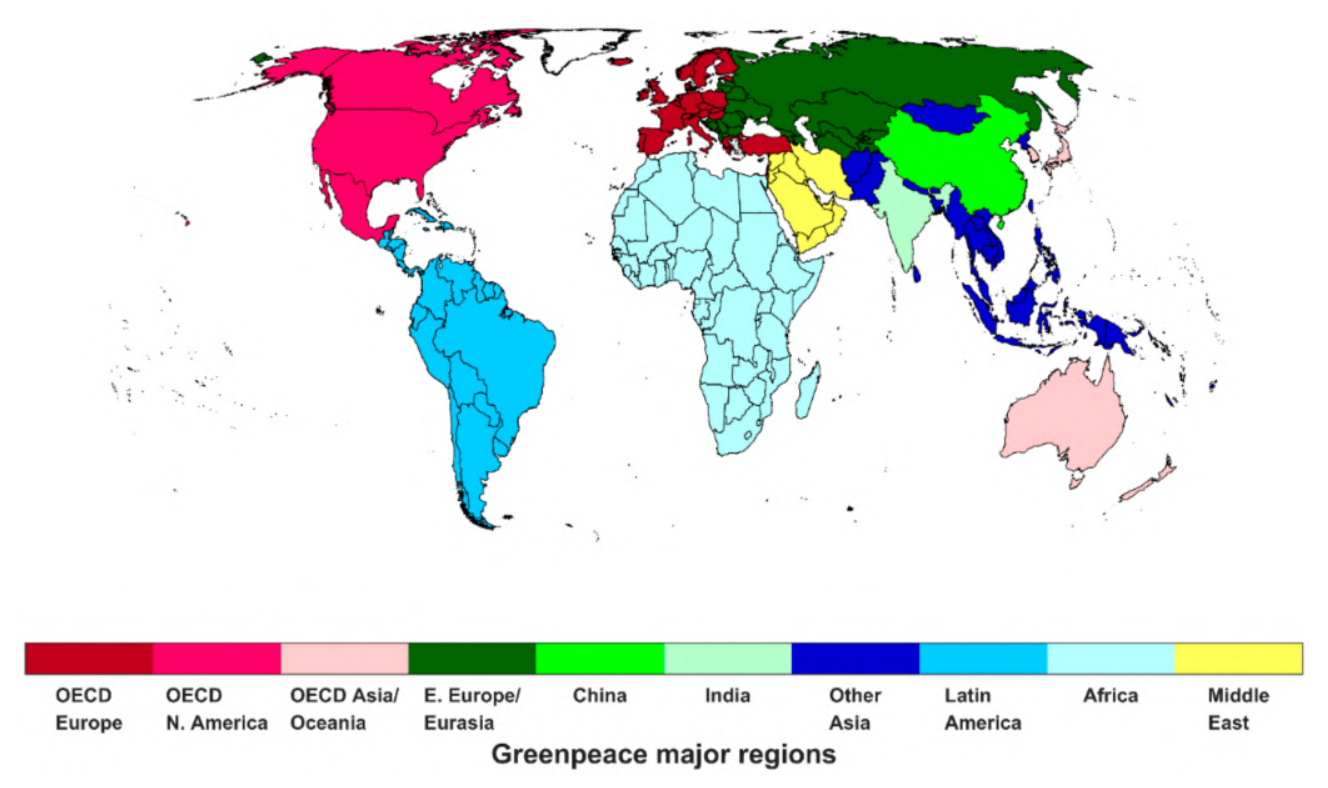

Figure 1. Aggregation of the countries to the Greenpeace major regions per definition as of [22].

Statistical data are given for the year 2012, which shall serve in this article as the base year for the heat demand basis. Numbers are given for the total heat supply for the regions, as well as the final heat demand and the breakdown for different energy sources. Table 2 shows the total final heat demand of the major regions from the Greenpeace report. One advantage of this report is, that the data tables explicitly exclude the non-energy use of (fossil) fuels. Furthermore, it distinguishes between transport, industry and other sectors. Additionally, the industry and other sectors are further partitioned into electricity, public district heat, hard coal and lignite, oil products, gas, solar, biomass, geothermal and hydrogen. Whereas electricity stands for its own, the preparation of the data allows us to assign all the other partitions towards heat utilisation. 
Table 2. Total heat demand and share for industrial heat services for the Greenpeace major regions, global cumulative (total heat demand) and global population-weighted average (share of industrial heat services). Numbers from [22] were converted to TWh.

\begin{tabular}{ccc}
\hline Region & Total Heat Demand [TWh] & $\begin{array}{c}\text { Share of Industrial Heat } \\
\text { Services [\%] }\end{array}$ \\
\hline OECD Europe & 5952 & 36 \\
OECD North America & 5542 & 45 \\
OECD Asia/Oceania & 2104 & 52 \\
East Europe/Eurasia & 4928 & 43 \\
China & 10,811 & 58 \\
India & 3029 & 41 \\
Other Asia & 2876 & 42 \\
Latin America & 2080 & 63 \\
Africa & 2043 & 16 \\
Middle East & 1780 & 64 \\
Global & 41,144 & 43 \\
\hline
\end{tabular}

However, as the numbers are only given for the major regions, a methodology for dividing the total heat demand into a higher spatial resolution is needed. The following subsections describe further input data and the methods for disaggregating the numbers for industrial heat, domestic hot water, biomass for cooking and space heating demand.

One central dataset for the dissemination of the regional heat demands is the gross domestic product (GDP) per capita. Numbers for the year 2012 are available from Toktarova et al. [37] on a country-wise resolution. An overview of the values for 2012 is displayed in Figure A1. Toktarova et al. [37] also provide projections for the GDP per capita for the countries until 2050.

Furthermore, numbers for population statistics were taken from the United Nations [38]. For future projections of the countries' population, the medium-fertility variant is used, which projects the world population to reach 9.74 billion by 2050. Input data, which are used for the respective heat demand type only, are presented in the subsections. All input data for major regions or countries can be found in Supplementary File S1.

\subsection{Determination of Heat Demand Data for the Base Year}

The base year for the heat demand data to be obtained is 2012. The method for the calculation of the heat demand for the four heat demand types consists of four steps, the first two steps can be seen in Figure 2:

1. Calculation of industrial, domestic hot water and biomass for cooking heat demand is based on respective input data. The data basis is the total heat consumption of the major regions as of [22].

2. Calculation of space heating demand is based on the respective input data. The data basis is the interim result for the total heat of "other" sectors and the deduction of domestic hot water and biomass for cooking demands.

3. Fitting trendlines and derivation of future estimations.

4. Dis-/Aggregation of national heat demands from a national scale into 145 mesoscale regions of the LUT Energy System Transition model (LUT model) [35,39]. 


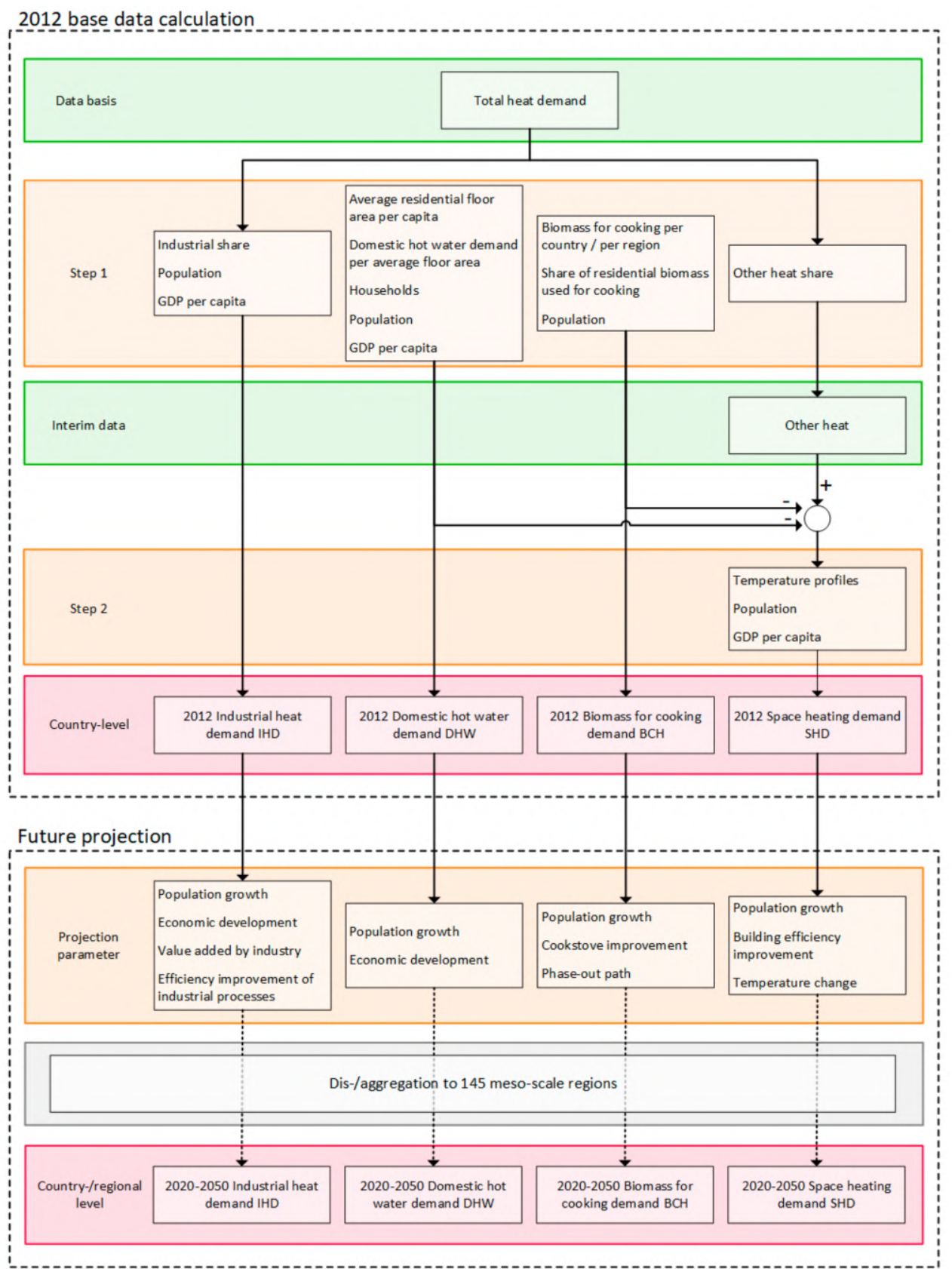

Figure 2. Process flow for the calculation of the heat demand types, based on the respective databases and input data for the two described steps as well as the parameter for the future heat demand projection.

The first two calculation steps take place as follows: Based on the total heat demand of every Greenpeace major region, and the respective share of industrial and other activities, the industrial share and share for other heat services are calculated. With the industrial share, the total heat demand, population data and GDP per capita, the industrial heat demand is calculated as described in Section 3.2.1. The share of other activities and the total heat demand gives the amount of heat of other sectors, which is later used for the calculation of the SHD. This is required since the other heat includes DHW, SHD and cooking heat demand. As electricity and oil-based fuels are listed separately, the included heat for cooking can be traced back to the traditional use of biomass for cooking $(\mathrm{BCH})$.

To determine the total amount of SHD per Greenpeace major region, DHW and BCH are calculated with external input data. For DHW, the average residential floor area per capita, the specific hot water demand per floor area, number of households, population and GDP per capita data are used for the calculation, as described in Section 3.2.2. In the 
case of $\mathrm{BCH}$, the share of people who rely on biomass for cooking, as well as the average energy needed for cooking purposes and total population data are then derived to the $\mathrm{BCH}$ per major region and country (Section 3.2.3). The difference of the total other heat, DHW and $\mathrm{BCH}$ give the total SHD. With respective temperature profiles and population data in high resolution, in addition to GDP per capita, the SHD per country can be estimated (Section 3.2.4).

The method of the first two steps requires comprehensive input data, such as the total heat demand for the major regions, allocation of the population on high detail for all future years to be considered, which are not available as needed. Therefore, for estimating future demands, in the third step, a trendline is fitted either for the relation of the DHW to GDP per capita, or SHD to the average temperature, as described in Figure 2. The development of IHD is estimated according to the value added by the industrial sector. For $\mathrm{BCH}$ a phase-out projection is presented. Details are explained in Section 3.4.

The fourth step then aggregates or disaggregates the heat demands from a national level to the 145 regions of the LUT model. Especially for big countries with several climatic regions and an uneven distribution of population, e.g., Brazil, China, India, Russia, or the United States, it is important to consider various regions and the allocation of respective energy demands. Some smaller countries are aggregate into a larger region in order to represent regions with preferably comparable populations. A description of the 145 mesoscale regions with included countries and spatial definition can be found in Supplementary File S1.

\subsubsection{Industrial Heat Demand}

The industrial heat demand of a country is assumed to be in direct correlation with its economic output [40], represented by the GDP per capita. Therefore, it can be assumed, that the higher the economic output of the country, the higher the industrial heat demand. For each country $c$, the industrial heat demand IHD is calculated by disaggregating the total industrial heat demand of a Greenpeace major region $I H D_{t o t, G P r}$ according to the share of the total GDP of the country:

$$
I H D_{c}=I H D_{t o t, G P r} \cdot \frac{G D P_{t o t, c}}{G D P_{t o t, G P r}} .
$$

The total GDP of a country GDP tot,c is calculated by multiplying the GDP per capita of the country $G D P_{c a p, c}$ with the respective population of the country pop $p_{c}$ and the total GDP of the Greenpeace region $G D P_{t o t, G P r}$ by summing up the total GDP values of all countries $c$ included in the set of countries GPr of each Greenpeace region:

$$
\begin{aligned}
G D P_{\text {tot }, c} & =G D P_{\text {cap }, c} \cdot \text { pop } \\
G D P_{t o t, G P r} & =\sum_{c \in G P r} G D P_{c a p, c} \cdot p o p_{c} .
\end{aligned}
$$

To determine the total industrial heat demand of every Greenpeace region, the share of industrial activities of the total heat demand has to be known. The Greenpeace report delivers detailed numbers for heat sources $S_{h}$, of "industry" and "other" sectors. Both activities include the heat $E_{h}$ from the sources $\operatorname{src}$ public district heat, hard coal and lignite, oil products, gas, solar, biomass, geothermal and hydrogen. The total heat demand also includes electricity for heat supply (electric direct heating) and heat supplied by heat pumps. The heat demand shares of the industry and other sectors may vary due to electricity used for industrial heat processes and heat pumps, which are not explicitly reported. The share of industry sector $p_{\text {ind }}$ and the share of other sectors $p_{\text {other }}$ are calculated as the relation of the sums for heat in industrial and other activities:

$$
p_{\text {ind }}=\frac{E_{h, \text { ind }}}{E_{h, \text { ind }}+E_{h, \text { other }}},
$$




$$
p_{\text {other }}=\frac{E_{h, \text { other }}}{E_{h, \text { ind }}+E_{h, \text { other }}},
$$

where

$$
\begin{aligned}
E_{h, \text { ind }} & =\sum_{s r c \in S_{h}} E_{h, \text { ind,src }} \\
E_{h, \text { other }} & =\sum_{\text {src } \in S_{h}} E_{h, \text { other,src }}
\end{aligned}
$$

Finally, the total industrial heat demand per Greenpeace region can be calculated from the total heat demand $H D_{t o t, G P r}$ of every Greenpeace region:

$$
I H D_{t o t, G P r}=p_{\text {ind }} \cdot H D_{t o t, G P r} .
$$

Similarly, the total other heat demand $O H D_{t o t, G P r}$ of every Greenpeace region can be calculated:

$$
O H D_{\text {tot }, G P r}=p_{\text {other }} \cdot H D_{\text {tot }, G P r},
$$

which is an interim result and serves later as a data basis for the calculation of the space heat demand, as indicated in Figure 2.

\subsubsection{Domestic Hot Water Demand}

In the literature, a strong relation between hot water use and income level was found [41]. With increasing income, the standards of living increase as well as the overall use of water [42,43], and heated water. The average DHW per capita and country $D H W_{c a p, c}$ is described, which can be multiplied with the population of the country $p_{0} p_{c}$ to determine a country's total domestic hot water demand $D H W_{t o t, c}$ :

$$
D H W_{t o t, c}=D H W_{c a p, c} \cdot p o p_{c} .
$$

The average domestic hot water demand itself can be described as a function of standards of living, which in turn can be expressed as the product of the country-specific available residential floor area RFA per capita and the country-specific DHW per capita and floor area $D H W_{c a p, r f a, c}$ :

$$
D H W_{c a p, c}=D H W_{c a p, r f a, c} \cdot R F A_{c a p, c},
$$

where

$$
D H W_{c a p, r f a, c}=\frac{D H W_{r f a, I P P C r}}{p p h_{c}},
$$

where $D H W_{r f a, I P P C r}$ is the specific DHW per floor area of a major region per definition of the International Panel on Climate Change (IPCC) and $p p h_{c}$ is the average number of people per household in a country.

To determine the specific DHW, data for hot water demands are needed in the best possible regional resolution, as the use of heated water depends on temperature, income, and cultural background. Additionally, the average number of people per household sharing each residential square metre is needed. In [44], specific heat demands for hot water in relation to residential floor areas are available for the 11 major regions as defined by IIASA [45] and adopted by the IPCC. An overview of the regions is shown in Appendix A in Figure A2. The respective specific DHW numbers are listed in Table 3. 
Table 3. Floor area-specific domestic hot water demands for the IPCC regions for the year 2010. Numbers are from [44].

\begin{tabular}{ccc}
\hline Region Short & Region Long & HWW $_{r f a, I P P C r}\left[\mathbf{k W h} / \mathbf{m}^{\mathbf{2}}\right]$ \\
\hline AFR & Sub-Saharan Africa & 36.6 \\
CPA & Centrally planned Asia and China & 36.4 \\
EEU & Central and Eastern Europe & 32 \\
FSU & Former Soviet Union & 80.2 \\
LAC & Latin America and the Caribbean & 46.4 \\
MEA & Middle East and North Africa & 40 \\
NAM & North America & 17.5 \\
PAO & Pacific OECD & 12.9 \\
PAS & Other Pacific Asia & 9.9 \\
SAS & South Asia & 24 \\
WEU & Western Europe & 18.6 \\
\hline
\end{tabular}

To get the average number of persons, who share each square metre of floor area in a residential dwelling, the total numbers of households are used from [46]. However, household data in general, as well as matching data for 2012, are very scarce. Therefore, the people per household $p p h$ for countries without available data are obtained via fitting a trendline to existing data. To minimise the error margin, only countries with available data between 2008 and 2017 are considered as given data. It is assumed, that the changes within a time span of $2012 \pm 5$ years are not significant. The average persons per household follow an exponential decline with regard to the GDP per capita. The relation can be expressed with the function

$$
p p h_{c}=\lambda_{1} \cdot \mathrm{e}^{\left(-\lambda_{2} \cdot G D P_{c a p}\right)}+\lambda_{3}
$$

where $\lambda_{1}$ and $\lambda_{2}$ are shape parameters of the exponential function and $\lambda_{3}$ is an offset parameter. A visualisation of this relation can be found in Appendix A in Figure A3.

The offset is set manually to $2.1 \mathrm{pph}$ in order to avoid function values below the threshold for high-income countries, as it is unlikely, that even in high-income industrialised countries, less than two persons will live in one household on average. As the total number of available data is not very high, two high-income countries are considered as statistical outliers: Saudi Arabia and Brunei Darussalam. They are not considered for fitting on the trendline. Including those two countries, the trendline would show an additional offset within the GDP per capita range, resulting in a value of almost three for high-income countries as of 2012. This would be unrealistically high, considering available data for already highly developed countries globally. In addition, Qatar is excluded from the countries considered with the given data. Available data for Qatar would result in 12 people per household at a GDP per capita of almost 100,000 EUR/cap. It is assumed, that this is due to incorrect data.

For further calculation, all countries with available data -72 in total-are considered with their respective value, the other countries are calculated according to the trendline function. Figure 3 shows the results of the $p p h$ calculation, including the given data based on 2012 data. 


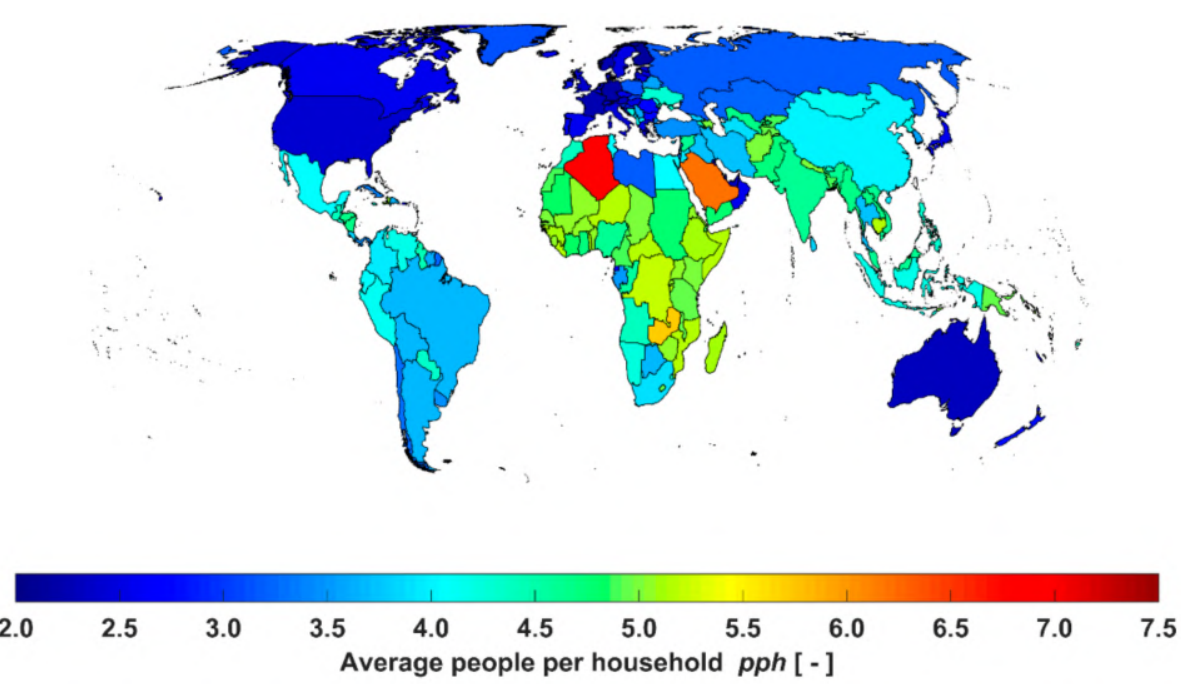

Figure 3. Average people per household globally, based on 2012 GDP per capita and total number of household data.

According to [24], the residential floor area per capita increases with GDP per capita:

$$
R F A_{\text {cap }, c}=6.33 \cdot \ln \left(G D P_{\text {cap },} \cdot 1.33 \cdot 0.68\right)-28.95
$$

The GDP per capita data has to be adjusted for the requirements of Equation (11). Firstly, the value is multiplied with the long-term conversion factor of 1.33 USD/EUR, as applied in [37], for the reconversion of the values to USD, for which Equation (11) was developed. Secondly, a factor of 0.68 for the inflation from 1995 to 2011 is applied, as the formula in [24] refers to 1995 values. This factor is calculated by using an online inflation calculator [47].

\subsubsection{Biomass for Cooking Demand}

Mostly in developing countries and especially in their rural areas, biomass is still a necessity for people to prepare their daily food [48]. In some developing countries, biomass for cooking can meet over 90\% of household energy needs [49]. Despite the urgency of reducing biomass for cooking due to health and environmental reasons [50], the availability of data for biomass used for cooking is particularly poor [51]. One reason is the scarce reporting of data, especially from developing countries [52]. In the context of this paper, if no data for the year 2012 are available, the data for the closest available year are used.

In the case of biomass for cooking demand, different approaches for different regions were chosen, depending on the availability and quality of data and the reasons for biomass use. The provided data for biomass in [22] are not sufficient, as the share of residential and industrial use is not available. The distinguished and relevant regions are Central and South America, Africa (including North Africa), South Asia, Southeast Asia (including Oceania) and Northeast Asia. A vast number of people in these areas are still depending on biomass as an energy source, especially for cooking. In the following, the sources of available data on biomass for cooking purposes and respective calculation methods are explained. A detailed listing of the country with given and calculated numbers, as well as the specific source of given numbers, can be found in Supplementary File S1.

For Africa, South Asia and Southeast Asia it can be assumed, that practically all of the residential biofuels (solid biomass) are used for cooking, as space heating is basically obsolete due to climatic conditions. In the case of Africa, comprehensive data of people relying on biomass for cooking are available in [18]. For many countries, the IEA energy balances [20] provide residential biofuel use. Additionally, the total residential biofuel use of the whole African region is available [20]. The share of biomass for countries without specific data is calculated from the difference of the total biomass demand of 
Africa $B C H_{\text {Africa }}$ and the sum of the available biomass for cooking demands $B C H_{C}$ for all the countries with available data of Africa $A_{a v}$, which is then distributed according to the share of total people relying on biomass for cooking:

$$
B C H_{c, \text { Africa }}=\left(B C H_{\text {Africa }}-\sum_{c \in A_{a v}} B C H_{c}\right) \cdot \frac{p o p_{c} \cdot p_{r e l, b i o, c}}{\sum_{c \in A}\left(p o p_{c} \cdot p_{r e l, b i o, c}\right)},
$$

where $\operatorname{pop}_{c}$ is the population of the country, $p_{\text {rel, }, b i o, c}$ is the share of people relying on biomass for cooking in specific a country and $A$ is the country set of all African countries including North Africa.

In the case of South Asia and Southeast Asia, data of people relying on biomass for cooking in [18] are not comprehensive, e.g., a few countries are cumulated as "other developing Asia". Furthermore, the total numbers in [20] do not match the regional resolution. Therefore, for countries without data in [20], numbers for residential biomass use from [53,54] are used. For India, domestic biomass numbers are available from [55].

Only three countries have relevant biomass for cooking consumption in the Northeast Asia region: China, the People's Republic of Korea and Mongolia. Chinese data are taken from [56], and for Mongolia from [57]. For the latter, data are given in cubic metre per household. With the average number of persons per household, an estimation can be made for the total biomass use for cooking. An energy density of $2000 \mathrm{kWh} / \mathrm{m}^{3}$ was assumed as an average for air dry and oven dry wood [58]. Data for the People's Republic of Korea are usually not available, tough in [59], data for domestic biofuels for the year 2000 are given. Without a considerable economic development and increase in electricity consumption until 2010 [59], the given value is assumed to be the same for 2012.

For some countries in Central and South America, specific numbers for residential biomass use are available. Values for Guatemala, Honduras and Nicaragua are given in [60]. Numbers for Mexico are given in [61,62], of which the average value is taken into account. For Bolivia, numbers are given in [63], for Brazil in [64], for Chile in [65] and for Guyana in [66]. In the case of Colombia, the total cooking energy demand is given in [67]. With the given numbers for the rural and urban population in Colombia, the share of rural population $p_{\text {pop, rural,co }}$ can be calculated to $25 \%$. In Colombia, the fuel mix for cooking indicates that around 2010, the biomass use of the urban population is negligible, whereas the share of biomass in the rural cooking fuel mix $p_{b i o, r u r a l, c o}$ is about $20 \%$. The total biomass used for cooking

$$
B C H_{c o}=C H_{t o t, c o} \cdot p_{\text {pop }, \text { rural }, c o} \cdot p_{\text {bio }, \text { rural }, c o}
$$

is the product of the total heat demand for cooking $\mathrm{CH}_{t o t, c o}$ in Colombia and the two shares for rural population and biomass as cooking fuel. For all the other Central and South American countries, residential firewood numbers are taken from [68]. One exception is French Guyana, for which no data are available in the database, so the number from [54] is taken.

In Central and South America, one problem is that residential biomass is not only used for cooking and space heating but serves other purposes such as, e.g., for the drying of clothes, illumination, toasting coffee, heating the iron or even to keep insects away [69]. The ratio of biomass used for cooking purposes and space heating for Uruguay can be calculated with numbers from [70]. For both Argentina and Chile the ratio can be obtained from [71]. For countries with a high average temperature and tropic climates, it is assumed that $80 \%$ of the residential biomass is used for cooking. A relation can be obtained for the share of residential biomass which is used for cooking and the (long-term) average temperature. For Mexico with a slightly less average temperature than Brazil, the biomass used for cooking purposes is estimated to be $75 \%$.

It can be assumed, that the main purpose of residential biomass use switches from cooking to heating if the average temperature is below the heating limit of $18{ }^{\circ} \mathrm{C}$. The whole correlation can be expressed with a logistic curve, whereas the parameters are chosen to have an upper limit of $80 \%$ and a lower limit of $5 \%$, which is the value derived for Uruguay. With this function, it is possible to estimate the share of biomass used for cooking. 
This approach is visualised in Figure A4 in Appendix A. As already mentioned, the data source for Colombia already uses values for cooking only, so the value for Colombia is not calculated with this relation.

As the numbers in [22] state the consumption or rather the end-use energy, but biomass for cooking is final energy, the actual heat for cooking supplied by biomass $\mathrm{CH}_{\text {bio }}$ has to be calculated by multiplying the biomass used for cooking with the efficiency of the cookstove $\eta_{c s}$ :

$$
\mathrm{CH}_{b i o, c}=B C H_{c} \cdot \eta_{c s}
$$

Conversion efficiencies for traditional biomass cookstoves are given in [72] with $<15 \%$ for standard, traditional cookstoves (TCS) and $12-35 \%$ for improved cookstoves (ICS). Getting the right end-use energy demands the share of TCS and ICS, which is given for 2012 on a regional basis in [73]. An overview of the available data is given in Table 4.

Table 4. Share of TCS and ICS in total cookstove mix, share of TCS and ICS in traditional biomass cookstoves (TBMC) and average cookstove efficiency per given region. Shares in total cookstove mix are taken from [73].

\begin{tabular}{|c|c|c|c|c|c|}
\hline Region & Share TCS * in Total & Share ICS ${ }^{* *}$ in Total & Share TCS in TBMC & Share ICS in TBMC & $\eta_{c s}$ \\
\hline $\begin{array}{l}\text { Latin America and } \\
\text { the Caribbean }\end{array}$ & $17 \%$ & $1 \%$ & $94.0 \%$ & $6.0 \%$ & $13.0 \%$ \\
\hline $\begin{array}{c}\text { Sub-Saharan } \\
\text { Africa }\end{array}$ & $74 \%$ & $8 \%$ & $90.2 \%$ & $9.8 \%$ & $13.8 \%$ \\
\hline South Asia & $61 \%$ & $7 \%$ & $90.0 \%$ & $10.0 \%$ & $13.8 \%$ \\
\hline East Asia & $9 \%$ & $38 \%$ & $19.1 \%$ & $80.9 \%$ & $26.6 \%$ \\
\hline Southeast Asia & $49 \%$ & $3 \%$ & 94.2 & $5.8 \%$ & $13.0 \%$ \\
\hline
\end{tabular}

* Including minimally improved chimney stoves. ${ }^{* *}$ Including advanced cookstoves.

\subsubsection{Space Heating Demand}

In case of the space heat demand, it is important to pay attention to the special distribution of both population and temperature. Average values are not sufficient. If most of the population of a country lives in an area with temperatures above the countries' average, the space heat demand would be represented distortedly. However, the first step for the space heat demand calculation is to obtain the total space heat demand $S H D$ for every Greenpeace region via

$$
S H D_{t o t, G P r}=O H D_{t o t, G P r}-\sum_{c \in G P r} D H W_{t o t, c}-\sum_{c \in G P r} C H_{b i o, t o t, c}
$$

where the sum of the domestic hot water and cooking heat supplied by biomass of all countries included in the country set GPr of each Greenpeace major region is subtracted from the total other heat demand of the respective Greenpeace region.

The interrelation of population and temperature is expressed with the heat degree hours $H D H$. The relation of a countries' adjusted heat degree hours $H D H^{\prime}$ and the sum of the heat degree hours of a Greenpeace major region is used to disaggregate the total space heating demand of a Greenpeace major region into the country values:

$$
S H D_{t o t, c}=S H D_{t o t, G P r} \cdot \frac{H D H_{\Sigma, c}^{\prime}}{H D H_{\Sigma, G P r}},
$$

with the adjusted heat degree hours of a country

$$
H D H_{\Sigma, c}^{\prime}=H D H_{\Sigma, c} \cdot\left(\frac{G D P_{c a p, c}}{G D P_{c a p, G P r, m i n}}\right)^{0.1}
$$


and the heat degree hours of a Greenpeace major region:

$$
H D H_{\Sigma, G P r}=\sum_{c \in G P r} H D H_{\Sigma, c}^{\prime} .
$$

The adjustment of the heat degree hours of a country with the relation of the countries' GDP per capita and the minimum GDP per capita of the respective Greenpeace major region enables the introduction of a higher standard of living into the calculation. As it was shown by [24], floor space, and therefore standard of living increase with increasing GDP per capita. However, a higher GDP per capita could also initiate a higher renovation rate and a trend towards higher building standards with a less area-specific heat demand [44]. A higher GDP per capita entails more commercial floor space to be heated. It is hereby difficult to find a specific relationship for the actual influence of the economic performance of a country on the space heat demand. For this reason, the presented relation is set to the power of 0.1 for roughly factoring in this effect, as besides the GDP, further aspects are of relevance.

The basis for the adjusted heat degree hours is the heat degree hours for each country. Here, the allocation of the population within a country plays a major role, which is why the calculation of the heat degree hours takes place considering the globe in a $0.045^{\circ} \times 0.045^{\circ}$ or $4000 \times 8000$ nodes resolution. Taking the average temperature of a country as the relevant parameter for calculating the total heat demand is not sufficient. For distributing the heat demand of the major regions to a country level, it is important to consider the need for space heating only for the areas where people actually live, based on the respective temperature characteristics of the same areas.

The calculation of the heat degree hours of every country takes place as described in Equation (19). Two databases are used in the above-mentioned resolution: The population and temperature, whereas the latter contains an 8760-h profile for every node. Temperature data are based on global weather data for the year 2005 from NASA [74,75].

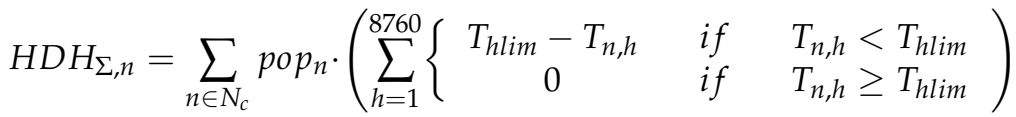

For every country $c$, a set of nodes $N_{c}$ can be assigned. For every node of the set, all hours of the temperature profile are checked whether the temperature $T_{n, h}$ of the node and hour is below the heating limit $T_{\text {hlim }}$. If yes, the heat degree hour is calculated as the difference between the heating limit and the temperature of the respective hour. The heating limit is set to $291.15 \mathrm{~K}\left(18^{\circ} \mathrm{C}\right)$, as applied in [24]. If the temperature exceeds the heating limit, the value is set to 0 . For all hours of the year, the heat degree hours are summed up and multiplied with the respective population of the node $\operatorname{pop}_{n}$. The sum of the population-dependent heat degree hours for all nodes in the node-set finally provides the full population-dependent heat degree hours of the country. Spatial distribution of population globally in 2012 is available from [76]. The map is adapted to match the needed side ratio and reshaped to match the needed resolution.

An important parameter is the share of the residential segment of the SHD, as residential space heating is one of the major heat sinks. The share of residential SHD for the ten Greenpeace major regions can be obtained from [22]. As it can be seen in Figure A5 in Appendix A, a clear dependency on GDP per capita is noticeable. The share of residential space heating $p_{\text {res,SHD }}$ can be estimated with a function of the form

$$
p_{\text {res }, \text { SHD }}=0.598+\lambda_{1} \cdot \mathrm{e}^{\left(-\lambda_{2} \cdot G D P_{c a p}\right)}
$$

where $\lambda_{1}$ and $\lambda_{2}$ are form parameters. The limitation of $59.8 \%$ is the population-weighted average of the OECD regions. Furthermore, due to the few available data points, the fit does not perfectly match the value of $100 \%$ for a GDP per capita equal to $0 \mathrm{EUR} / \mathrm{cap}$. For 
countries with a very low GDP per capita, values slightly above $100 \%$ are possible, which are limited to $100 \%$.

\subsection{Projection of Future Demands}

After a database for 2012 was built, the projection for future demands was made. Using the 2012 data as the starting point, the estimation is based on parameters, as explained in the following. All future estimations are made on a per capita scale to describe general relations. The effect of population development is considered by multiplying the final per capita values with the respective population.

\subsubsection{Projection of Industrial Heat Demand}

On one hand, the IHD can be directly linked to the economic performance of a country expressed by its GDP per capita. On the other hand, industrial activities do not solely cause the economic value added. The other two sectors are agriculture and service. The respective value added by industrial activities (VAI) as a share of the total value added is therefore one corresponding parameter on which the projection of the IHD has to be based. In addition, efficiency measures have to be considered. Assuming an ongoing shift towards the introduction of new and more efficient processes and heat utilisation in industry, a decoupling of increasing industry productivity and heat demand can be achieved.

A comprehensive dataset of the VAI is available from [77]. An estimation of the development of the VAI is possible, using the general trend for the development of the VAI regarding the economic situation of the country, expressed by the GDP per capita. For this projection, the latest available values of each country for the VAI and the respective GDP per capita are used. As the data are relatively widespread, a general trend is created by dividing the data into five income groups. The intervals for the income groups are chosen on a logarithmic scale, as the countries are unevenly distributed over the whole GDP per capita range. Figure 4 shows the five income groups and the trendline function as described by Equation (21)

$$
\operatorname{VAI}\left(G D P_{c a p}\right)=\lambda_{1} \cdot \mathrm{e}^{\lambda_{2} \cdot G D P_{\text {cap }}}+\lambda_{3} \cdot \mathrm{e}^{\lambda_{4} \cdot G D P_{\text {cap }}}
$$

and the parameters $\lambda_{1}, \lambda_{2}, \lambda_{3}$ and $\lambda_{4}$ for the fitting function. For the trendline fit only the average values for the VAI and GDP per capita are used, as the data for all countries due to their diversity would not allow a general trend fitting according to the usual trend of countries within the process of industrialisation [78].

As shown in Figure 4, the VAI first increases for GDP per capita up to about EUR 20,000 and then starts to decrease again. The reasons for this are manifold [78], though the most important reason is the fact that in the process of industrialisation, the agriculture sector which is one of the most important sectors loses its importance, whereas the industry and service sectors are growing. Once a country is industrialised, only the service sector shows a relevant increase [78]. 


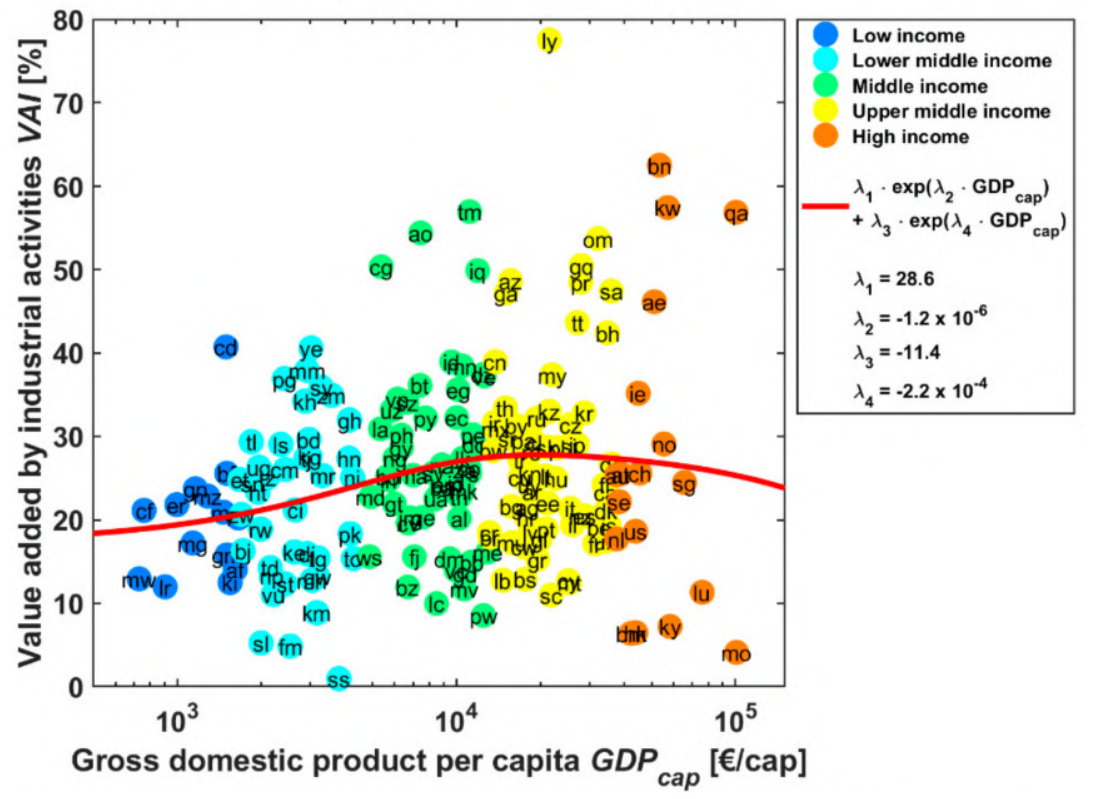

Figure 4. Available data for value added by industrial sector, coloured by the five income groups and the respective trendline. The countries with available data are labeled with their internet domain.

For each country, the future VAI is estimated by approximating the trendline function. As it was shown in [78], the structural shift is a lengthy process. Therefore, it is assumed that all countries finally approximately match the trendline by the year 2100 . The actual VAI is calculated by weighting the trendline and the trendline plus the initial offset

$$
\begin{gathered}
V A I_{c}(y)=\begin{array}{c}
w_{T L, V A I}(y) \cdot V A I\left(G D P_{c a p, c, y}\right)+\left(1-w_{T L, V A I}(y)\right) \\
\left.\cdot V A I\left(G D P_{c a p, c, y}\right)+\left(V A I_{c, 2019}-\operatorname{VAI}\left(G D P_{c a p, c, 2019}\right)\right)\right]
\end{array}
\end{gathered}
$$

where $G D P_{c a p, c, y}$ is the respective GDP per capita of the country and the year, $V A I_{c, y, 2019}$ is the initial value as plotted in Figure 4 and GDP ${ }_{c a p, c, 2019}$ is the GDP per capita of 2019 of each country, respectively. The weight of the trendline $w_{T L, V A I}$ is described by a linear function in the form

$$
w_{T L, V A I}(y)=\frac{y-2012}{2050-2012}
$$

to ensure a smooth approximation towards the trendline. For countries without available VAI data, the VAI is directly calculated with the trendline function.

Respective data for efficiency measures on a country basis are not available. Here, a threshold from the EU member states shall be used. In the 1990s, the EU showed an average 2.6\%/year efficiency improvement [79]. Assuming a global orientation towards broadening efficiency measures and policies supporting this development on the way to a carbon-neutral future in 2050, a strong efficiency improvement for industry $\varepsilon_{I N D}$ of $3 \% /$ year is used in this context. This also correlates with a $2.9 \% /$ year improvement, which will be necessary to reach the sustainable development goal (SDG) 7 [80].

Finally, the IHD can be calculated. This is made in two different ways, depending on the status of development of a country. For developing and emerging countries ramping up the industrial sector, the energy efficiency in industry is basically U-shaped, which means that with increasing GDP per capita, the efficiency first decreases and then increases again [81]. To represent this effect, it is considered, that the IHD per capita increases directly according to the GDP per capita until it reaches 17,500 EUR/cap, which is about where the maximum VAI occurs. Up to that point, the industrial efficiency improvement is assumed to increase linearly to reach 3\%/year at the GDP per capita limit. Afterward, the IHD per capita increases according to the relative increase in the GDP per capita, however, the absolute increase is counterbalanced by the relative decrease in the VAI and the full 
industrial efficiency improvement $\varepsilon_{I N D}$. For $G D P_{c a p, c, y} \leq 17,500 \mathrm{EUR} /$ cap Equation (24) is applied:

$$
I H D_{c a p, c}(y)=I H D_{c a p, c, y-\Delta t} \cdot \frac{G D P_{c a p, c, y}}{G D P_{c a p, c, y-\Delta t}} \cdot\left(1-\varepsilon_{I N D, l i n}\left(G D P_{c a p, c, y}\right)\right)^{\Delta t}
$$

with

$$
\varepsilon_{I N D, l i n}\left(G D P_{c a p, c, y}\right)=3 \cdot 10^{-6} \cdot G D P_{c a p, c, y}
$$

For $G D P_{c a p, c, y}>17,500 € /$ cap Equation (26) is applied:

$$
I H D_{c a p, c}(y)=I H D_{c a p, c, y} \cdot \frac{G D P_{c a p, c, y} \cdot V A I_{c, y}}{G D P_{c a p, c, y-\Delta t} \cdot V A I_{c, y-\Delta t}} \cdot \eta_{I E}
$$

with

$$
\eta_{I E}=\left(1-\varepsilon_{I N D}\right)^{\Delta t}
$$

where $\Delta t$ gives the number of years between the last time step and the regarded year and $\varepsilon_{I N D}$ is the annual efficiency improvement. The total IHD is then calculated by multiplication with the respective population per year and country.

\subsubsection{Projection of Domestic Hot Water Demand}

The consumption of DHW is basically dependent on the standards of living and the involved availability of clean and hot water, which means it can be described by a relation with the GDP per capita. However, at a certain level of standards of living, the DHW per capita does not increase anymore, as the use of hot water per person for taking showers/baths, etc. has its limits. For the 2012 results of the DHW on a per capita base, a trendline in the form of a Gompertz curve is used:

$$
D H W_{c a p}\left(G D P_{c a p}\right)=\lambda_{1} \cdot \exp \left(\lambda_{2} \cdot \exp \left(\lambda_{3} \cdot G D P_{c a p}\right)\right) .
$$

Future DHW per capita values are then estimated, similarly to the estimation of the future VAI, by weighting the trendline and the trendline minus the initial offset for the values to approximate the trendline function:

$$
\begin{aligned}
& D H W_{c a p, c}(y)=w_{T L, D H W}(y) \cdot D H W_{c a p}\left(G D P_{c a p, c, y}\right)+\left(1-w_{T L, D H W}(y)\right) \\
& \cdot\left[D H W_{c a p}\left(G D P_{c a p, c, y}\right)+\left(D H W c a p_{c, 2012}-D H W_{c a p}\left(G D P_{c a p, c, 2012}\right)\right)\right]
\end{aligned}
$$

The weight of the trendline $w_{T L, D H W}$ has a linear character:

$$
w_{T L, D H W}(y)=\frac{y-2012}{2050-2012}
$$

It is assumed, that all countries approximate the trendline function in 2050. The total DHW is then calculated by multiplication with the population per year and country.

\subsubsection{Biomass for Cooking Phase-Out Path}

The factors affecting a household's cooking fuel choice are manifold, including several socio-economic, behavioural, cultural and other external factors [82]. As a consequence, the projection of the biomass for cooking demand cannot be linked easily to GDP per capita or another parameter. Besides the climate impacts of burning more biomass than can be regrown, the health impacts of which mostly women and children are affected, are significant [83]. Phasing out the traditional use of biomass, especially to avoid indoor pollution, but also for maintaining forests sustainably, is therefore a necessity and has to be completed within the energy transition time frame until 2050.

The phase-out of end-use cooking energy from biomass per capita $\mathrm{CH}_{c a p, b i o}$ is modeled by defining a phase-out function $\xi(y)$, which shall express the amount of $C H_{c a p, b i o}$ left relative to the previous time step. With each time step, the relative remainder shall be less 
than for the previous time step. This gives the phase-out of the $\mathrm{CH}_{\text {cap bio }}$ the character of a sigmoid curve. Compared to conventional sigmoidal functions such as the Gompertz or logistic function, this approach distributes the phase-out over the whole transition period more equally, whereas with common logistic curves most of the phase-out would already be completed around 2040. The $\mathrm{CH}_{\text {cap, bio }}$ is calculated relative to its previous value according to Equation (31)

$$
C H_{c a p, b i o}(y)=C H_{c a p, b i o}(y-\Delta t) \cdot \xi(y)
$$

with the phase-out function described as a polynomial of second degree:

$$
\xi(y)=\lambda_{1} \cdot y^{2}+\lambda_{2} \cdot y+\lambda_{3}
$$

where $\lambda_{1}=-6.822, \lambda_{2}=2.745$ and $\lambda_{3}=-2760.06$. The advantages of the proposed phaseout approach are:

- Delayed ramp-up of the biomass-based cooking between 2012 and 2020, so the total $\mathrm{CH}_{\text {bio }}$ even increases in the first years of the studied time period in countries with strong population growth. This phenomenon can be observed especially in subSaharan Africa in recent years;

- Long and almost linear phase-out period;

- After $\xi(t)$ becomes less than 0.5, a turning point is created to follow the shape of a logistic curve;

- Compared to default sigmoid curves such as the Gompertz or the logistic function, this adjusted function approaches the value 0 in 2050 more steeply instead of reaching very low values already before 2045.

In Figure $5 \mathrm{a}$, the phase-out function $\xi(t)$ and the phase-out path of a normalised example with the starting value of 1 in 2012 is shown.
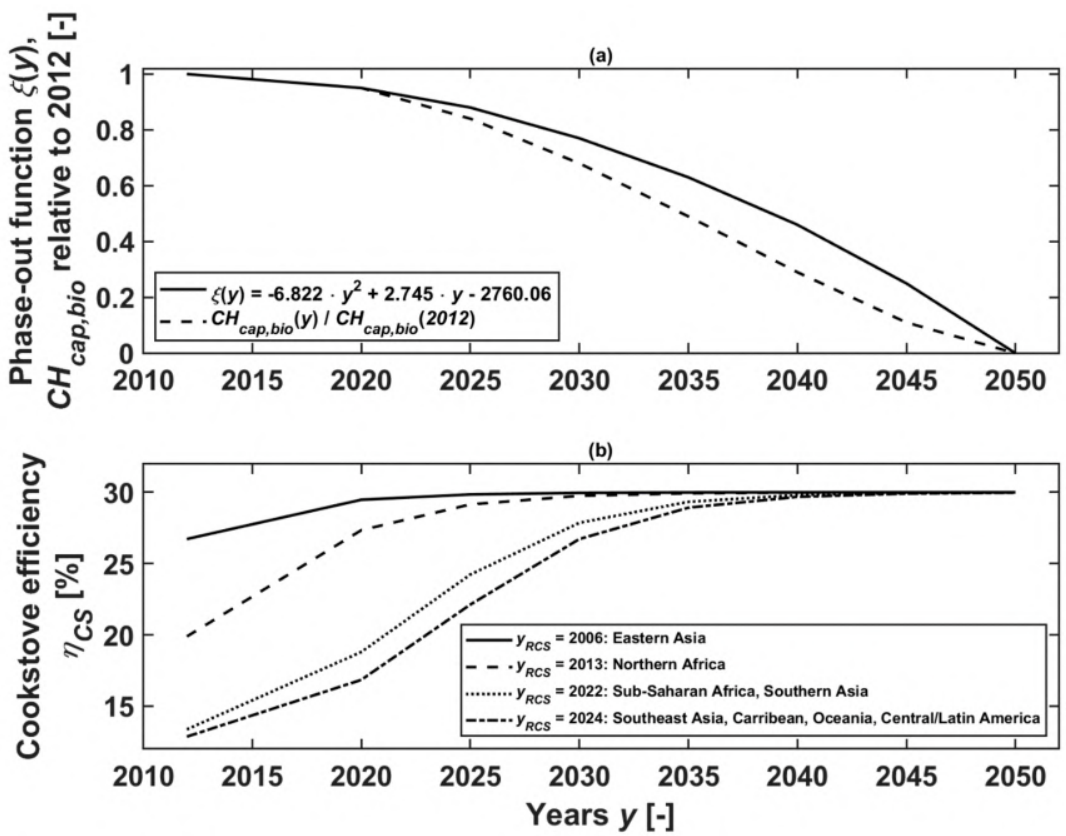

Figure 5. Functions for the phase-out of biomass-based cooking and phase-in of ICSs: (a) Phase-out function polynomial $\xi(y)$ and biomass-base end-use heat for cooking based on biomass relative to 2012; (b) Functions for describing the cookstove efficiency for the cookstove regions.

Based on the per capita phase-out path, the actual biomass input for cooking is calculated with respect to the average cookstove efficiency. For this, it is assumed that ICSs are introduced relatively fast. A worst-case would be if the average cookstove efficiency 
would be at the lowest possible value of $12 \%$ in 2012 and ICSs would be phased in until 2050 to reach an average cookstove efficiency of $30 \%$ in 2050 . The basic function for $\eta_{C S}$ over time for the different cookstove efficiency regions RCS as defined in Table 3 is described in Equation (33)

$$
\eta_{C S, R C S}(y)=0.12+\frac{0.3-0.12}{1+\mathrm{e}^{-0.25 \cdot\left(y-y_{R C S}\right)}}
$$

This basic function is shifted along the $x$-axis by assigning every region a different turning point $y_{\text {Reg }}$, which is set for the above function to match the cookstove efficiency values in 2012 as given in Table 3. The resulting phase-in function for the different regions is shown in Figure $5 b$.

Finally, the BCH of every country $c$ as part of a cookstove efficiency region $R C S$ can be calculated as:

$$
B C H_{c a p, c, b i o}(y)=\frac{C H_{c a p, c, b i o}(y)}{\eta_{C S, R C S}(y)} .
$$

Cooking heat demand, which is not supplied by biomass anymore, is assumed to be provided by electricity and therefore, falls out of the scope of this study. The total BCH is then calculated by multiplication with the respective population per year and country.

\subsubsection{Projection of Space Heating Demand}

Two factors are considered to influence the demand for space heating: Progress in the energy efficiency of the building stock and change of temperature due to climate change. For energy efficiency in terms of relative energy savings per year no comprehensive data are available on a country scale. Only for the EU, a long-term value of $0.7 \%$ /year energy efficiency improvement for space heating due to building refurbishment and new buildings is available [79]. This value shall serve as a global average value for active policies in line with the Paris Agreement. For the impact of changing temperatures, temperature data on a country-scale as of the IPCC Fourth Assessment Report (AR4) [84] are provided by the World Bank's Climate Data API [85]. As a reference, the time period 1980-1999 is chosen (and 1990 as reference year), for the future the time period 2040-2059 shall represent the 2050 value. The IPCC AR4 scenario B1 is used.

Firstly, the temperature values from 2012 to 2050 are estimated by linear interpolation. Secondly, the respective SHD values are sorted according to the average temperature of 2012 and fitted with a horizontally flipped Gompertz function with an offset:

$$
\operatorname{SHD}_{\text {cap }}\left(T_{\text {ave,2012 }}\right)=\lambda_{1} \cdot \exp \left(\lambda_{2} \cdot \exp \left(\lambda_{3} \cdot T_{\text {ave,2012 }}\right)\right)+\lambda_{4}
$$

The horizontal flip is ensured by limiting the signs of the parameter to positive values. Future values are then estimated by weighting the trendline and the trendline plus the offset of the initial value in 2012 as described in Equation (36):

$$
\begin{aligned}
& \operatorname{SHD}_{\text {cap }}(y)=w_{T L, S H D}(y) \cdot \operatorname{SHD}_{\text {cap }}\left(T_{\text {ave }, y, c}\right) \cdot \eta_{B E}+\left(1-w_{T L, S H D}(y)\right) \cdot \\
& {\left[\operatorname{SHD}_{\text {cap }}\left(T_{\text {ave }, y c}\right) \cdot \eta_{B E}+\left(\operatorname{SHD}_{\text {cap }, c, 2012}-\operatorname{SHD}_{\text {cap }}\left(T_{\text {ave }, c, 2012}\right)\right)\right]}
\end{aligned}
$$

where the weight of the trendline $w_{T L, S H D}$ equals the weight of the trendline $w_{T L, D H W}$ as described earlier in Equation (30),

$$
\eta_{B E}=\left(1-\varepsilon_{B E}\right)^{\Delta t}
$$

is the efficiency gain due to building refurbishment and renewal of the building stock, $\Delta t$ is the number of years between the time step, and $\varepsilon_{B E}$ the efficiency improvement per year. The total SHD is then calculated by multiplication with the respective population for a given year and country. 


\subsection{Aggregation and Disaggregation to 145 Mesoscale Regions}

The results are adapted to comply with the 145 mesoscale regions of the LUT model. Results for total heat demands of countries $c$ which are aggregated to a mesoscale region $r$ with more than one country are summed up:

$$
\begin{aligned}
I H D_{r} & =\sum_{c \in r} I H D_{t o t, c} \\
D H W_{r} & =\sum_{c \in r} D H W_{t o t, c} \\
B C H_{r} & =\sum_{c \in r} B C H_{t o t, c} \\
S H D_{r} & =\sum_{c \in r} S H D_{t o t, c} .
\end{aligned}
$$

In the case of countries that are split into several regions, the $I H D, D H W$ and $B C H$ are disaggregated according to the share of the population in each mesoscale region:

$$
\begin{aligned}
I H D_{r} & =I H D_{t o t, c} \cdot \frac{p o p_{r}}{p_{p}} \\
D H W_{r} & =D H W_{t o t, c} \cdot \frac{p o p_{r}}{p o p_{c}} \\
B C H_{r} & =B C H_{t o t, c} \cdot \frac{p o p_{r}}{\text { pop }_{c}}
\end{aligned}
$$

The SHD cannot be disaggregated that easily, as the influence of temperature and population distribution have to be taken into account. For every country, the SHD profile is calculated based on a population-weighted $H D H$ calculation for every node in a $400 \times$ 800 node global map, similarly as explained in the next sub-section. Knowing the nodes of every region, the space heating profiles are summed up for the respective nodes. By summing up all values of the profile itself, the total SHD can be calculated:

$$
S H D_{r}=\sum_{n \in N_{r}} \sum_{h=1}^{8760} S H D_{n, h}
$$

where

$$
S H D_{n, h}=S H D_{t o t, c} \cdot \frac{H D H_{\Sigma, n}}{\sum_{n \in N_{c}} H D H_{n}}
$$

using the approach of heat degree hours as explained in Section 3.2.4. As some data, especially the map for population does not exactly match the node maps used for the country and region allocation, some minor distortion in the total heat demand can be observed. Therefore, the resulting SHD of every mesoscale region is normalised to the total SHD of the whole country, or in the case of mesoscale regions including several countries, to the sum of the SHD of all countries included.

\subsection{Calculating Hourly Heat Demand Profiles}

For obtaining the profile of the $S H D$, two factors have to be considered: temperature and population allocation. This means the resulting demand profile has to be a weighted average of the whole region. For this purpose, the temperature profiles, and the population data are used. Firstly, for every node $n$ of the $400 \times 800$ node map, the share of $S H D$ of the respective country $p_{S H D, n, c}$ is calculated based on the population and $H D H$, the latter as described in Equation (19).

$$
\forall n \in N_{c}: p_{S H D, n, c}=\frac{H D H_{n} \cdot p o p_{n}}{\sum_{n \in N_{c}} p o p_{n}}
$$


Secondly, the hourly temperature profiles are adjusted to represent a heating profile. Considering the heating threshold of $18{ }^{\circ} \mathrm{C}$, for every node $n$ in a set of nodes of a country $N_{c}$ this value $(291.15 \mathrm{~K})$ is subtracted from every data point at hour $h$. Afterward, all values greater than 0 are set to 0 . These are the hours where no space heating is required. As the $S H D$ is inversely proportional to lower temperatures, the absolute value of the temperature profile is taken. At this point, the thermal inertia of buildings has to be considered. The detailed modeling of the thermal inertia of buildings is a highly complex matter [86]. In this study, the inertia is built-in by applying an $8 \mathrm{~h}$ running average to the profile. Next, for every node the value of every hour $h$ is normalised to the sum of all values of the respective profile, for each hourly value representing the share of the total annual space heating demand:

$$
\forall h \in[1,8760], \forall n \in N_{c}: S H D_{n o r m, n, h}=\frac{T_{n, h}}{\sum_{h=1}^{8760} T_{n, h}}
$$

For every node, the $S H D$ profile can then be calculated by multiplying the profile with the respective $S H D$ demand:

$$
\forall h \in[1,8760], \forall n \in N_{c} S H D_{n, h}=S H D_{n o r m, n, h} \cdot S H D_{c} \cdot p_{S H D, n, c}
$$

Finally, by summing up the $S H D$ profiles of every node in a set of nodes of a mesoscale region $N_{r}$ the total $S H D$ profile of a mesoscale region can be obtained. A normalised profile for every mesoscale region $r$ is created by diving every hourly value of the profile by the sum of the whole annual profile:

$$
\forall h \in[1,8760]: S H D_{n o r m, r, h}=\frac{\sum_{n \in N_{r}} S H D_{n, h}}{\sum_{n \in N_{r}} \sum_{h=1}^{8760} S H D_{n, h}}
$$

Even though changing temperatures will have some influence on the heating characteristics and the number of hours when heating will be necessary, the SHD profile is considered to stay the same until 2050. Climate change might change the profile in the regions differently, from stronger or weaker seasonality to stronger or weaker diurnal temperature variation during the day. This information is not available on a comprehensive basis. The influence of changing temperature is considered in the calculation of the total SHD per country.

For the DHW profiles, it is assumed that the use of hot water correlates to the use of energy in residential dwellings. Therefore, the DHW profiles are oriented on the residential electricity profiles obtained in [15]. An exemplary week of such obtained load profiles is taken as the basis. The amount of hot water used per day differs according to the season, or rather the temperature, as for colder temperature conditions, more energy is needed for heating cold freshwater, together with some behavioural changes [41,87]. However, the impact of the temperature is not very significant. The seasonality is obtained by calculating a factor $\vartheta_{T, d}$ expressing the deviation of the population-weighted daily average temperature from the annual average temperature:

$$
\forall d \epsilon[1,365]: \vartheta_{T, r, d}=\frac{\overline{T_{a v e, r, h}}}{T_{a v e, r, a}}
$$

with

$$
\begin{gathered}
\forall n \epsilon N_{r}: T_{a v e, r, h}=\frac{T_{n, h} \cdot p o p_{n}}{\sum_{n \epsilon N_{r}} p o p_{n}} \\
T_{a v e, r, a}=\frac{\sum_{i=1}^{8760} T_{a v e, r, h}}{8760}
\end{gathered}
$$


in 24-h steps for each day $d$ of the year, so $d \propto 24 \cdot h$. Every hourly value of the hourly residential electricity profile $\operatorname{Res}_{e l, h}$ is then scaled according to the seasonality factor and a scaling factor

$$
\forall d \epsilon[1,365]: \operatorname{Res}_{e l, h}^{\prime}=\operatorname{Res}_{e l, h} \cdot \vartheta_{T, r, d}{ }^{\tau}
$$

by stepping 365 times through 24 -h slices of the profile. The scaling exponent $\tau$, which expresses the impact of the seasonality on the profile, is obtained by calibration on the case of Finland as a country with a strong seasonality for the use of hot water in relation to the annual average, as given in [87]. The best result is found for $\tau=5.5$. By calculating

$$
\forall h \in[1,8760]: D H W_{n o r m, r, h}=\frac{\operatorname{Res}^{\prime}{ }_{e l, h}}{\sum_{i=1}^{8760} \operatorname{Res}^{\prime}{ }_{e l, h}}
$$

the profile is then normalised to the annual total. These profiles are also considered not to change over time and are the same for the whole investigated time period.

The common way to consider IHD demand is a simple baseload approach as, e.g., in [88]. A simple baseload approach does not consider two facts:

1. Not all the industry runs in $24 / 7$ operation. Some industry applying a two-shift system will require IHD only during the daytime, even if is only a minor share;

2. As for all heat demand types, seasonality will most certainly play a role.

The modeling of the IHD profiles is based on the national electricity profiles available from [37]. The approach is to filter out peaks of the day and to obtain a baseload for every day and the baseload of the intraday load. This intraday baseload is defined as the load between the baseload and the minimum value between load peaks (morning and evening) of the day. For every country $c$, the load profile $N a t_{e l, c, h}$ in hourly resolution is stepped through in 24-h slices representing a whole daily load cycle per step. First, the daily baseload is eliminated by subtracting the minimum value of each daily profile slice $\mathrm{Nat}_{e l, c, d}$

$$
N a t_{p e a k, c, d}=N a t_{e l, c, d} \cdot \min \left(N a t_{e l, c, d}\right)
$$

which gives the daily peak profile $N a t_{p e a k, c, d}$. The hours of each day, where a possible intraday baseload occurs are obtained by taking the first derivative of the daily peak profile:

$$
N a t \prime_{p e a k, c, d}=\frac{d N a t_{p e a k, c, d}}{d h}
$$

Due to the hourly resolution, simply zeroing the derivate to get the index of the required hour might not lead to a solution. Therefore, possible indices are defined when the sign of the derivative changes from negative to positive, which indicates a load valley. This also eliminates solutions for the top of peaks, where the sign of the derivative changes from positive to negative. A further limitation for possible solutions is that the hour has to be between 6 a.m. in the morning and 6 p.m. in the evening to avoid using a night valley occurring earlier or later as usual as the solution. In case that there are two possible solutions the one giving the lower load value in the daily profile is taken, giving the index of the intraday baseload value $i d x_{I D B L}$ and the intraday baseload value IDBL defined as

$$
I D B L_{c, d}=N a t_{p e a k, c, d}\left(i d x_{I D B L}\right)
$$

The profile of the respective day is then defined as

$$
I H D_{c, d}=B L_{c, d}+I D L_{c, d}
$$

where the baseload $B L$ and the intraday load IDL are defined as

$$
B L_{c, d}=\min \left(N a t_{e l, c, d}\right)
$$




$$
I D L_{c, d}=\left\{\begin{array}{c}
N a t_{\text {peak }, c, d} \text { if } \mathrm{Nat}_{\text {peak }, c, d}<I D B L_{c, d} \\
I D B L_{c, d} \text { if Nat peak,c,d } \geq I D B L_{c, d}
\end{array}\right.
$$

Stringing together all daily profiles for the whole year gives the annual profile $I H D_{c, h}$ in hourly resolution. One problem occurs if the daily profile only consists of one peak, which makes it not possible to obtain an intraday baseload, especially if the electricity profile changes the daily load character from two peaks to one peak during the year, a strongly distorted profile would be the consequence. This problem is circumvented in the next step when the seasonality is factored in. The method for factoring in the seasonality based on the temperature is equal to the one described in Equations (46), (47a) and (47b), with two modifications:

1. The seasonality factor $\vartheta_{T, r, d}$ is adjusted to a 30-day running average, as it is assumed that the industrial heat demand depends on rather general changes of seasonality than daily or weekly fluctuations of the temperature;

2. The exemplary week is a representative week, calculated as the average of the 52 weeks of the year.

This step also includes the conversion of the profiles from country scale to mesoscale region scale. When building the exemplary week and several countries are part of the sub-region, the profiles are summed up, so that in total the profile of a country with a higher population has a higher impact on the resulting profile, as the population is already considered in the electricity profiles. For mesoscale regions consisting of a part of a country and includes another country, the profile of the country which is split is multiplied with the population share of the mesoscale region before addition. No further division is necessary, due to the concluding normalisation of the profile:

$$
\forall h \in[1,8760]: I H D_{n o r m, r, h}=\frac{I H D_{c, h}^{\prime}}{\sum_{i=1}^{8760} I H D_{c, h}^{\prime}}
$$

with

$$
\forall d \in[1,365]: I H D_{c, h}^{\prime}=I H D_{c, h} \cdot \vartheta_{T, r, d} \tau
$$

In the context of industrial heat demand, an interesting parameter is the baseload ratio $B R$, indicating the share of $24 / 7$ baseload demand and intraday baseload demand. It is calculated as the sum of the daily baseloads divided by the sum of the daily baseload and the intraday load:

$$
B R_{c}=\frac{\sum_{d=1}^{365} 24 \cdot B L_{c, d}}{\sum_{d=1}^{365} 24 \cdot B L_{c, d}+\sum_{d=1}^{365} \sum_{h=1}^{24} I D L_{c, d, h}}
$$

The aim of this parameter is to find a measure of how much of the IHD is used in a baseload manner and how much of the IHD is used in a daily cycle.

\section{Results}

Firstly, total IHD, DHW, BCH and SHD are presented based on the data processing of the Greenpeace [R]evolution report for the year 2012, which is used as the basis for future heat demand projections. Thereafter, auxiliary results, which are necessary to structure the 2012 data for future estimations are provided. Finally, heat demand projections for all heat demand types and 145 mesoscale regions globally are presented. All results are available in Supplementary File S1. Visualised results based on the 145 mesoscale regions are available in Supplementary Files S2 and S3. Heat demand profiles for the 145 mesoscale regions and all heat demand types are given in Supplementary File S4. 


\subsection{Base Data of the Year 2012}

The first step of this study was to determine the base data from the Greenpeace $[R]$ evolution report major regions to country-wise values. The results are shown in Figure 6 on a global scale for all countries.
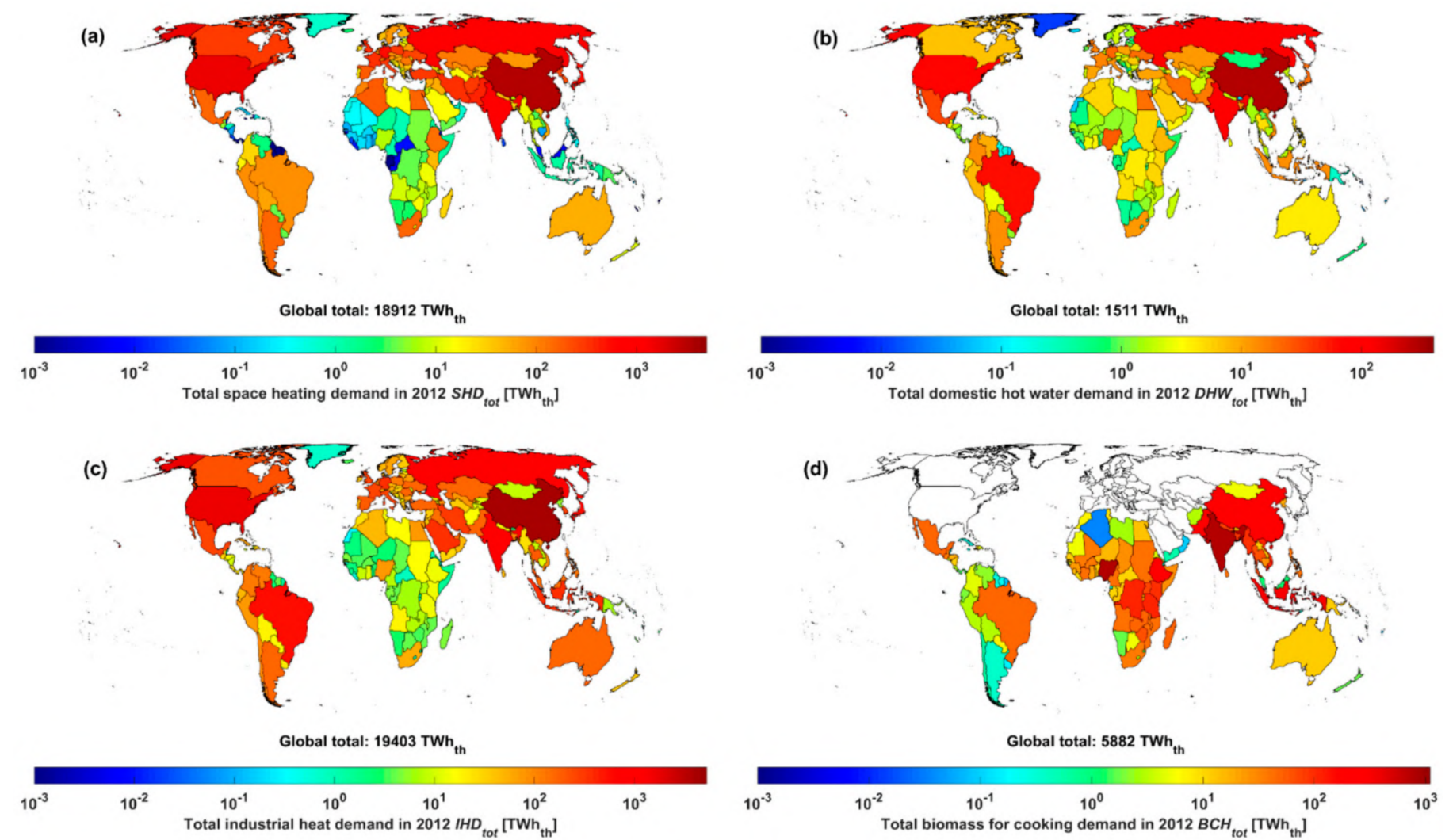

(c)

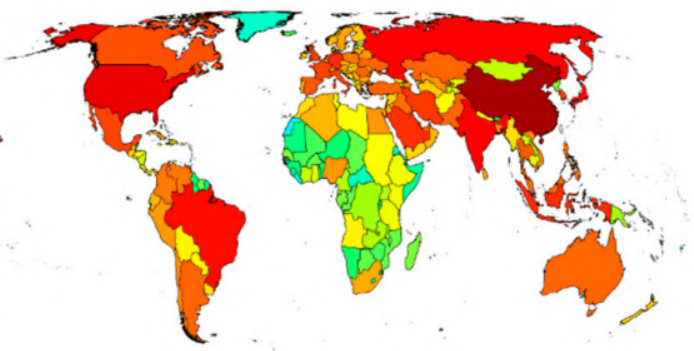

Global total: $19403 \mathrm{TWh}_{\text {th }}$

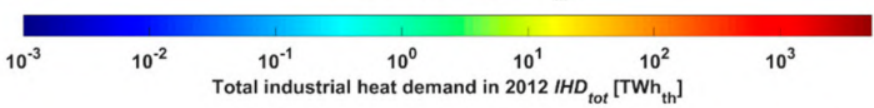

(b)

Global total: $1511 \mathrm{TWh}$

(d)

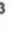

Figure 6. Global distribution of the heat demand results for the 2012 base data on a country-scale. Values below $1 \mathrm{GWh}$ $\left(10^{-3} \mathrm{TWh}\right)$ are coloured in dark blue: (a) Total space heating demand SHD in 2012; (b) Total domestic hot water demand DHW in 2012; (c) Total industrial heat demand IHD in 2012; (d) Total biomass for cooking demand BCH in 2012.

The used method for disaggregating the SHD of a major region with regard to temperature data leads to a reasonable distribution of the SHD over the continents. Most of the SHD is located in the northern hemisphere in North America, Europe, Eurasia and Northeast Asia, where strong winter periods drive the demand for space heating energy. Some countries with cool areas also show a significant SHD, mostly located in South Asia and generally in mountainous regions. Some countries in South America, especially those in the Andes region, also have a noticeable demand for space heating. In Central America, sub-Saharan Africa and Southeast Asia, space heating does not play a major role, independent of the population. However, it is important to consider that, in some developing countries, most households lack modern space heating.

DHW results represent nicely both the standards of living as well as population size. Highly populated countries with a low or average standard of living show a high DHW in addition to countries with a relatively high population but high standards of living, e.g., Brazil, China, India, Mexico, or Russia. In sub-Saharan Africa and Southeast Asia with most countries being still in the development phase, DHW is significantly lower. Only Nigeria points out due to its high population. Otherwise, some countries with a high standard of living but a relatively low population also show a significantly lower DHW, such as Australia, Canada, or the Nordic countries.

For the IHD it can be seen that the heat demand is basically located in industrialised countries and transitioning countries. Mostly countries in Africa, Central Asia, Southeast 
Asia, and Central America show a significantly lower IHD due to their lower level of industrial activities. For India and especially China the main driver for their high IHD is their high population. Within Europe, where most of the countries have achieved a similar level of economic development on a per capita level, the IHD difference is basically represented by the difference in population.

The majority of $\mathrm{BCH}$ is located in sub-Saharan Africa, China, India, and Southeast Asia. Most of the countries in South America already perform quite well in phasing out biomass-based cooking. This also applies to countries in the Middle East and North Africa. Australia is the only highly developed, industrialised country showing a noticeable use of biomass for cooking purposes. Basically, the whole Northern hemisphere does not use biomass for cooking anymore. Countries of West Asia and the Middle East that are not yet on the standard of living of highly developed countries, but do not use biomass for cooking, most certainly use fossil fuels such as natural gas, liquified petroleum gas (LPG) or kerosene for cooking. In the context of this paper, only biomass-based cooking is studied.

\subsection{Heat Demand Trendlines}

As was described in Sections 3.3.2 and 3.3.4, the SHD and DHW projections are based on trendlines for the per capita values of the heat demands in 2012. Both, the results of the calculation for the year 2012 and the respective trendlines are shown in Figure 7. Additionally, the IHD of countries outside the scope of the Greenpeace [R]evolution report is estimated by using a trendline for the existing results, representing already most of the countries. The total values are presented in TWh, and the per capita values are presented in $\mathrm{kWh} / \mathrm{cap}$.

The calculation of the SHD for 2012 has already been based on temperature input, so the good and satisfying alignment of the demand with annual average temperature data is not surprising. Only Mongolia is a strong outlier. The reason for the high $S H D_{c a p}$ of Mongolia is, that basically, the whole population lives in harsh climatic conditions with very cold and long winter periods. In addition, $60 \%$ of the urban households lived in traditional Gers, nomadic houses built out of wood and wool [89]. Already at about $25^{\circ} \mathrm{C}$, the $S H D_{\text {cap }}$ begins to increase. A reason for that is that countries with high average temperatures, which are located in a desert climate, are affected by high-temperature fluctuations between summer and wintertime.

In the case of DHW, most of the countries are rather close to the trendline. Only countries of the IPCC-PAS regions (Pacific/Southeast Asia) show significantly lower values due to the input data. However, the total error is not very large as the range of values is quite narrow and lies at a maximum of about $350 \mathrm{kWh} / \mathrm{cap}$. Furthermore, the results for 2012 show the stagnation of DHW per capita above a GDP per capita of around 15,000 $\mathrm{EUR} / \mathrm{cap}$, which is represented by the chosen trendline type. 

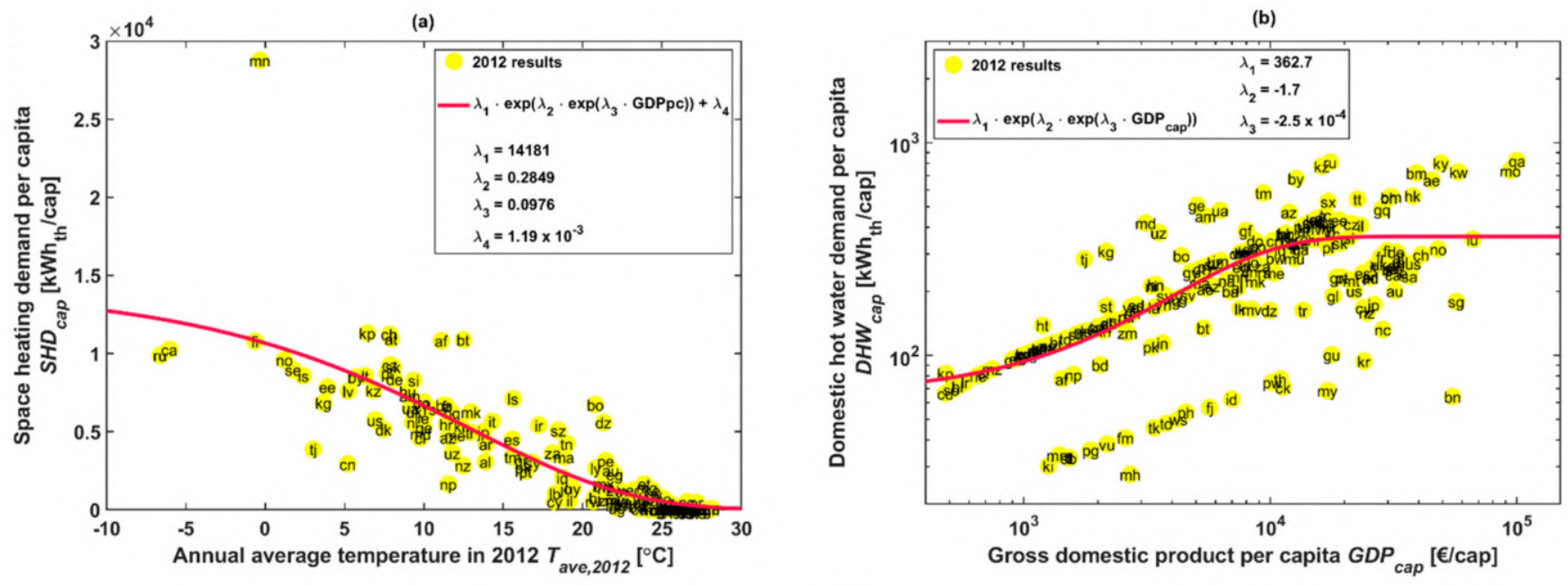

(c)

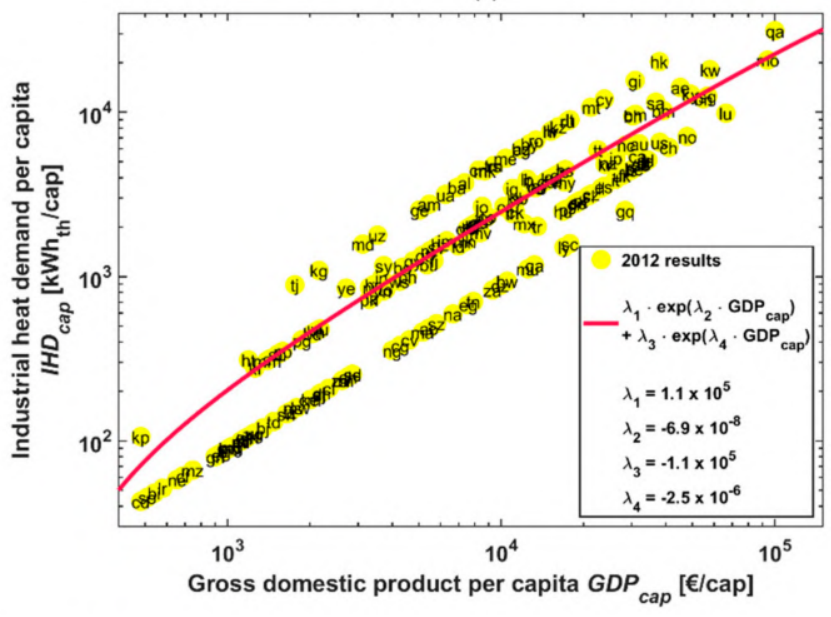

Figure 7. Calculation results for 2012 with the fitted trendline and trendline parameters. Countries are marked with their internet domain: (a) Space heating demand per capita $\mathrm{SHD}_{\text {cap }}$; (b) Domestic hot water demand per capita $\mathrm{DHW}_{\text {cap }}$; (c) Industrial heat demand per capita $\mathrm{IHD}_{\text {cap }}$.

It can be clearly seen, that the IHD was disaggregated on the basis of the total GDP. By removing the impact of the population from both IHD and GDP, the linear breakdown for each major region can be seen again. The IHD per capita for countries that are not included in the Greenpeace [R]evolution report is estimated with the trendline function.

\subsection{Future Heat Demand Projections}

In this section, the future demand projections until 2050 are presented. Firstly, the total global heat demand trajectory and the application-wise heat demand trajectories for the nine major regions of the LUT model are presented. Secondly, the trends for each heat demand-type based on the 145 mesoscale regions of the LUT model are described. Results on a country-scale and comprehensive specific numbers are available in the Supplementary Materials.

Figure 8 shows the total global heat demand development until 2050 for the four heat demand types and the relative share of the total global heat demand of each heat type. 

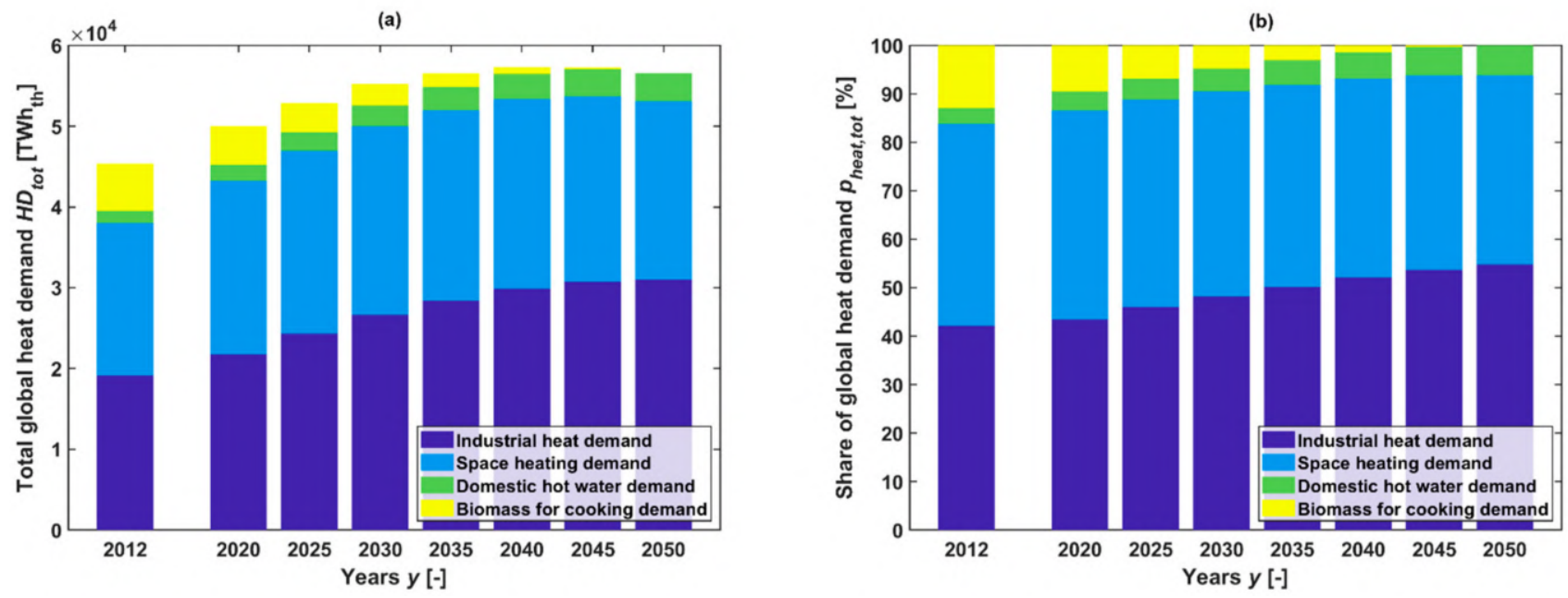

Figure 8. Global cumulative heat demand results from 2012 to 2050: (a) Total cumulative heat demand; (b) Share of heat demand types of the total global heat demand. Only countries included in the 145 mesoscale regions of the LUT model are considered.

In 2012, the total global heat demand amounted to about $45,400 \mathrm{TWh}_{\text {th }}$. Until midcentury, the heat demand is projected to increase to about $56,600 \mathrm{TWh}_{\mathrm{th}}$. The development shows a flattening/decreasing character. This is induced by phasing out biomass for cooking, which is considered to pass over to the electricity sector and is then not part of the heat sector anymore, by the flattening of the IHD as well as by a decrease in the SHD after 2035. Efficiency measures applied to newly built and existing buildings lead to a peak in SHD in 2035, and a shrinking SHD afterward. Furthermore, the industrial heat demand is projected to almost level out in 2050 as industrialised regions applying efficiency measures balance the heat demand growth from developing and emerging regions. A detailed investigation of the demand trajectories is carried out in the following subsection.

During the whole transition period, IHD and SHD are the main heat demand types. In 2012, IHD had a share of $42.2 \%$ of the total heat demand and SHD had a share of $41.6 \%$. DHW had the lowest share of $3.3 \%$, whereas $\mathrm{BCH}$ had a share of $12.9 \%$. By 2050, the share of $\mathrm{BCH}$ is projected to be reduced to a minor share of $0.001 \%$, thus practically phased out. Increasing standards of living and DHW demand growth changes the share of DHW to $6.2 \%$. Continued economic development increases the role of industrial heat demand until 2050, with an increase in the IHD heat share to $54.8 \%$. The share of SHD decreases to $39.0 \%$, which is a consequence of efficiency improvements in buildings but is also driven by higher overall temperatures due to climate change. The highest share of SHD is expected in 2025 at a level of $42.9 \%$. However, the contribution of climate change is rather small but noticeable. If the temperature change would not be considered, the SHD in 2050 would be by $1919 \mathrm{TWh}_{\text {th }}$ higher, giving a share of SHD of $41 \%$ and $53 \%$ for IHD. On the contrary, building efficiency measures have a quite strong impact. Without the building efficiency improvement, the SHD in 2050 would be by $6754 \mathrm{TWh}_{\text {th }}$ higher, leading to a share of $45.5 \%$ of SHD and $49 \%$ of IHD. Total heat demand savings of buildings of over $60 \%$ due to retrofitting and renovation are within the realms of possibility [90].

Relative changes within the time steps can be expressed by the CAGR, which is listed in Table 5 for all time steps and heat demand types, as well as the total cumulative heat demand. The CAGRs of all heat demand types and 9 major regions of the LUT model in comparison with the CAGRs of the GDP per capita can be found in Supplementary File S1. 
Table 5. CAGR of the heat demand types and the total cumulative global heat demand for the seven time steps of the investigated time frame from 2012 to 2050.

\begin{tabular}{cccccccc}
\hline \multirow{2}{*}{ Demand Type } & \multicolumn{7}{c}{ CAGR of Heat Demand [\%] } \\
\cline { 2 - 7 } & $\mathbf{2 0 1 2 - 2 0 2 0}$ & $\mathbf{2 0 2 0 - 2 0 2 5}$ & $\mathbf{2 0 2 5 - 2 0 3 0}$ & $\mathbf{2 0 3 0 - 2 0 3 5}$ & $\mathbf{2 0 3 5 - 2 0 4 0}$ & $\mathbf{2 0 4 0 - 2 0 4 5}$ & $\mathbf{2 0 4 5 - 2 0 5 0}$ \\
\hline IHD & 1.6 & 2.3 & 1.9 & 1.3 & 1.0 & 0.6 & 0.2 \\
SHD & 1.7 & 1.0 & 0.6 & 0.2 & -0.1 & -0.4 & -0.8 \\
DHW & 3.5 & 3.0 & 2.6 & 2.1 & 1.6 & 1.3 & 0.9 \\
BCH & -2.6 & -5.4 & -6.0 & -8.3 & -13.6 & -23.5 & -69.0 \\
Total & 1.2 & 1.1 & 0.9 & 0.5 & 0.3 & 0.0 & -0.2 \\
\hline
\end{tabular}

The flattening character of the IHD can be seen by the decreasing CAGR from $1.6 \%$ of the first time step to $0.2 \%$ of the last time step. The same is the case for the DHW, which shows the highest CAGR of all heat demand types of $3.5 \%$ in the first time step and shrinks to $0.9 \%$ in the last time step. For the SHD, the growth rates shrink from $1.7 \%$ to $0.2 \%$ from the first time step to the fourth time step until 2035 and afterward continue with negative CAGRs reaching $-0.8 \%$ in the last time step. Only the CAGRs for $\mathrm{BCH}$ are continuously negative, starting at $-2.6 \%$ and reaching $-69 \%$ in the last time step. Then, in absolute terms, high numbers of $\mathrm{CAGR}$ for $\mathrm{BCH}$ are the result of phasing out the heat demand for biomass in increasing phase-out shares. For the total heat demand, it results in a rather moderate CAGR of $1.2 \%$ in the first-time step, reaching almost $0 \%$ or a rather small negative value by the time step ending $2040(-0.017 \%)$, and continuing with degrowth reaching $-0.2 \%$ in the last time step until 2050. Between 2012 and 2035, the CAGR is $1.0 \%$, whereas beyond 2035 until 2050, the CAGR is below $0.001 \%$.

Another way to describe the global heat demand development is the heat demand per capita. In 2012, every person on the planet accounted for about $6.4 \mathrm{MWh}_{\text {th }} /$ cap of heat demand. Until 2035, the value decreases to $6.4 \mathrm{MWh}_{\text {th }} / \mathrm{cap}$, even though the total heat demand is expected to grow. Efficiency improvements in the heat sector counterbalance the heat demand increase induced by higher standards of living, leading to a lower heat demand per capita. After 2035, the decrease accelerates due to the combination of decreasing SHD and slowing down of the IHD growth. In 2050, the average heat demand per capita is $5.9 \mathrm{MWh}_{\text {th }} /$ cap.

\subsubsection{Major Regions Heat Demand Projection}

The 145 mesoscale regions of the LUT model are grouped into nine major regions: Europe, Eurasia, Middle East and North Africa (MENA), sub-Saharan Africa (SSA), South Asian Association for Regional Cooperation (SAARC), Northeast Asia, Southeast Asia, North America, and South America. Figure 9 shows the results cumulatively for the nine major regions for 2012 and from 2020 to 2050 in 5-year time steps for all heat demand types. Detailed results for the major regions can be found in Supplementary File S1.

On a global scale, the SHD does not change extensively within the investigated time period until 2050. From a total of 18,890 $\mathrm{TWh}_{\text {th }}$ in 2012, it increases and peaks in 2035 at about $23,560 \mathrm{TWh}_{\mathrm{th}}$. Afterward, the efficiency measures are more effective and the global SHD decreases to about 22,000 $\mathrm{TWh}_{\text {th }}$ in 2050. Only Europe continuously decreases its SHD, which is an effect of decreasing population numbers for most of the countries and good matching data points on the trendline. On the opposite, in Northeast Asia, the SHD continuously increases until 2050, even though the population of the country with the highest impact, China, is expected to decrease from 2035 onwards, following the trend of neighbouring countries. Here, the reason is the approximation of the rather low Chinese per capita SHD towards the trendline. The increase due to the approximation is stronger than the reduction due to efficiency measures and population degrowth. The total SHD for SSA increases until 2045 and then stagnates. Due to warm climatic conditions, the Sun Belt regions of SSA, Southeast Asia and South America only have a share of the total global SHD of $7.0 \%$ in 2012, which minorly increases to $7.5 \%$ in 2050 . 

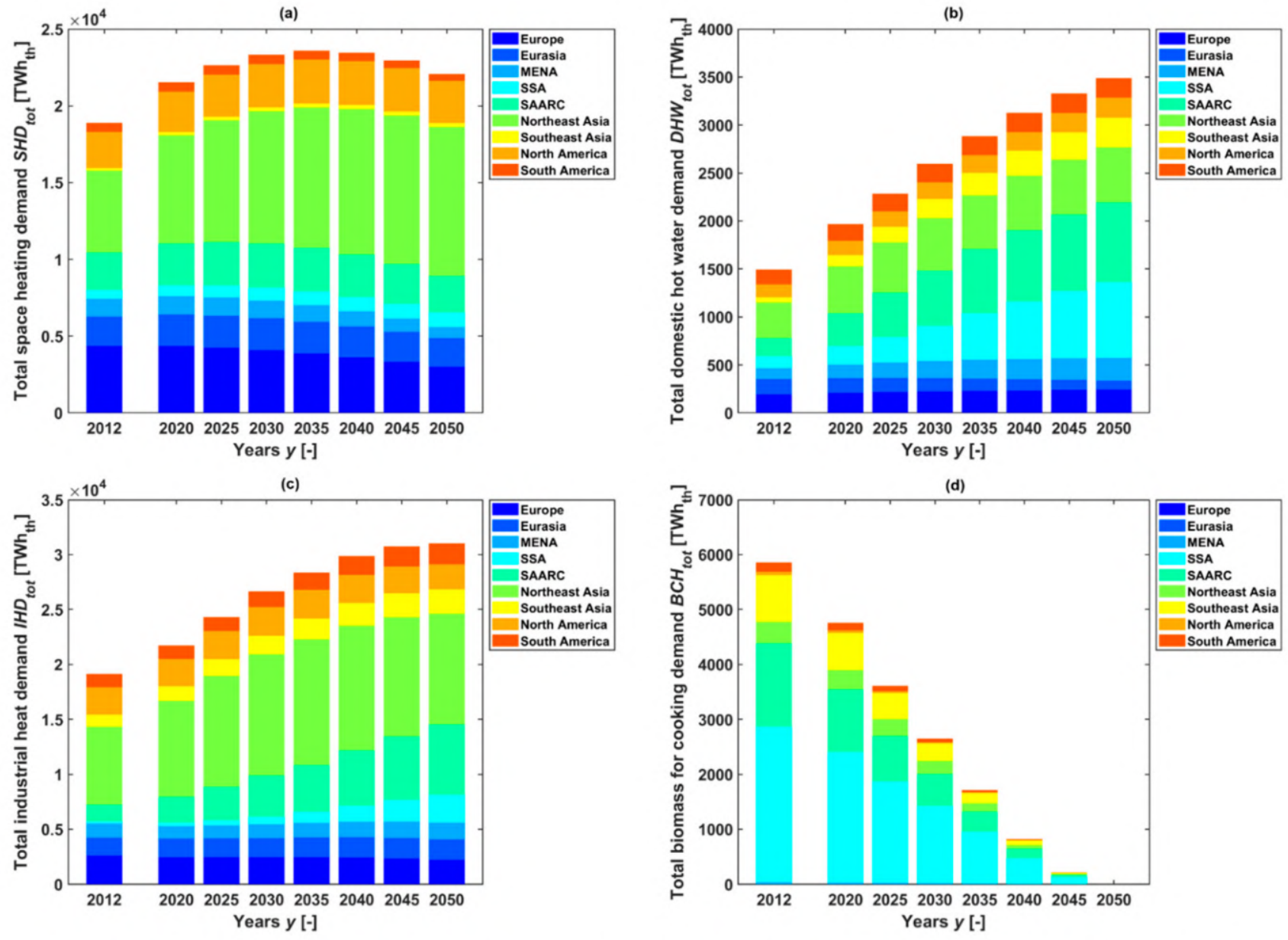

Figure 9. Global heat demand result trajectories for the 9 major regions of the LUT model from 2012 to 2050: (a) Total space heat demand SHD; (b) Total domestic hot water demand DHW; (c) Total industrial heat demand IHD; (d) Total biomass for cooking demand $\mathrm{BCH}$.

The increase in economic development and the respective increase in standards of living can mostly be observed for the DHW trajectory. From about $1500 \mathrm{TWh}_{\text {th }}$ in 2012, the total DHW is more than doubling until 2050, when it reaches about $3500 \mathrm{TWh}_{\mathrm{th}}$. The main drivers for this development are SSA, SAARC and Southeast Asia. For SSA, the combination of increased DHW per capita due to economic development and strong population growth leads to more than six-fold DHW of $622 \%$ in 2050. Similar effects can be observed in SAARC, where the relative value in 2050 is $443 \%$. In the case of Southeast Asia, the combination of trendline approximation, economic development and population growth leads to a total DHW in 2050 of $558 \%$ compared to 2012. Only Eurasia shows a decreasing trend until 2050, as the per capita DHW of the Former Soviet Union countries are quite above average in the 2012 base data.

Similar to DHW, significant growth in IHD can be observed until 2050. The total global IHD in 2012 of almost 19,150 $\mathrm{TWh}_{\text {th }}$ is projected to increase to approximately 31,000 $\mathrm{TWh}_{\mathrm{th}}$ in 2050. Even though SSA has the lowest total value during the whole period, this region shows the highest increase and an IHD of 1208\% in 2050 compared to 2012. As SSA is expected to realise a major economic development including a strong industrialisation process in the decades to come, such a high relative increase is the consequence. The same trend can be observed for the SAARC region, which increases its IHD more than fourfold $(425 \%)$ in 2050 compared to 2012. Northeast Asia with China as the main contributor, increases the IHD until 2035 and decreases afterward. Decelerating economic development and decreasing population are the reason for this characteristic. Europe and North America show a negative IHD development, where the 2050 value is $85.5 \%$ and $91.6 \%$, respectively, 
of the initial value in 2012. Most of the European and North American countries show a decreasing demand trend due to efficiency measures, including a population decline as for many industrialised countries.

The proposed path for phasing out biomass-based cooking in combination with introducing a more efficient cookstove during the transition period leads to an almost linear phase-out of BCH. Whereas in 2012, $5860 \mathrm{TWh}_{\text {th }}$ of BCH was needed, the demand is gradually reduced and in 2050, only a small remainder is left (ca. $0.62 \mathrm{TWh}_{\mathrm{th}}$ ). SSA has by far the largest share of BCH globally with $48.3 \%$ in 2012 and almost $60 \%$ in 2045 . The reason for the growing share is the combination of cooking demand per capita and high expected population growth. This effect can be seen in Figure A6 in Appendix A, where the total end-use cooking heat based on biomass is shown.

The actual heat demand for cooking is expected to have risen between 2012 and 2020 and is going to decline from 2020 onwards. As the population grows and the related total demand for cooking is faster than the introduction of cleaner and more efficient cooking technologies, this effect is most noticeable for the SSA region. Here, it is expected that population growth and cookstove efficiency gain level each other out, thus the $\mathrm{CH}_{\text {bio }}$ does not change significantly. This delays the demand decline for $\mathrm{BCH}$ as well and increases the share of SSA in total BCH demand.

\subsubsection{Heat Demand Projection for Regions}

As already indicated in the previous subsection, the global SHD does not vary significantly until 2050. This can also be seen in Figure 10 presenting the distribution of the total SHD in 145 regions.

(a)

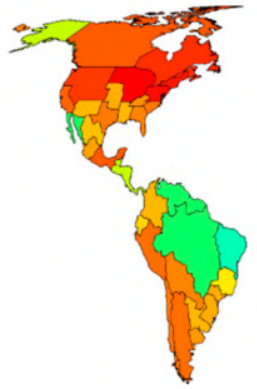

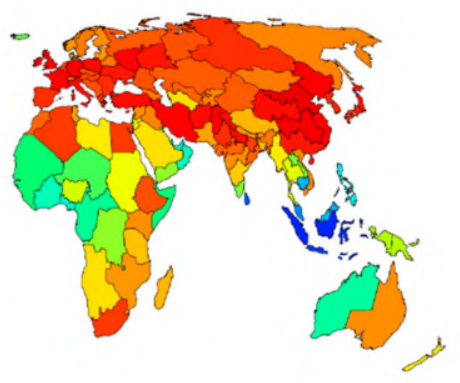

Global total: $18890 \mathrm{TWh}$ th

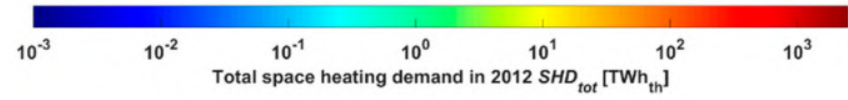

(c)
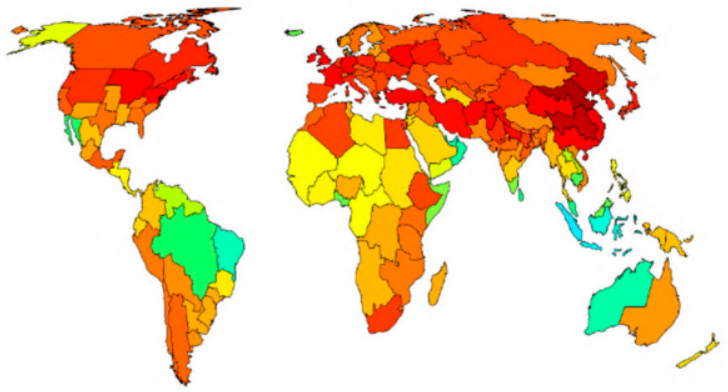

Global total: $23325 \mathrm{TWh}_{\text {th }}$

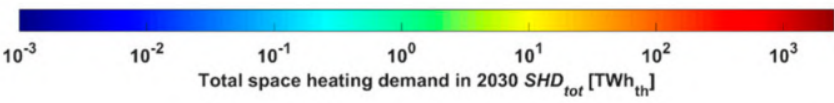

(b)
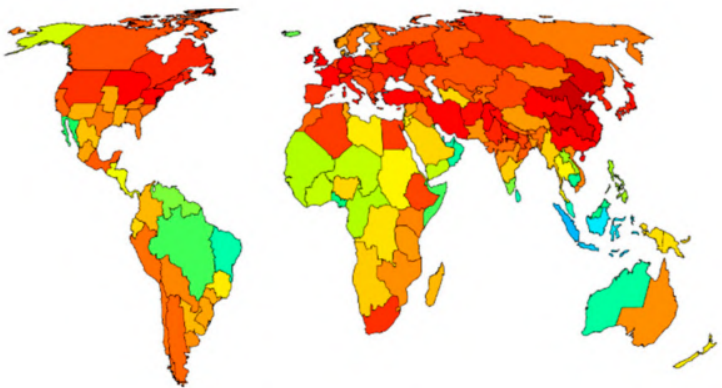

Global total: $21536 \mathrm{TWh} \mathrm{th}_{\mathrm{th}}$

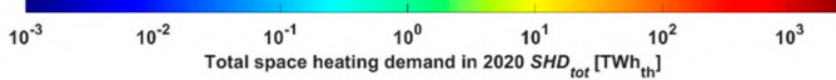

(d)
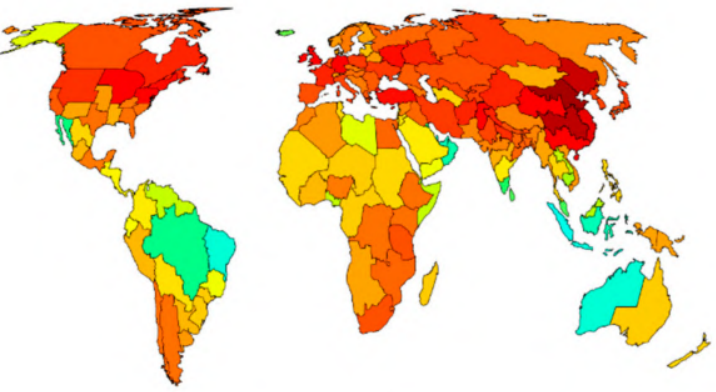

Global total: $22073 \mathrm{TWh}_{\text {th }}$

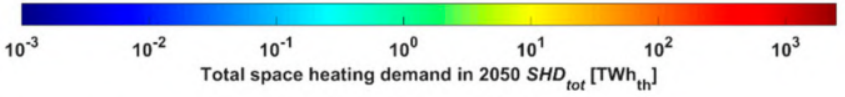

Figure 10. Global distribution of the results for total space heating demand SHD for 145 mesoscale regions of the LUT model in (a) 2012; (b) 2020; (c) 2030; (d) 2050. 
Parts of Southeast Asia show a significant increase in SHD up to 2050, as well as western regions of sub-Saharan Africa. This development is mainly driven by a strong expected population growth. In entire Southeast Asia, it is expected that the population grows by a third between 2012 and 2050. In Western Africa, the population grows even more substantially. Here, on average the population is expected to more than double and grow by $131 \%$ until 2050. For the Chinese regions, the expected SHD growth mentioned in the previous subsection can also be seen. The demand is located mostly in the eastern, more densely populated regions. However, the eastern and southeastern regions located at the sea show a reduced amount of SHD, due to more mild climatic conditions. For the rest of the world, the heating demand is distributed as expected. There is a slight difference between Nordic countries and Central/Southern Europe due to population differences. In the United States, states located in the North and Northeast have a higher SHD than southern states. In South America, the Andes regions have a higher SHD compared to warmer regions in the East and Northeast of South America. The results for the share of residential space heating of the total SHD per country and region can be found in Supplementary File S1.

Most of the additional DHW is projected to be located in East and South Asia, as well as in sub-Saharan Africa, as it is shown in Figure 11. Especially regions with a strong economic development plus a strong population growth are expected to increase their hot water demand significantly until 2050.

(a)

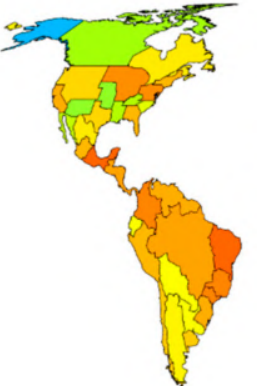

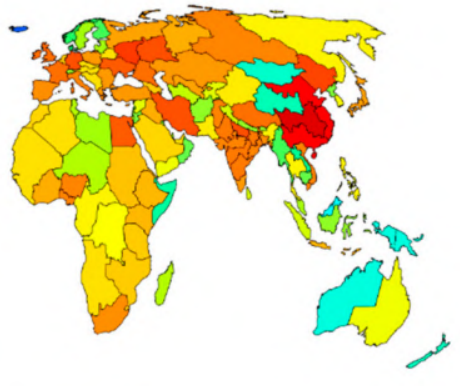

Global total: $1493 \mathrm{TWh}_{\mathrm{th}}$

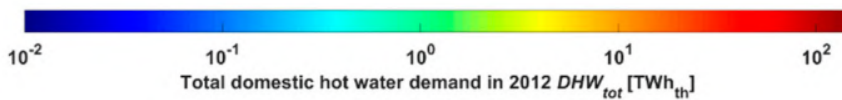

(c)
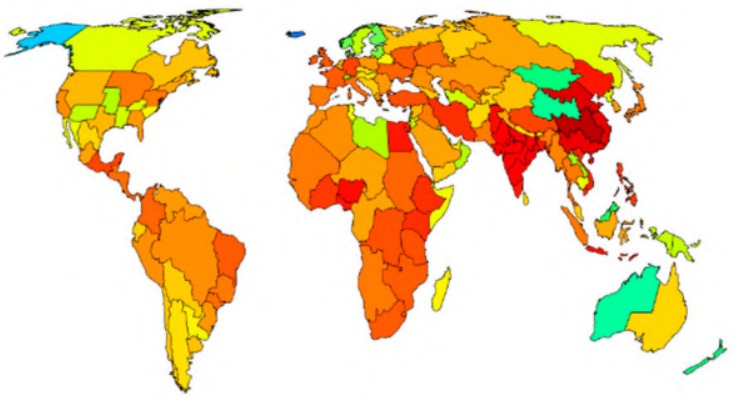

Global total: $2596 \mathrm{TWh}_{\text {th }}$

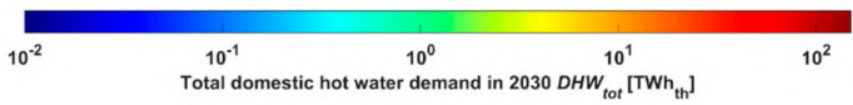

(b)
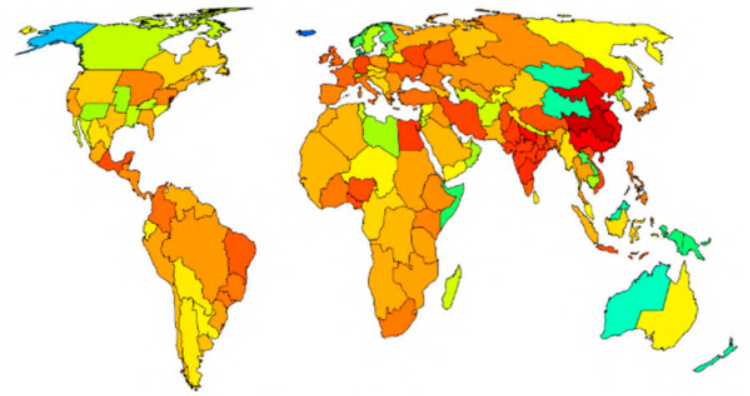

Global total: $1968 \mathrm{TWh}_{\text {th }}$

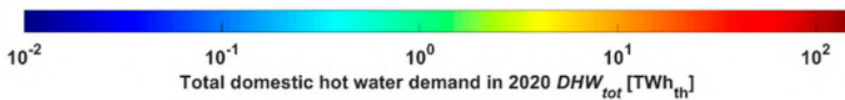

(d)
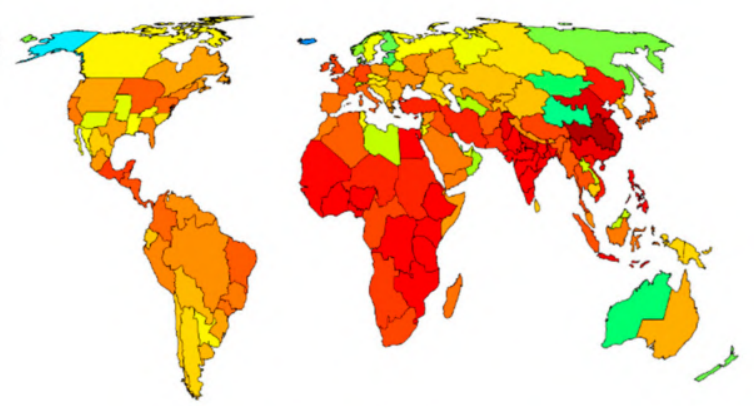

Global total: $3488 \mathrm{TWh}_{\text {th }}$

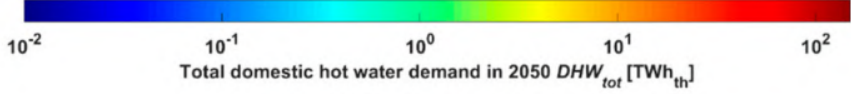

Figure 11. Global distribution of the results for total domestic hot water demand DHW for 145 mesoscale regions of the LUT model in (a) 2012; (b) 2020; (c) 2030; (d) 2050.

In China and India, a high DHW demand stands out, for the case of China already in 2012 due to a very high population. For India, a strong increase is projected between 2030 and 2050. Over the whole transition period, the additional DHW in sub-Saharan 
Africa is exceedingly visible. On average, sub-Saharan Africa regions increase in their DHW demand by a factor of 7.4 from 2012 to 2050, in Southeast Asia (excluding Australia and New Zealand), the DHW increases by a factor of 7.2 until 2050. The biggest rise can be found for the Democratic Republic of Congo with a DHW in 2050 of almost 1540\% compared to its 2012 value, which is a result of a significant GDP per capita growth and population growth. The most significant reduction is expected for Russian regions. As already mentioned, the countries of the former Soviet Union have an initially above-average per capita DHW demand. As this value approaches the trendline, Russia is already at the stage where the DHW per capita does not increase with the GDP per capita anymore but decreases to reach the global trendline. In addition, a population decline is expected for Russia. This leads to the effect that the Russian regions are more than halving their DHW until 2050. Other regions in Eurasia are not affected as strongly as Russia. For the other regions, which are also having a DHW per capita above the trendline, mostly the population growth levels out the declining DHW per capita in the process of the trendline approximation, leaving mainly Russia with such a strong impact. In the rest of the world, the DHW development basically follows the combination of GDP per capita development with population growth. For many regions, for instance in Europe, a slightly increasing DHW per capita levels out with a slightly decreasing population.

Besides SHD, process heat in industry has a major share in total global heat demand. The results for IHD are presented in Figure 12.

(a)

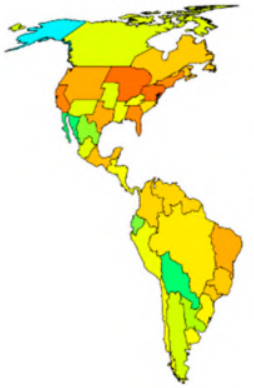

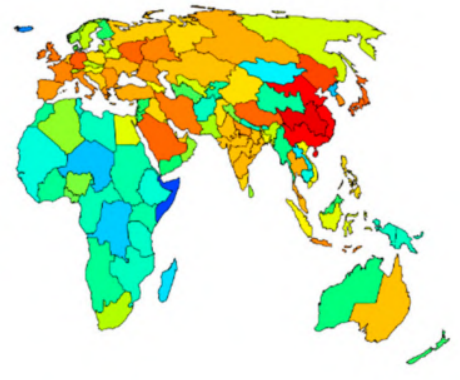

Global total: $19128 \mathrm{TWh}_{\mathrm{th}}$

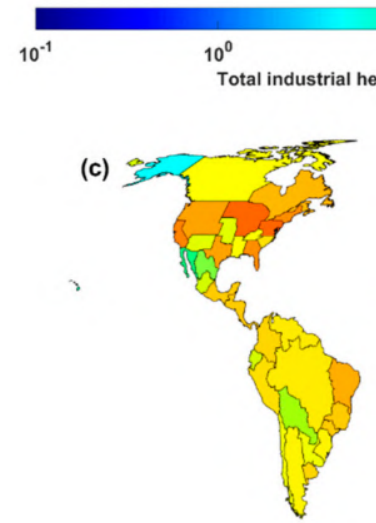

Global total: $26642 \mathrm{TWh}_{\text {th }}$

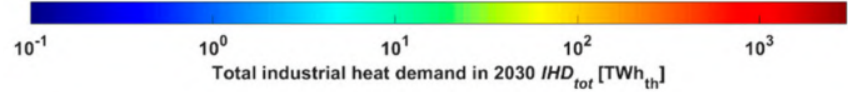

(b)
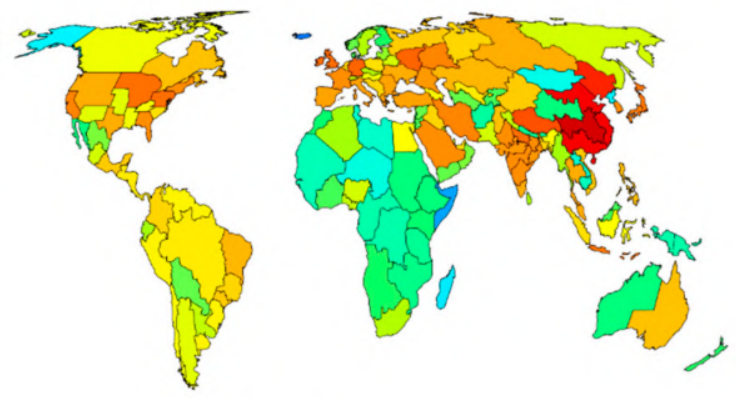

Global total: $21720 \mathrm{TWh}_{\text {th }}$

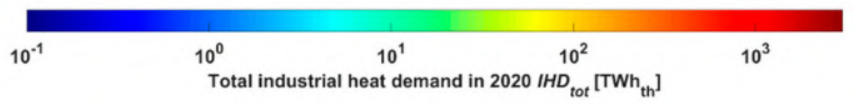

(d)
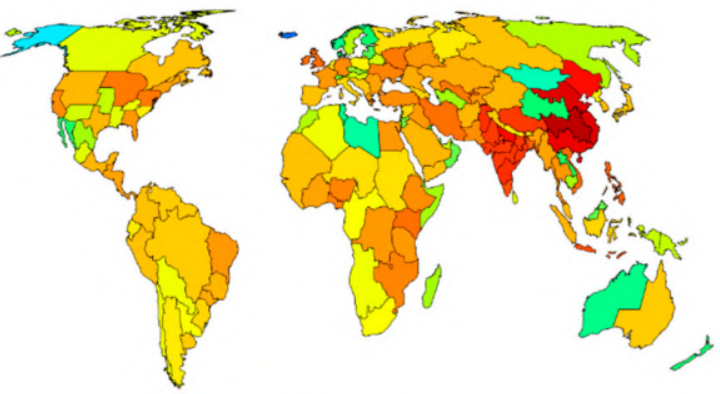

Global total: $31013 \mathrm{TWh}_{\text {th }}$

$10^{-1}$

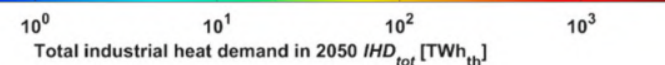

Figure 12. Global distribution of the results for total industrial heat demand IHD for 145 mesoscale regions of the LUT model in (a) 2012; (b) 2020; (c) 2030; (d) 2050.

China has the major share of 87\% of Northeast Asia's IHD in 2012 and 95.4\% in 2050, making China alone responsible for $32.2 \%$ and $30.9 \% \%$ of the global industrial heat demand in 2012 and 2050, respectively, and the foremost highest user of industrial process heat. It is 
projected that China still increases its process heat demand until 2035 and afterward, is able to reduce its IHD. One reason is the peaking population at around 2030, the second reason is the already relatively advanced economic development of China, with an expected annual GDP per capita growth rate peak in 2030 and declining growth rates afterward. Emerging economies in South Asia also show a significantly increasing IHD, especially in Pakistan, India and Bangladesh. As expected, sub-Saharan Africa shows a huge gain in IHD from 2012 to 2050, driven by the combination of strong economic growth and increasing population. After 2050, a further major economic development of sub-Sahara African countries is to be expected, which will lead to further growth of total IHD. In already industrialised regions the change in total IHD is not as dynamic as in developing countries. Most of the countries in the northern hemisphere have a balanced development of the economy and population, which is expected for many industrialised countries to decrease, accompanied by efficiency gains. If a country/region can already be considered industrialised, the decreasing VAI limits the increase in IHD, avoiding an extreme and most unlikely growth for IHD. For many regions, degrowth in population further limits the total IHD. Considering the efficiency gain in industrial heat processes is a very important matter, which has to be prosecuted in the future.

Figure 13 shows the results for the global distribution of the proposed $\mathrm{BCH}$ phase-out until 2050.

(a)
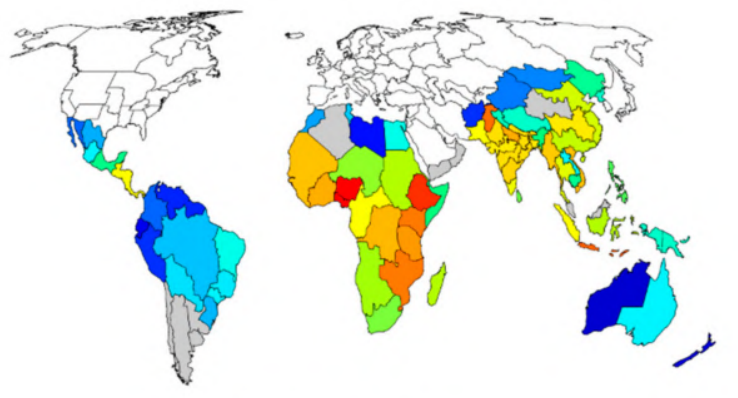

Global total: $5857 \mathrm{TWh}_{\text {th }}$

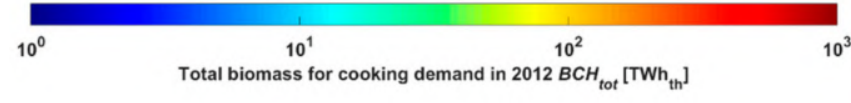

(c)
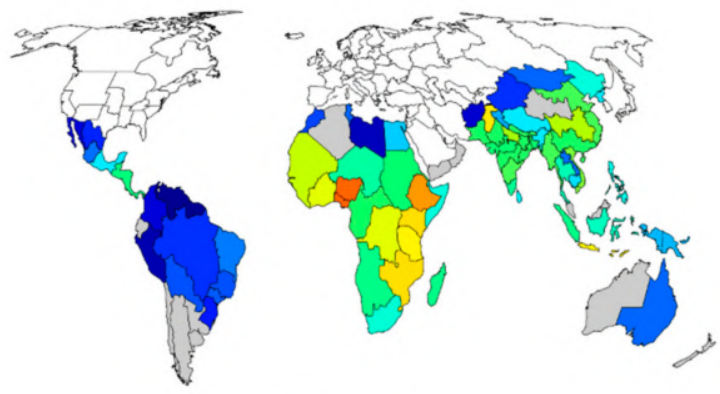

Global total: $2648 \mathrm{TWh}_{\text {th }}$

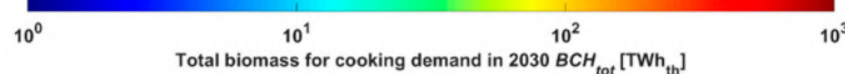

(b)
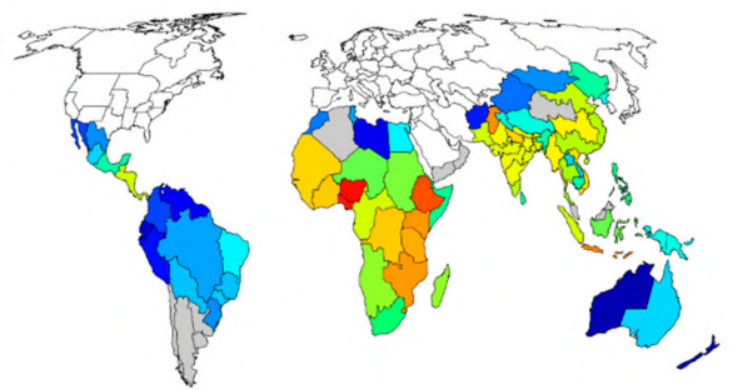

Global total: $4757 \mathrm{TWh}_{\text {th }}$

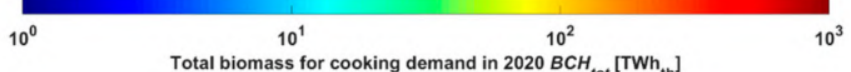

(d)
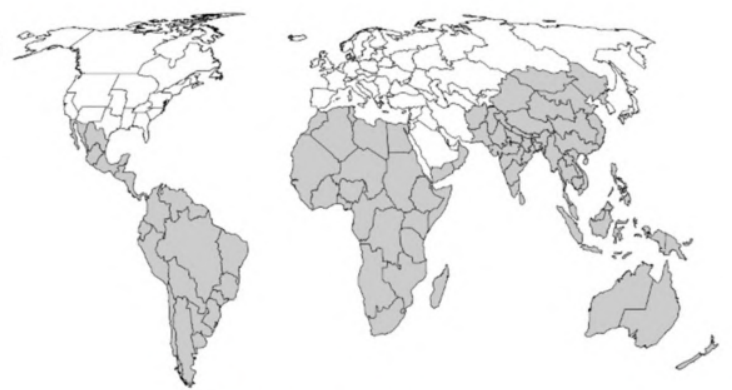

Global total: $1 \mathrm{TWh}_{\text {th }}$

$10^{0}$

$10^{1}$

$10^{2}$

Total biomass for cooking demand in $2050 \mathrm{BCH}_{\text {tot }}\left[\mathrm{TWh}_{\text {th }}\right]$

Figure 13. Global distribution of the results for total biomass for cooking demand $\mathrm{BCH}$ for 145 mesoscale regions of the LUT model in (a) 2012; (b) 2020; (c) 2030; (d) 2050. For better visibility of regions successfully phasing out biomass-based cooking, regions with a $\mathrm{BCH}$ of less than $1 \mathrm{TWh}_{\mathrm{th}}$ are coloured in grey.

$\mathrm{BCH}$ is generally located in the Global South. Particularly regions in sub-Saharan Africa, South Asia, Northeast Asia and Southeast Asia still use a considerable amount of biomass for cooking purposes. South American regions also use a certain amount; however, the total volume is not considerably high, which on the contrary is different in 
Central America. Between 2012 and 2020, the reduction in BCH is relatively moderate in sub-Saharan Africa, which is basically a consequence of a fast-growing population. In the upcoming decade until 2030, even if it is only two years longer than from 2012 to 2020, the total reduction potential is almost double as high as for the first time step. This is visible for all regions globally. After 2030, the 10-year reduction slows down minorly until in 2050, apart from a small residue, all $\mathrm{BCH}$ will be substituted by clean cooking technologies. Some regions already reach a $1 \mathrm{TWh}_{\mathrm{th}}$ threshold between 2030 and 2040. The last regions to reach this level are the biomass-intensive regions of sub-Saharan Africa and the highly populated regions in Asia.

\subsection{Heat Demand Profiles}

Profiles for the heat demand types are presented exemplarily for four regions with different climatic conditions, namely Finland (FI, northern hemisphere, strong seasonality), Northwest Mexico (MX-NW, northern hemisphere, low seasonality), Eastern Indonesia of Kalimantan and Sulawesi (ID-KL-SW, equatorial/tropical, very low seasonality) and West Australia (AU-W, southern hemisphere, moderate seasonality). All profiles for all regions can be found in numeric values in Supplementary File S4. Figure 14 shows the exemplary profiles for the SHD of the abovementioned regions.
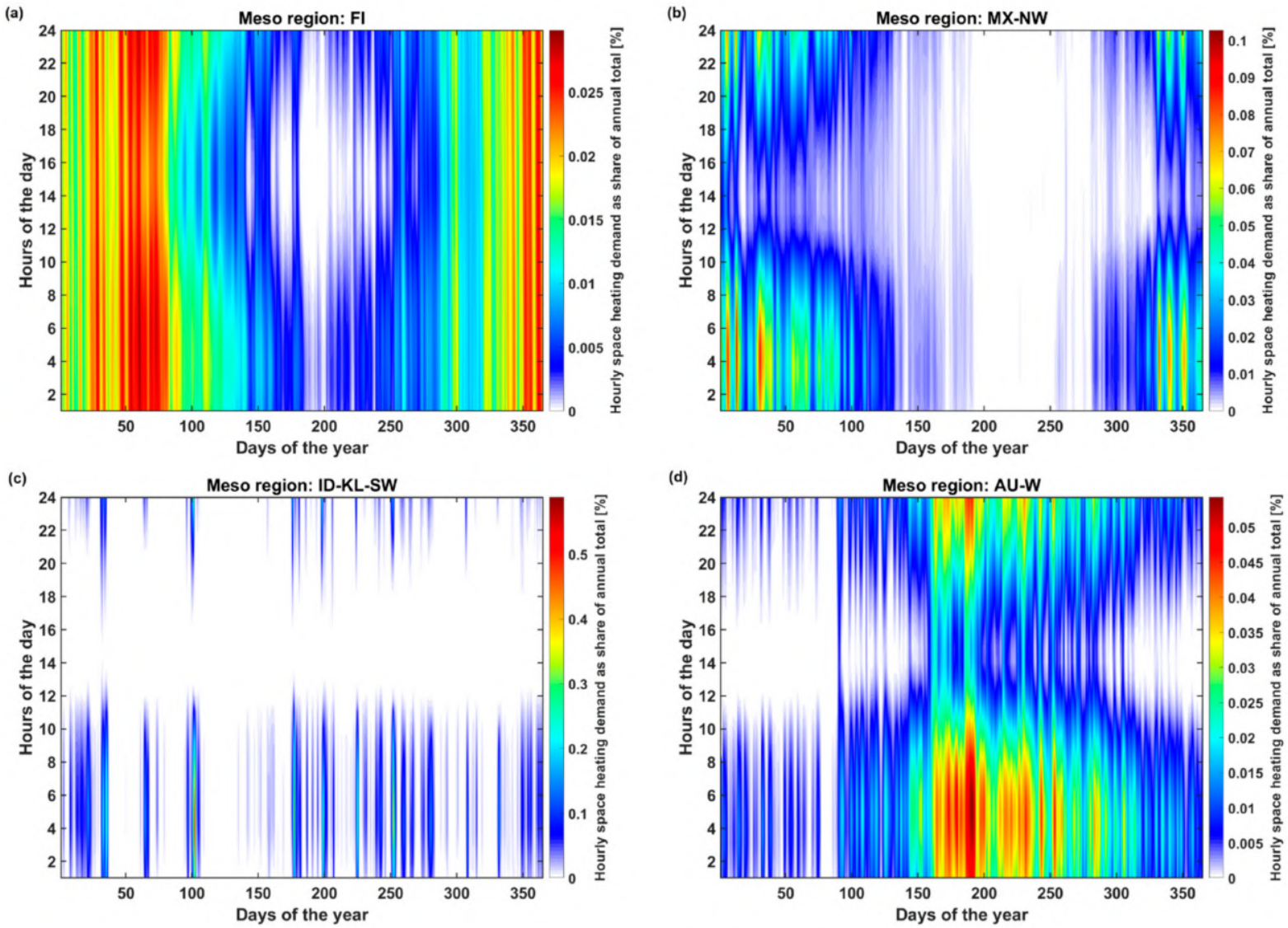

Figure 14. Annual space heat demand profiles as hourly values relative to the annual total, representative for different climatic conditions of the globe in local time: (a) Finland-FI; (b) Northwest Mexico-MX-NW; (c) Eastern Indonesia of Kalimantan and Sulawesi-ID-KL-SW; (d) West Australia-AU-W.

The differences in the SHD profiles for the different representative regions can be spotted quite easily. In Finland, long and strong winter periods concentrate the heating demand in the winter months, however, even in summertime cold periods can occur to make heating necessary, although, these summerly heating periods are not as intensive as in wintertime. Such a seasonality can also be seen in Northwest Mexico, even as the 
seasonality is not as significant as in Finland. Here, in the summertime, heating is not needed for longer periods. Even in wintertime, on some days no heating is required. For Kalimantan and Sulawesi in Indonesia, due to the location near the equator, a different picture emerges: Space heating is required throughout the whole year but on a very low absolute level. On the contrary to the other SHD profiles, no specific heating period occurs, and the heating is distributed more evenly. West Australia representing the southern hemisphere shows a shift of the heating demand to the middle of the year due to the shift of seasons. Interesting is the maximum amount of heating relative to the annual total, or rather the spread of the maximum between the regions: In Finland, the maximum is $0.03 \%$ per hour, while in East Indonesia the maximum hourly value is about $0.75 \%$ of the annual total.

In Figure 15, the profiles of DHW are shown for the exemplary regions.
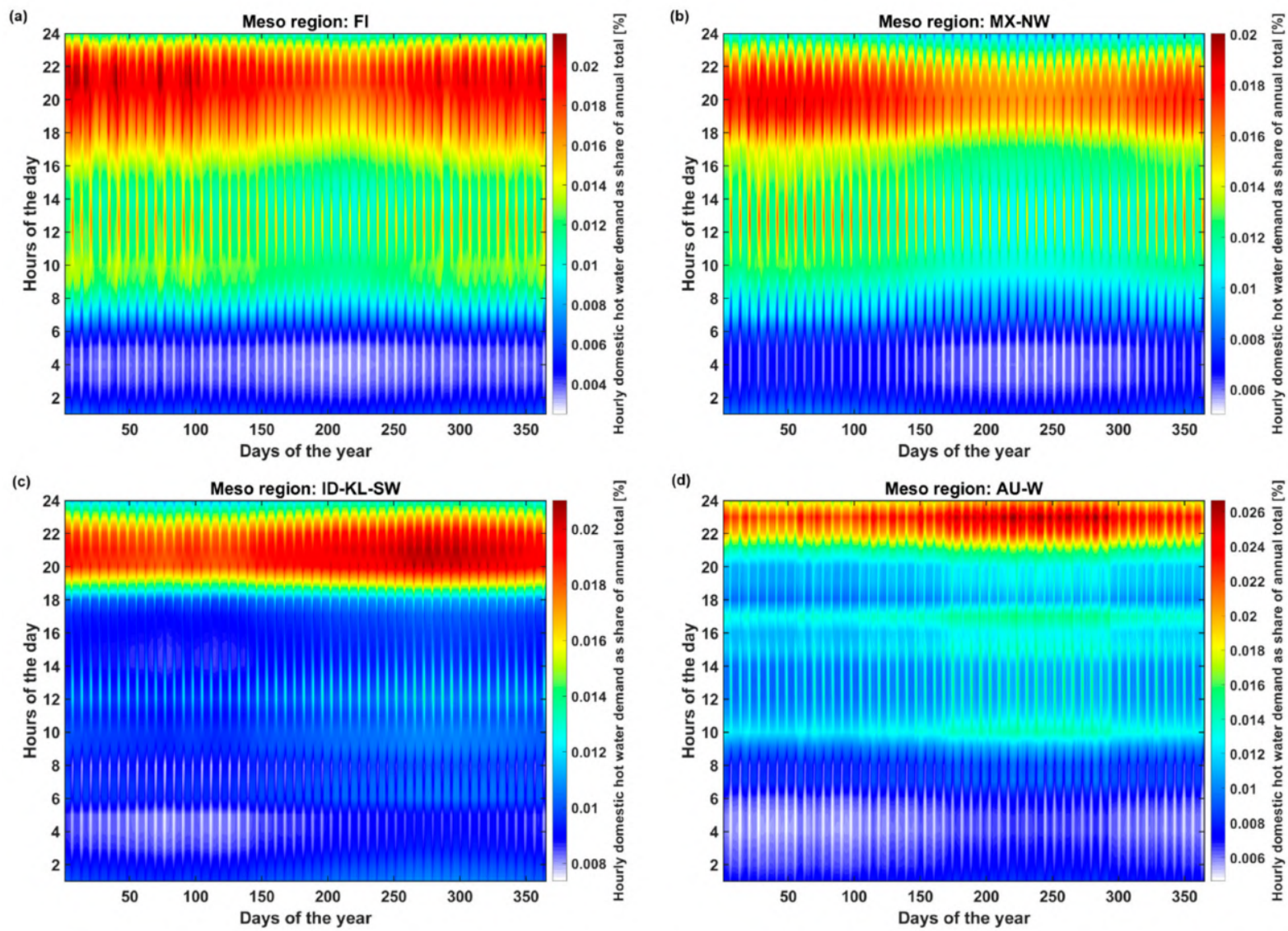

Figure 15. Annual domestic hot water demand profiles as hourly values relative to the annual total, representative for different climatic conditions of the globe in local time: (a) Finland-FI; (b) Northwest Mexico-MX-NW; (c) Eastern Indonesia of Kalimantan and Sulawesi-ID-KL-SW; (d) West Australia-AU-W.

The DHW demand is concentrated in the evening hours for every mesoscale region. Human activities are usually concentrated in the evening hours, especially for activities demanding high amounts of hot water, such as taking a shower or bathing. In East Indonesia, most of the DHW is used during the evening hours, whereas for the other three mesoscale regions, some of the demand occurs already in the morning. What can be seen for all regions are the weekends as fine stripes between the working days with a different energy consumption behaviour. The higher the seasonality of the mesoscale region, the higher is the effect of changed DHW demand, especially noticeable in Finland and Northwest Mexico. 
The profiles for IHD were calculated for each time step. The profiles for 2020 are presented in Figure 16. All numeric profiles can be found in Supplementary File S4 (for the years 2020 until 2050 in 5-year steps).

(a)

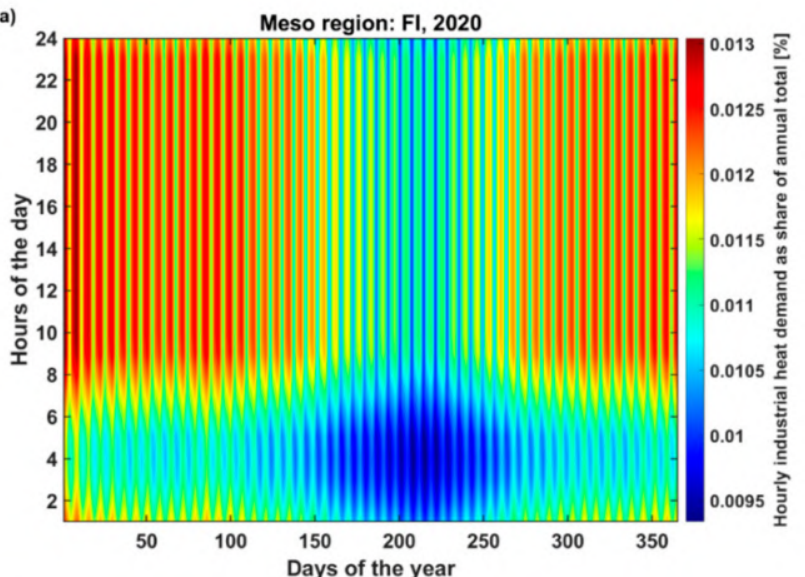

(c)

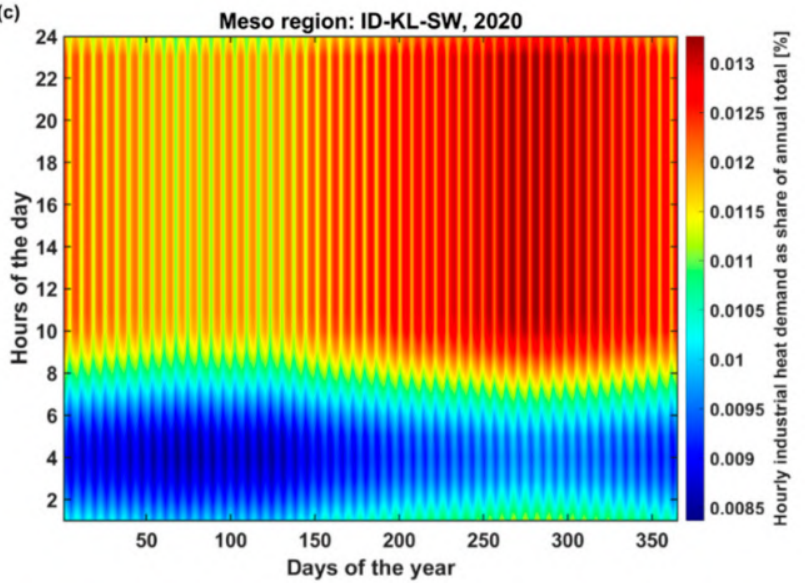

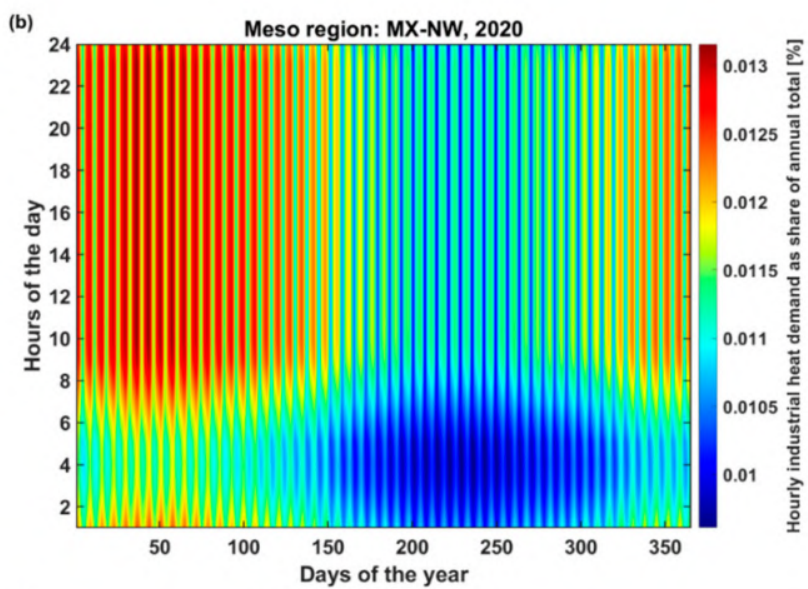

(d)

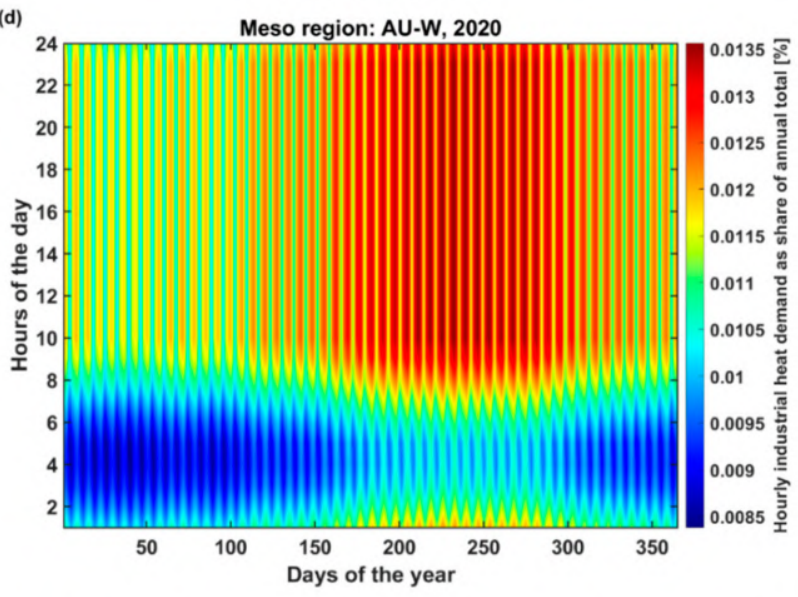

Figure 16. Annual industrial heat demand profiles as hourly values relative to the annual total, representative for different regions of the globe and the year 2020 in local time: (a) Finland-FI; (b) Northwest Mexico-MX-NW; (c) Eastern Indonesia of Kalimantan and Sulawesi-ID-KL-SW; (d) West Australia-AU-W.

For all four exemplary mesoscale regions, the difference between baseload and increasing demand during daytime can be observed, whereas the IHD demand during the day does not significantly change once it is ramped up, following the approach of an intraday baseload. The ramping up happens in the morning hours from around 6 a.m. to 8 a.m., when typically morning shifts are starting and companies, which only operate during the day start to use heat. The intensity of IHD coupled to the seasonality can also be observed, however, the impact on the profile shape is only significant for likewise significant seasonality changes. In Finland for example, during the few warm summer months, the reduced process heat demand clearly stands out. Assuming that the consumption of industrial heat is dependent on the climatic conditions, e.g., when colder ambient air is heated for a process, more heat is needed to provide the same temperature and vice versa. On the contrary, in Indonesia without a significant change in season, the difference can in fact be seen, but the total change of hourly heat demand share of the annual total demand is not as much influenced.

The baseload ratio is indicating the share of $24 / 7$ baseload and intraday load, as shown in Figure 17 for the years 2020 and 2050. 
(a)
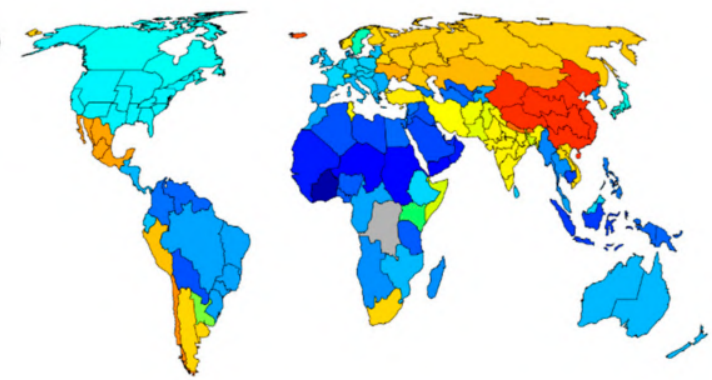

75

80

85

90

95

75 (b)
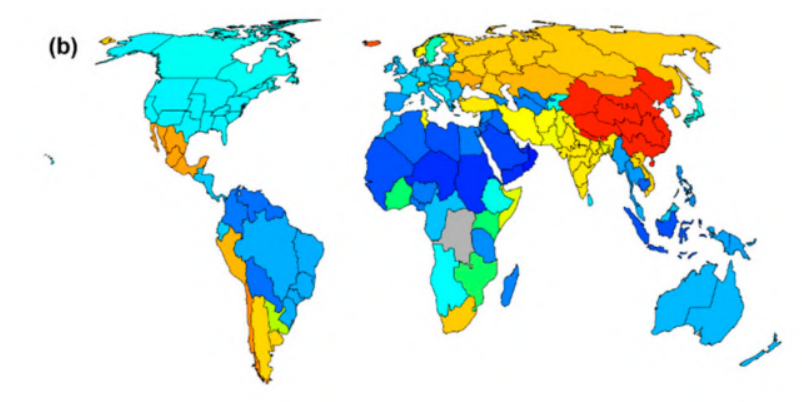

$\begin{array}{cccc}80 & 85 & 90 & 95 \\ \text { Baseload ratio of industrial heat demand in } 2050 B R_{I H D} & {[\%]}\end{array}$

Figure 17. Baseload ratio BR of industrial heat demand IHD globally in (a) 2020; (b) 2050. The Democratic Republic of the Congo-COG is coloured in grey due to no available electricity profile.

The baseload ratio reaches in 2020 from $76 \%$ in the mesoscale region West South Sahara including Benin, Burkina Faso, Cote D'Ivoire, Ghana and Togo to $96 \%$ for all regions of China. In general, the BR does not change significantly until 2050, only for the developing countries in the southern part of sub-Saharan Africa a noticeable change can be seen. In 2050, the lowest BR occurs on the Arabian sub-continent for the United Arab Emirates, Oman and Yemen, respectively. During the investigated time period, the mesoscale region West South Sahara has the highest change and gains $12 \%$ abs BR until 2050, from the already mentioned $76 \%$ in 2020 to $88 \%$ in 2050 . Whereas the majority of the regions increase their BR, on average by $0.45 \%$ abs, five regions show a decrease in BR: Norway $\left(-0.33 \%_{a b s}\right)$, Switzerland $(-0.05 \%$ abs $)$, Eastern Malaysia of Sarawak, Sabah, Labuan and Brunei $\left(-0.32 \%_{\text {abs }}\right)$, Kenya and Uganda $(-0.29 \%$ abs $)$ and the Indian Ocean region including Comoros Islands, Madagascar, Mayotte, Seychelles and Mauritius $\left(-0.23 \%_{\text {abs }}\right)$.

\section{Discussion}

This section first discusses the global cumulative heat demand results of the present study by a comparison of the global results of the studies reviewed in Section 2. Afterward, the results on a country-scale are validated with available literature data for the example of the European Union. The section concludes with an outlook on improvement options for heat demand modeling.

\subsection{Global Heat Demand}

Due to the lack of comprehensive and detailed heat demand data, it is difficult to compare and classify the results within existing data. However, some studies and reports modeled global energy systems until 2050 including the heat sector, as was shown in the literature review. In this section, the results of this research shall be compared to the range of the studies of the literature review reflecting existing energy system studies and other major reports and discussed in the context of these studies for the period until 2050. A comparison of total global heat demand is presented in Figure 18. As the first year in the studies varies, the comparison is made from 2020 onwards. 


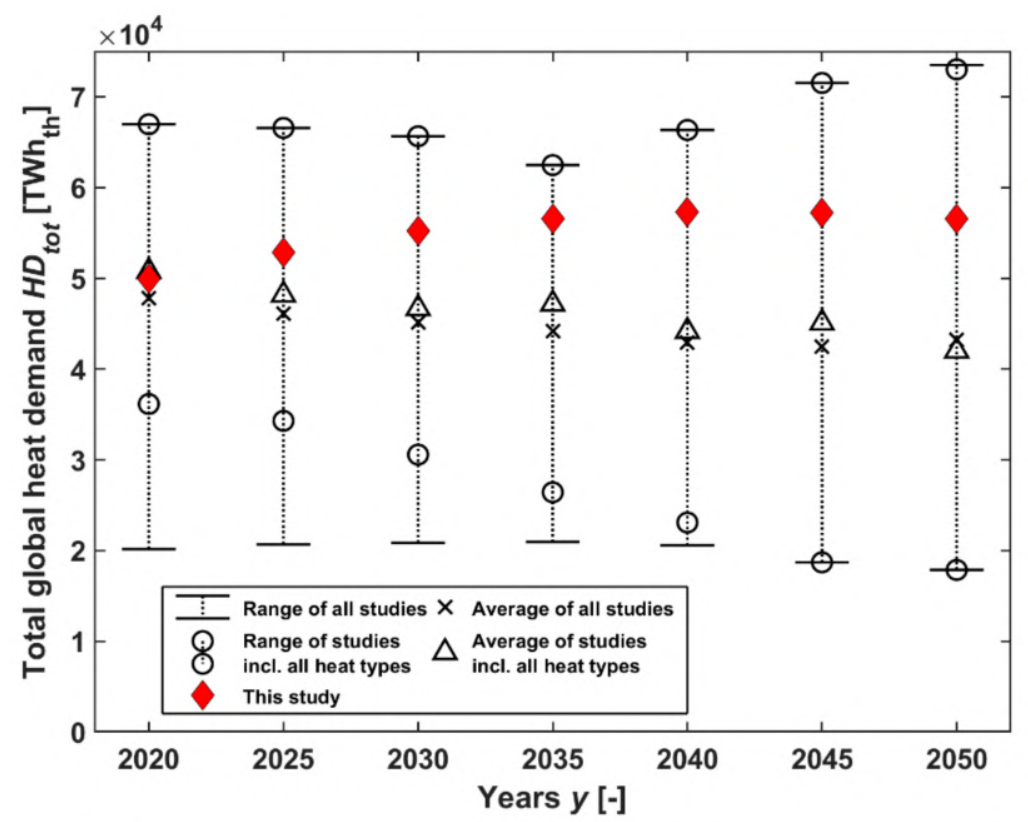

Figure 18. Comparison of the total global heat demand of existing global future energy system studies and the present study for the time period from 2020 to 2050. See Section 2 for the literature review for more details to the studies.

The modeling of heat demand is a very complex matter and available data are not very specific, which is confirmed by the large spread of total global heat demand values in the studies, in particular also for the value of 2020. Reasons for the substantial range, even for studies including all heat demand types, might be a not aligned reporting of heat demands and insufficient resolution in results, data and different methodologies. However, if the value of this study is compared to the average of all studies in 2020, the error margin is rather small. This study derives a total heat demand of about $50,000 \mathrm{TWh}_{\mathrm{th}}$, whereas the average of all studies is $47,850 \mathrm{TWh}_{\mathrm{th}}$. For studies including all heat demand types, the average is about $50,800 \mathrm{TWh}_{\mathrm{th}}$. After 2020 the average values and the values of this study diversify. Most of the available studies assume a decrease in total heat demand, whereas this study finds a rather increasing heat demand, despite the phase-out of $\mathrm{BCH}$, limited growth of IHD and SHD influenced by efficiency gains. In 2035, the total heat demand of 56,600 $\mathrm{TWh}_{\text {th }}$ of this study faces an average of 47,200 $\mathrm{TWh}_{\mathrm{th}}$ and 44,200 $\mathrm{TWh}_{\text {th }}$ for all studies and studies including all heat types, respectively. Even though the number of studies providing values for uneven years are less than for even years, the discrepancy between the average values and this study seems not to be influenced very much. At the end of the investigated time period, a total of $56,600 \mathrm{TWh}_{\text {th }}$ stands against $42,000 \mathrm{TWh}_{\text {th }}$ and $43,250 \mathrm{TWh}_{\text {th }}$ for all studies and studies including all heat types, respectively. This study projects about a $32 \%$ higher total heat demand until 2050 than the average of the studies also including all heat types. The range of projected heat demand in studies is very high from less than $20,000 \mathrm{TWh}_{\text {th }}$ to more than 70,000 $\mathrm{TWh}_{\mathrm{th}}$, which documents a lack of consensus on the further development in studies projecting the global heat demand. These structural results were already found for the transport sector by Khalili et al. [91]. The strong deviation seems to be influenced by quite diverging assumptions on improvements in overall efficiency, standards of living and economic development.

Factors, which affect the increase or decrease in the future heat demand have a strong impact on the heat demand until 2050. The present study considered several factors for the heat demand projections, such as population growth (all heat demand types), economic development (IHD, DHW), VAI (IHD), annual efficiency improvement of industrial heat processes and buildings (IHD, SHD), the introduction of ICS (BCH) and the temperature change due to climate change (SHD). The use of such factors are very important and should 
be reported in more detail along with a more comprehensive heat demand projection methodology.

The majority of the global cooling demand is provided by air conditioning, which is part of the power sector [37] as air conditioners are powered by electricity. Toktarova et al. [37] offer a broader discussion on this topic. Besides air conditioning, cooling appliances such as refrigerators on both a residential, as well as industrial scale, are also part of the power sector. In the context of this paper, cooling is not included in the heat demand investigation and results.

\subsection{Country-Level Validation}

Verification of the results per country and heat demand type is complicated, as one of the reasons for this study was the scarce availability of comprehensive heat demand data on a country-scale. For the EU some comparable data were found, which shall be used to validate the results for 2012 and the accuracy of the used method. Highly accurate data matching cannot be expected, as available data are scarce and if data are available, they have a rather high range, as it was shown in the last paragraph.

Verification of the SHD and DHW results in 2012 by means of a comparison of the literature data and the results of this study is presented in Figure 19a. Only two sources had been found providing numbers for space heating on country-scale: Connolly [92] and European Commission [93]. Connolly only provides numbers for 2010, which can be used as an approximation for the numbers of 2012, as they will not have changed significantly within two years. In the case of DHW, only European Commission [93] provides numbers.

(a)

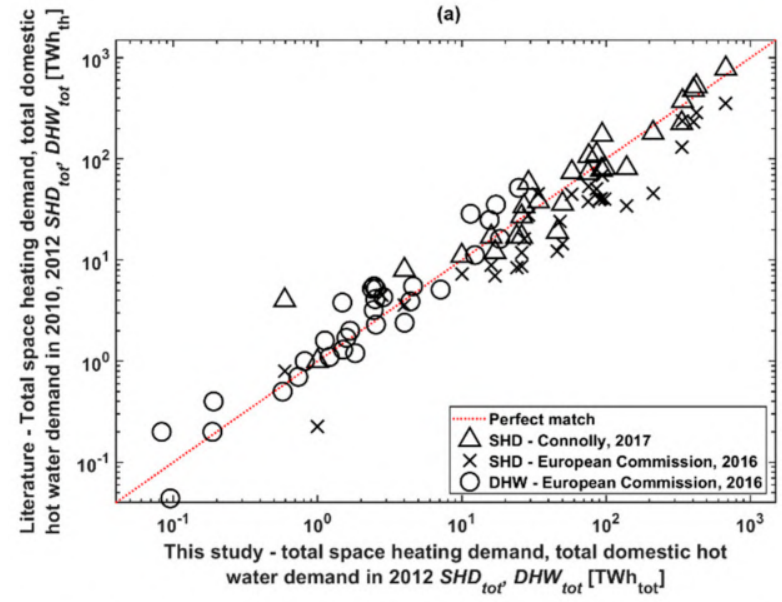

(b)

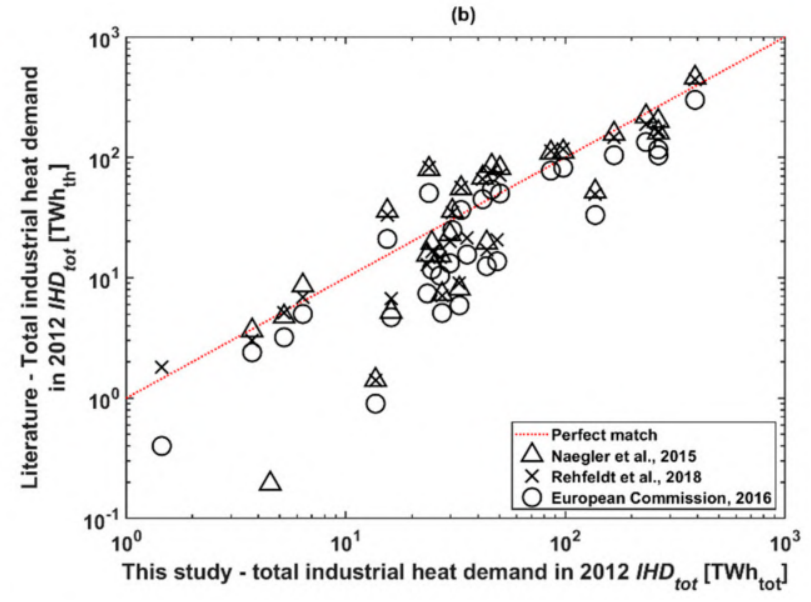

Figure 19. Comparison of results of the present study with the literature data: (a) EU-28 SHD data in relation to data from Connolly [92] (2010 data) and European Commission [93]; (b) Comparison of EU-28 and EU-28+3 IHD data in relation to data form Naegler et al. [40] (Approach 2, process heat only without space heating and hot water), Rehfeldt et al. [94] (without space heating) and European Commission [93].

Despite the fact that the data of Connolly presents 2010 numbers, the match is quite good. Some deviations can be observed, however in general, the data of the literature source and this study verify the success of disaggregating SHD data of the major regions according to population allocation and respective heat requirements. The same is valid for comparing the numbers with those of the European Commission, however, the present study rather overestimates the heat demand for space heating. On average, the numbers for DHW match the numbers from European Commission very well, while the deviation seems to be acceptable. In general, SHD as well as DHW numbers for 2012 show very good accordance with available data for the EU in 2012. No extreme outliers exceeding a decimal power in comparison to the compared number are visible.

A comparison of the disaggregating results for IHD in 2012 of the EU-28 and EU$28+3$ countries can be made using results from Naegler et al. [40], Rehfeldt et al. [94] and 
European Commission [93], which can be seen in Figure 19b. Unlike the general approach of redistributing total heat demands from major regions to country-scale, those studies used specific data for the industry structure and energy intensity of the countries to estimate the process heat demand.

Naegler et al. quantify the EU-28 industrial heat demands based on IEA data and available datasets for the process heat demand of different industry branches. As it can be seen, for most of the countries the results of this study match the values of Naegler et al. relatively well. As Naegler et al. considered the respective industry characteristics of the countries, some deviations of the data around the perfect fit line are not surprising. Apart from bigger deviations for data between $10 \mathrm{TWh}_{\mathrm{th}}$ and $100 \mathrm{TWh}_{\text {th }}$ and one major outlier, the fit seems to be better for countries with either low or high IHD. The same effect can be recognised when comparing the results of this study with the results provided in Rehfeldt et al., who use a similar bottom-up approach as Naegler et al. for describing process heat demand based on specific data for industries. The value for the extreme outlier, which is the value for Malta, is not plotted for the Rehfeldt et al. comparison, as Rehfeldt et al. estimate no IHD at all. Beyond that, the values show also a good fit. Again, between 10 $\mathrm{TWh}_{\mathrm{th}}$ and $100 \mathrm{TWh}_{\mathrm{th}}$, the deviation of the data fit is higher than for smaller and higher IHDs. The same characteristic can be found for comparing the numbers of this study with that of the European Commission. A reason could be, that the disaggregating with regard to the total GDP of a country favours better results for countries with either only small industrial activities or a large industry. In between, the structure of the industry of a country apparently influences the variation of the IHD more strongly. Aggregating countries to mesoscale regions can or cannot have a positive effect. If a country, which may be underrepresented by the applied method is aggregated with a country, which is overrepresented, in total the combined mesoscale regions may fit the actual value for the whole mesoscale region better. However, if two or more underrepresented countries are aggregated, the total discrepancy may be propagated. Even though, if the markers in Figure $19 \mathrm{~b}$ are under the perfect match line, it means that the numbers of this study are higher than those from the literature. As this is the case for the majority of the values, it appears that the presented method of this paper rather overestimates the IHD compared to the literature data.

Due to the lack of available comprehensive heat data, however, this makes it difficult to compare results with actual values or other literature data. It was shown that the spread for total heat demand data among similar studies can be significant. This can also be assumed on a country or regional basis. Unless comprehensive data are published by official institutions this uncertainty will be persisting. Detailed reporting of results and mentioning final energy demand should be standardised, e.g., by guidelines for reporting the accounting of heat pumps with their output heat. In addition, even the same organisational entity, here European Commission, uses two entirely different metrics for the case of ambient heat for heat pumps. For energy efficiency measures ambient heat utilised by heat pumps is excluded from the energy balance [95], while for renewable energy targets on a final energy basis ambient heat is included. Physically correct is the inclusion of ambient heat. This example highlights that more unified accounting standards are required, and the lack of such standards may partly explain the range of heat demand used in energy scenarios. There is especially a lack of data beyond the EU on a national scale for comparison and verification.

\subsection{Outlook for Improvements}

The present study aimed to find a methodology to create a comprehensive heat demand database on a global-local scale. Even though the results are validated in the context of available literature, some improvements can be pointed out.

This study only analysed biomass-based cooking demand. Further research on heat demand for cooking will be carried out. In this light, more detailed modeling of the heat demand for cooking for used energy carriers, particularly non-electricity cooking heat 
demand including LPG, natural gas (NG), oil and petroleum products, biogas, and solid fossil fuels. In addition, various transition pathways and scenarios will be analysed that could cater, for instance, to achieving sustainable cooking solutions globally.

For the SHD, some improvement might be possible using projected temperature profiles. For this, more details on more specific impacts of climate change on the temperature profiles would be necessary, e.g., the impact on the diurnal temperature variation for different regions in the world and a higher variation of numbers for the average temperature change at least on country scale for the latest climate change scenarios. In this context, the impact of climate change on various input parameters (as shown in Figures 4 and 7), as well as on the respective outcome (as presented in Figures 8 and 9 and Table 5) could be analysed in a multidimensional approach. Modeling the SHD and the respective heat demand profiles of one of the major heat demand types including as much detail as possible are expected to have a significant impact on heat and energy system modeling.

The same is valid for industrial process heat. In this case, major industries can be singled out, such as cement, steel, aluminium, pulp and paper, so that better statistical data for these industries can be used and an industry-specific heat demand tracing can be carried out. Fully integrated energy-industry transition studies are the next step [96], and if carried out on a global scale, require a most detailed mapping of the industry heat demand. A further necessity is the definition of temperature levels of the IHD, as this is the basis for choosing the best suitable heat supply technologies. The IHD may be classified in low-, medium- and high-temperature classes. Temperature levels could be chosen to be about $<100{ }^{\circ} \mathrm{C}$ for low temperature, $100-400{ }^{\circ} \mathrm{C}$ for medium temperature and $>400{ }^{\circ} \mathrm{C}$ for high-temperature applications, for the most important industry branches [3,40,97], while a more detailed temperature level breakdown could be possible $[40,98]$. Defining temperature levels may also enable a downwards use of heat, if available. This includes a specific investigation on the required heat demand per temperature class of industrial process heat. IHD profiles have to be adapted to specific industries and their typical heat demand structure, especially in the case of the baseload ratio and the impact of seasonality on the IHD.

In general, an expansion of the heat demand investigation to the end of the century will be necessary. To fully understand the mitigation options for climate change, the future energy system until the end of the century will have to come into focus. A more detailed view of industrial cooling and space cooling demand may lead to further improvements and more detailed investigations of the heat sector. Factors that have an influence on the different heat demand types have to be reported in more detail and a broader discussion on these parameters would strengthen the process towards a more standardised heat demand projection methodology. Heat demand as one of the major contributors to global energy consumption will play a vital role in the second half of the 21st century.

\section{Conclusions}

A thorough investigation of the global heat demand by different heat types is provided by the present study. Modeling the heat demand for the time of the energy transition until 2050 was shown to be challenging, due to the lack of well-accepted methods and especially due to the lack of comprehensive and consistent databases for the current heat demand. Each heat demand-type requires its specific method and input data. A general estimation of the future heat demand without considering the characteristic dependencies does not provide detailed and applicable heat demand results. The present study prepared methods and linked them to available data for obtaining and projecting data for the transition period until 2050.

The total global heat demand is estimated to increase from about $50,000 \mathrm{TWh}_{\mathrm{th}}$ in 2020 by about $6600 \mathrm{TWh}_{\text {th }}$ to $56,600 \mathrm{TWh}_{\text {th }}$ by 2050 . The main driver for heat demand growth is expected to be industrial process heat, initiated by a strong economic development in South Asia and sub-Saharan Africa. Hot water demand in domestic dwellings is also expected to rise significantly, due to strong population growth in sub-Saharan Africa and 
increasing standards of living. The heat used for space heating is expected to peak in a few decades, after which more energy-efficient buildings will lead to a slight reduction of the space heating demand by 2050. On the contrary to the generally increasing heat demand, a phase-out path is provided for almost $6000 \mathrm{TWh}_{\text {th }}$ of biomass for cooking achievable by 2050. Traditional biomass for cooking use is not only highly inefficient energy use, but also highly harmful for the health of people, in particular for women and children. A detailed database for the global heat demand until 2050 has been created, including hourly heat demand profiles. For the case of space heating, the profiles based on temperature profiles constitute a good representation of the times when energy for space heating is needed. The profiles for domestic hot water are based on residential electricity profiles and are a good reflection of the energy consumption in residential dwellings. Industrial heat has been assigned to follow a derivation of the national electricity profiles. Even though this is an acceptable representation of industrial activities over the year, a more detailed investigation on heat demand profile modeling and respective parameters influencing the need for industrial process heat require more research effort in the future.

Heat, together with electricity, is one of the most important energy sectors globally. Particularly when it comes to climate change mitigation and reducing $\mathrm{CO}_{2}$ emissions, the heat sector, still mostly fired by fossil fuels, has to contribute substantially to a successful energy transition. Reliable and comprehensive data for energy system modeling help to understand the mitigation options for the global-local heat supply and finally to find the best solutions to reduce the carbon footprint of this energy sector.

Supplementary Materials: The following are available online at https:/ / www.mdpi.com/article/10 .3390 /en14133814/s1, File S1: Input data and results, File S2: Results visualisation in global maps based on 145 mesoscale regions, File S3: Cumulative heat development for all heat demand types for 145 mesoscale regions, File S4: Hourly heat demand profiles for 145 mesoscale regions and all heat demand types (in \% of annual demand).

Author Contributions: Conceptualization, D.K., L.D.S.N.S.B., C.B.; methodology, D.K., L.D.S.N.S.B.; software, D.K., L.D.S.N.S.B.; validation, D.K., L.D.S.N.S.B., D.B., A.A., A.G., S.O., M.C., S.K., C.B.; formal analysis, D.K., L.D.S.N.S.B., D.B., S.K., C.B.; investigation, D.K., L.D.S.N.S.B., A.A., A.G., S.O., M.C., S.K.; resources, D.K., L.D.S.N.S.B., D.B., A.A., A.G., S.O., M.C., S.K.; data curation, D.K., L.D.S.N.S.B., D.B., A.A., A.G., S.O., M.C., S.K.; writing—original draft preparation, D.K.; writingreview and editing, D.K., L.D.S.N.S.B., D.B., A.A., A.G., S.O., M.C., S.K., C.B.; visualization, D.K.; supervision, C.B. All authors have read and agreed to the published version of the manuscript.

Funding: The authors gratefully acknowledge the public financing of Tekes for the "Neo-Carbon Energy" project under the number 40101/14. Ashish Gulagi and Ayobami Solomon Oyewo would like to thank Fortum Foundation and LUT Foundation, respectively, for the valuable scholarships.

Informed Consent Statement: Not applicable.

Data Availability Statement: See Supplementary Material.

Conflicts of Interest: The authors declare no conflict of interest. 


\section{Nomenclature}

Abbreviations and Symbols

A

$\mathrm{A}_{\mathrm{av}}$

BL

$\mathrm{CH}$

$\mathrm{BCH}$

CAGR

$\mathrm{CO}_{2}$

DHW

$\mathrm{E}_{\mathrm{h}}$

$\eta_{\mathrm{BE}}$

$\eta_{C S}$

$\eta_{\mathrm{IE}}$

$\varepsilon_{\mathrm{BE}}$

$\varepsilon_{\text {IND }}$

EU

GDP

GPr

HD

$\mathrm{HDH}$

$\mathrm{HDH}^{\prime}$

ICS

IDBL

IDL

idx

IEA

IHD

$\mathrm{IHD}^{\prime}$

IPCC

GHG

$\lambda$

LPG

$\mathrm{Nat}_{\mathrm{el}}$

$\mathrm{Nat}_{\text {peak }}$

$\mathrm{N}_{\mathrm{c}}$

NG

$\mathrm{N}_{\mathrm{r}}$

$\mathrm{OHD}$

$\mathrm{p}$

pop

pph

RES

Resel $_{\mathrm{el}}$

$\operatorname{Res}^{\prime}{ }_{\mathrm{el}}$

RFA

$\mathrm{S}_{\mathrm{h}}$

SHD

$\mathrm{T}$

$\tau$

TBMC

TCS

$\vartheta$

VAI

W

WEO

$\xi$
Set of all countries in Africa incl. North Africa

Set of countries in Africa with available biomass data

Baseload

Cooking heat consumption

Biomass for cooking heat demand

Compound annual growth rate

Carbon dioxide

Domestic hot water demand

Heat energy of sector

Building efficiency factor

Cookstove efficiency

Industry efficiency factor

Building efficiency improvement per year

Efficiency improvement per year of industry sector

European Union

Gross domestic product

Set of countries in a Greenpeace region

Total heat demand

Heat degree hour

Adapted heat degree hour

Improved cookstove

Intraday baseload

Intraday load

index of intraday baseload reference value in daily profile

International Energy Agency

Industrial heat demand

Industrial heat demand profile adapted to seasonality

Intergovernmental Panel on Climate Change

Greenhouse gases

Form parameter

Liquefied petroleum gas

National electricity profile

First derivative of the baseload reduced national electricity profile

Set of nodes of a specific country

Natural gas

Set of nodes of a specific mesoscale region

Other heat demand

share

population

people per household

Renewable Energy Sources

Residential electricity profile

Residential electricity profile adapted to seasonality

Residential floor area

Set of heat sources

Space heating demand

Temperature

Seasonality impact scaling exponent

Traditional biomass cookstove

Traditional cookstove

Seasonality factor

Value added by industry

weight

World Energy Outlook

Phase-out function for biomass-based cooking 


\begin{tabular}{|c|c|}
\hline \multicolumn{2}{|c|}{ Subscripts } \\
\hline a & annual \\
\hline Africa & with regard to Africa \\
\hline av & available \\
\hline ave & average \\
\hline bio & biomass \\
\hline c & country \\
\hline cap & per capita \\
\hline $\mathrm{CO}$ & with regard to Colombia \\
\hline $\mathrm{d}$ & day, daily \\
\hline$\Delta \mathrm{t}$ & time step \\
\hline GPr & Greenpeace region \\
\hline $\mathrm{h}$ & hour, hourly \\
\hline hlim & heating limit \\
\hline ind & industry sector \\
\hline IPPCr & IPPC region \\
\hline $\min$ & minimum \\
\hline $\mathrm{n}$ & node \\
\hline norm & normalised \\
\hline other & other sectors \\
\hline r & mesoscale region \\
\hline RCS & Cookstove efficiency region \\
\hline rel & relative \\
\hline res & residential sector \\
\hline rfa & per residential floor area \\
\hline$\Sigma$ & summed up value \\
\hline SHD & of total space heating demand \\
\hline src & heat source \\
\hline TL & trendline \\
\hline tot & total \\
\hline $\mathrm{y}$ & year \\
\hline
\end{tabular}

Appendix A

Supporting Figures

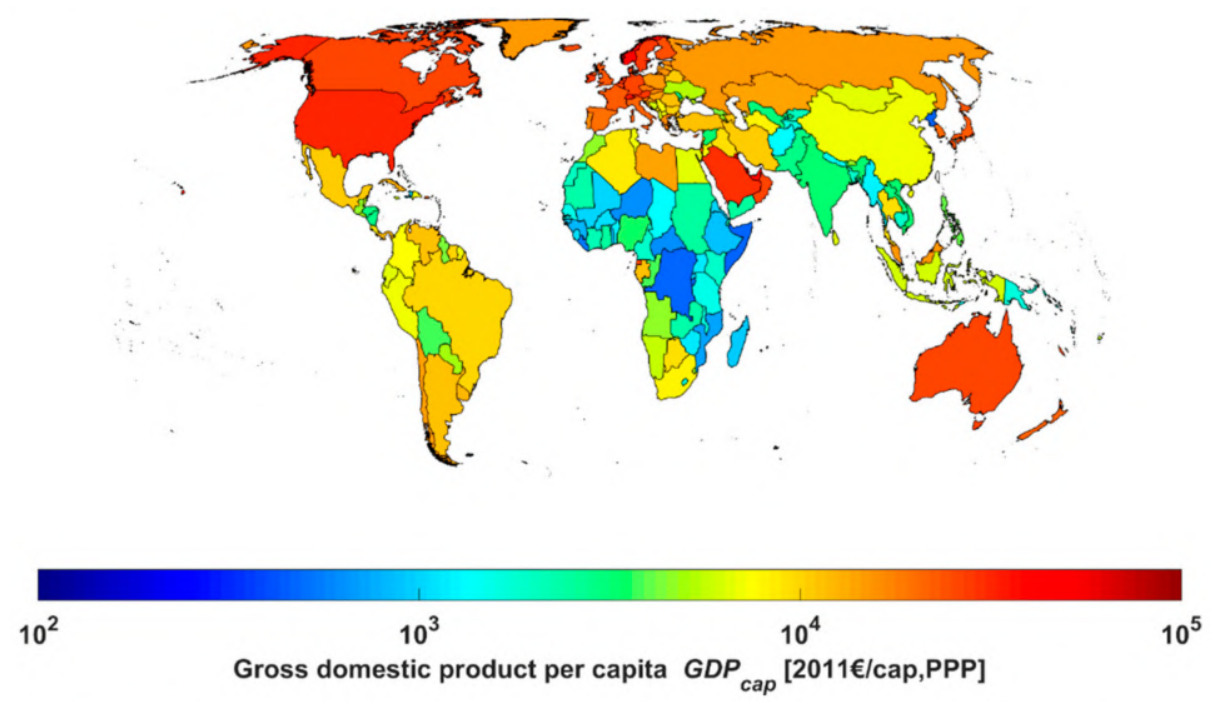

Figure A1. GDP per capita for the year 2012. Numbers are taken from [37]. 


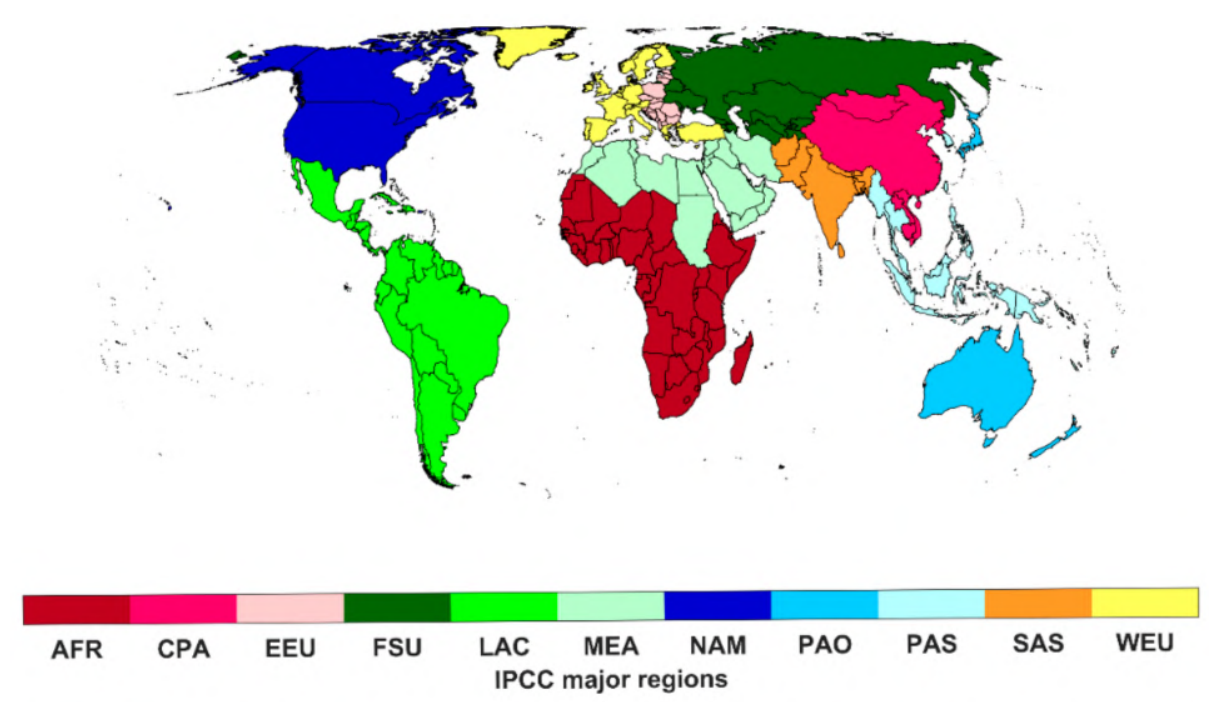

Figure A2. Aggregation of the countries to the IPCC major regions per definition as of [45]. Countries that are not included in the region description, but are included in Greenpeace major regions, were assigned to a respective IPCC region. These countries are Western Sahara (AFR), Macao (CPA), Timor-Leste (PAS), British Virgin Islands (LAC), Cayman Islands (LAC), Turks and Caicos Islands (LAC) and Cook Islands (PAS).

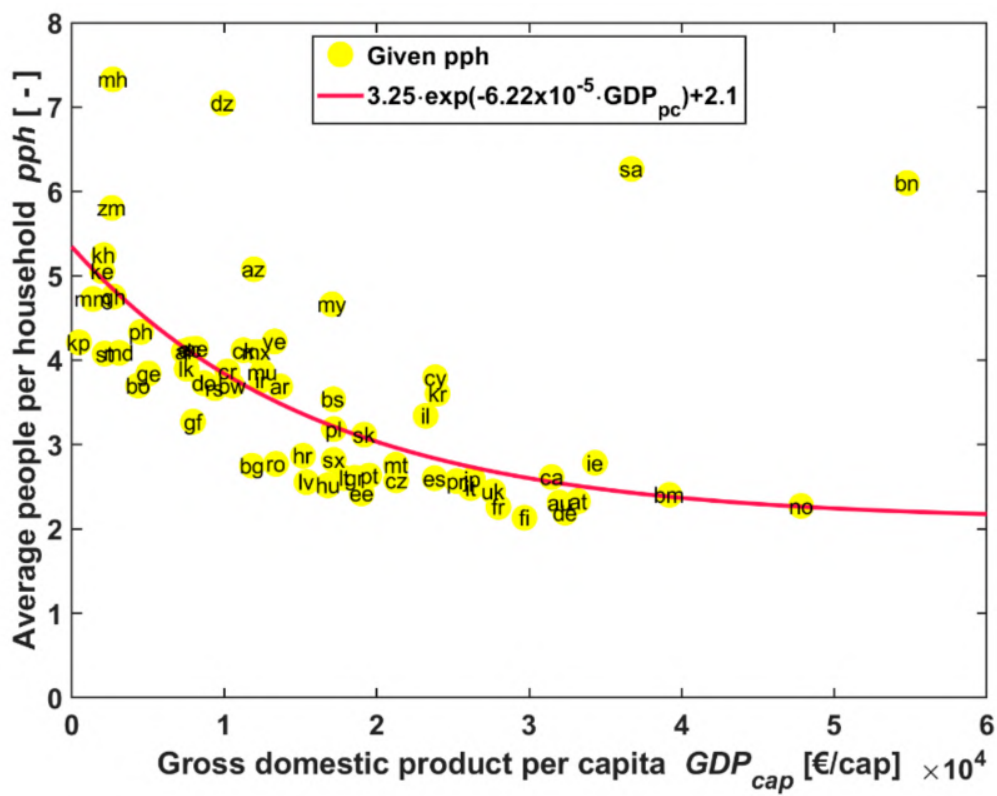

Figure A3. Data for people per household given in [46] for $2012 \pm 5$ years over GDP per capita [37] and trendline function. Countries are indicated by their internet domain. 


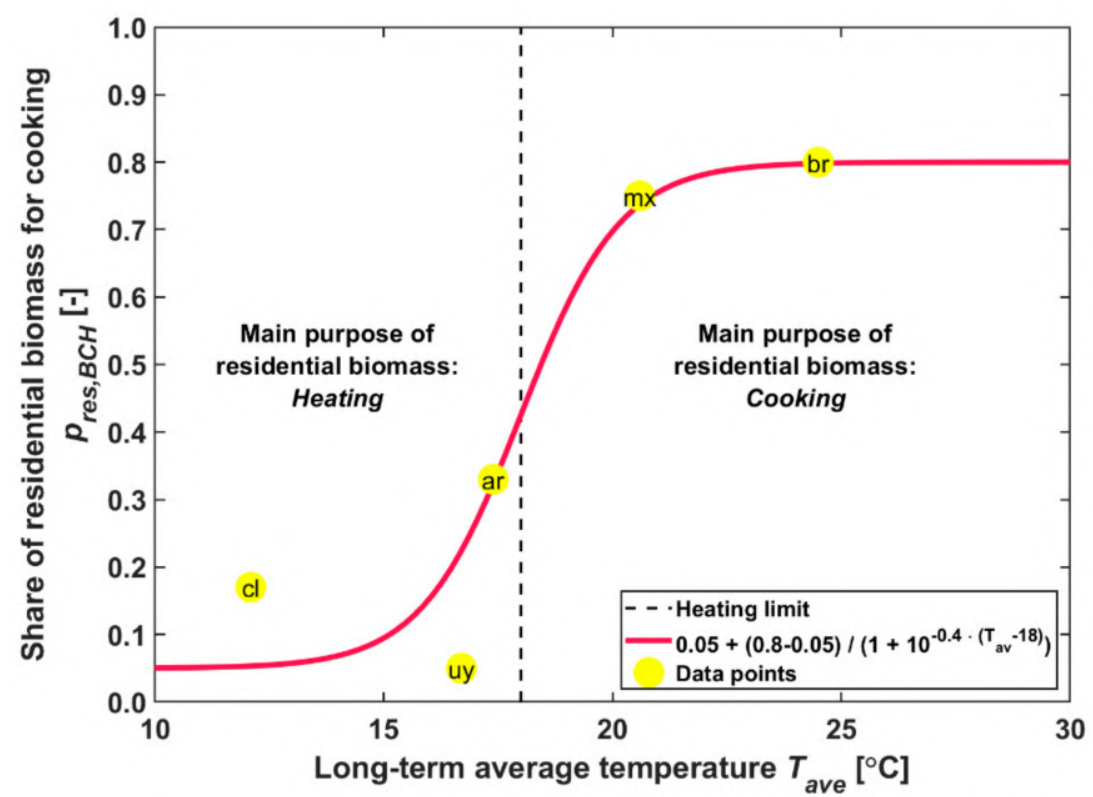

Figure A4. Correlation of percentage of total residential biomass used for cooking and long-term average temperature in Central and South America. Exemplarily shown are the countries Argentina, Brazil, Chile, Mexico and Uruguay, indicated by their internet domain and an estimation of the correlation with a logistic function.

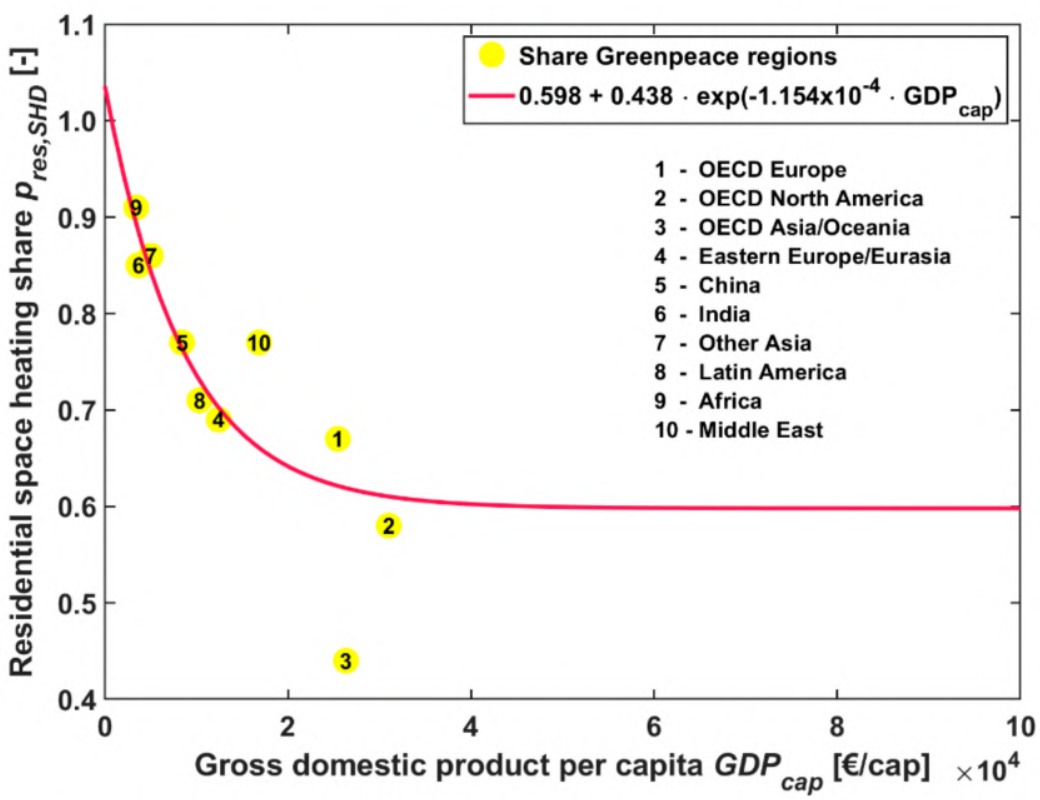

Figure A5. Share of residential space heating in total SHD for the ten Greenpeace major regions over the population-weighted GDP per capita of the regions and trendline function. 


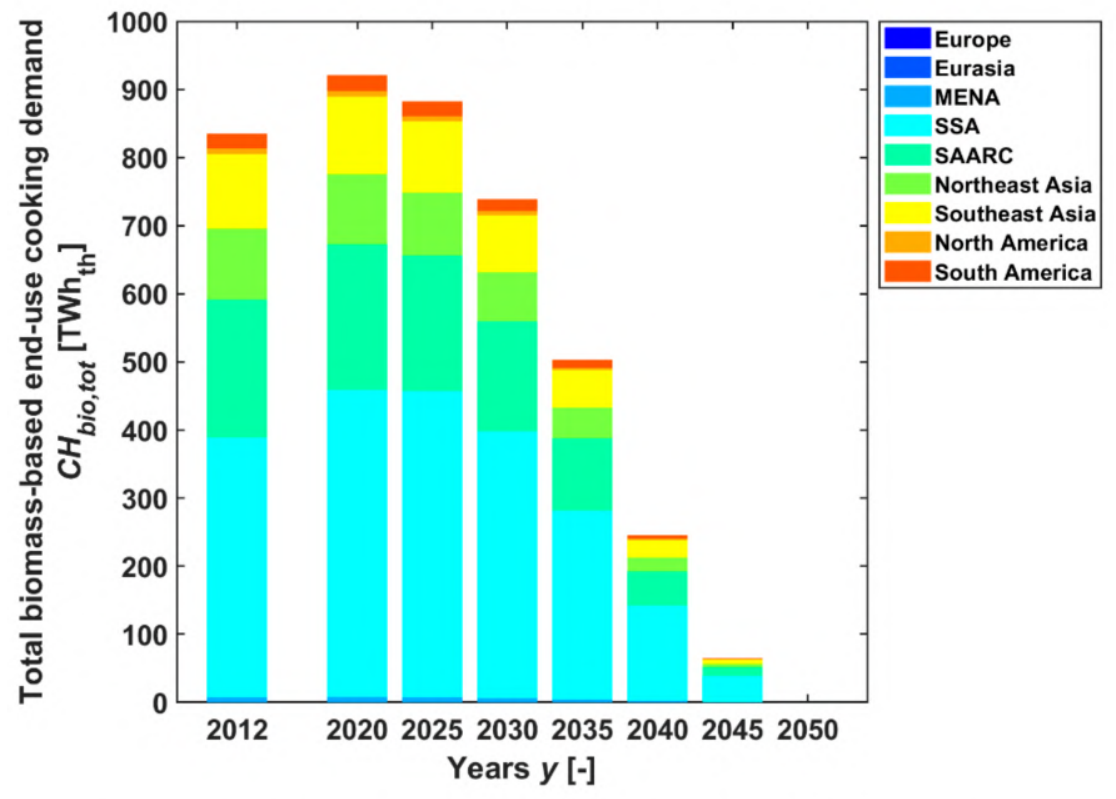

Figure A6. Global end-use cooking heat based on biomass for the 9 major regions of the LUT model from 2012 to 2050 .

\section{References}

1. United Nations Framework Convention on Climate Change (UNFCC). Report of the Conference of the Parties on its Twenty-First Session FCCC/CP/2015/10/Add.1; UNFCC: Paris, France, 2015.

2. Ürge-Vorsatz, D.; Petrichenko, K.; Staniec, M.; Eom, J. Energy use in buildings in a long-term perspective. Curr. Opin. Environ. Sustain. 2013, 5, 141-151. [CrossRef]

3. International Energy Agency (IEA). Clean and Efficient Heat for Industry; IEA: Paris, France, 2018; Available online: https: / / www.iea.org/commentaries / clean-and-efficient-heat-for-industry (accessed on 20 January 2021).

4. International Renewable Energy Agency (IRENA). Global Energy Transformation: A Roadmap to 2050, 2019th ed.; IRENA: Abu Dhabi, United Arab Emirates, 2019; ISBN 978-92-9260-121-8.

5. Renewable Energy Policy Network for the 21st Century (REN21). Renewables Global Futures Report-Great Debates towards 100\% Renewable Energy; REN21: Paris, France, 2017; ISBN 9783981810745.

6. International Energy Agency (IEA). Renewables 2019-Analysis and Forecast to 2024; IEA: Paris, France, 2019; ISBN 978-92-64-369986.

7. Kavvadias, K.; Jimenez-Navarro, J.; Thomassen, G. Decarbonising the EU Heating Sector-Integration of the Power and Heating Sector, EUR 29772 EN, JRC114758. Publications Office of the European Union: Luxembourg, 2019; ISBN 978-92-76-08386-3.

8. Thomaßen, G.; Kavvadias, K.; Jiménez Navarro, J.P. The decarbonisation of the EU heating sector through electrification: A parametric analysis. Energy Policy 2021, 148, 111929. [CrossRef]

9. Arpagaus, C.; Bless, F.; Uhlmann, M.; Schiffmann, J.; Bertsch, S.S. High temperature heat pumps: Market overview, state of the art, research status, refrigerants, and application potentials. Energy 2018, 152, 985-1010. [CrossRef]

10. Schoeneberger, C.A.; McMillan, C.A.; Kurup, P.; Akar, S.; Margolis, R.; Masanet, E. Solar for industrial process heat: A review of technologies, analysis approaches, and potential applications in the United States. Energy 2020, 206, 118083. [CrossRef]

11. Farjana, S.H.; Huda, N.; Mahmud, M.A.P.; Saidur, R. Solar process heat in industrial systems-A global review. Renew. Sustain. Energy Rev. 2018, 82, 2270-2286. [CrossRef]

12. Fischer, D.; Madani, H. On heat pumps in smart grids: A review. Renew. Sustain. Energy Rev. 2017, 70, 342-357. [CrossRef]

13. Lund, H.; Østergaard, P.A.; Nielsen, T.B.; Werner, S.; Thorsen, J.E.; Gudmundsson, O.; Arabkoohsar, A.; Mathiesen, B.V. Perspectives on fourth and fifth generation district heating. Energy 2021, 227, 120520. [CrossRef]

14. David, A.; Mathiesen, B.V.; Averfalk, H.; Werner, S.; Lund, H. Heat Roadmap Europe: Large-Scale Electric Heat Pumps in District Heating Systems. Energies 2017, 10, 578. [CrossRef]

15. Keiner, D.; Ram, M.; Barbosa, L.D.S.N.S.; Bogdanov, D.; Breyer, C. Cost optimal self-consumption of PV prosumers with stationary batteries, heat pumps, thermal energy storage and electric vehicles across the world up to 2050. Sol. Energy 2019, 185, 406-423. [CrossRef]

16. World Future Council; Hivos. Beyond Fire: How to Achieve Sustainable Cooking; The Hague: Hamburg, Germany, 2016.

17. World Future Council; Hivos. Beyond Fire: How to Achieve Electric Cooking; The Hague: Hamburg, Germany, 2019.

18. International Energy Agency (IEA). World Energy Outlook 2015; IEA: Paris, France, 2015; ISBN 978-92-64-24366-8.

19. International Energy Agency (IEA). World Energy Outlook 2020; IEA: Paris, France, 2020; ISBN 978-92-64-44923-7. 
20. International Energy Agency (IEA). Data and Statistics; IEA: Paris, France, 2021; Available online: https://www.iea.org/data-andstatistics / data-tables (accessed on 20 January 2021).

21. Teske, S.; Pregger, T.; Simon, S.; Naegler, T. High renewable energy penetration scenarios and their implications for urban energy and transport systems. Curr. Opin. Environ. Sustain. 2018, 30, 89-102. [CrossRef]

22. Prentiss, M. Energy Revolution; Harvard University Press: Hamburg, Germany; Brussels, Belgium, $2015 ;$ ISBN 9780674736139.

23. Sachs, J.; Moya, D.; Giarola, S.; Hawkes, A. Clustered spatially and temporally resolved global heat and cooling energy demand in the residential sector. Appl. Energy 2019, 250, 48-62. [CrossRef]

24. Isaac, M.; van Vuuren, D.P. Modeling global residential sector energy demand for heating and air conditioning in the context of climate change. Energy Policy 2009, 37, 507-521. [CrossRef]

25. Shell International, B.V. Sky Scenario-Meeting the Goals of the Paris Agreement; Shell International B.V.: Den Haag, The Netherlands, 2018.

26. Jacobson, M.Z.; Delucchi, M.A.; Cameron, M.A.; Coughlin, S.J.; Hay, C.A.; Manogaran, I.P.; Shu, Y.; von Krauland, A.-K. Impacts of Green New Deal Energy Plans on Grid Stability, Costs, Jobs, Health, and Climate in 143 Countries. One Earth 2019, 1, 449-463. [CrossRef]

27. International Energy Agency (IEA). Net Zero by 2050; IEA: Paris, France, 2021.

28. DNV. Energy Transition Outlook 2020; DNV: Høvik, Norway, 2019.

29. Löffler, K.; Hainsch, K.; Burandt, T.; Oei, P.-Y.; Kemfert, C.; von Hirschhausen, C. Designing a Model for the Global Energy System-GENeSYS-MOD: An Application of the Open-Source Energy Modeling System (OSeMOSYS). Energies 2017, 10, 1468. [CrossRef]

30. Intergovernmental Panel on Climate Change (IPCC). Global Warming of $1.5^{\circ} \mathrm{C}$. An IPCC Special Report on the Impacts of Global Warming of $1.5^{\circ} \mathrm{C}$ above Pre-Industrial Levels and Related Global Greenhouse Gas Emission Pathways, in the Context of Strengthening the Global Response to the Threat of Climate Change; IPCC: Geneva, Switzerland, 2018.

31. U.S. Department of Energy. International Energy Outlook 2019; U.S. Department of Energy: Washington, DC, USA, 2019.

32. World Wildlife Fund (WWF). The Energy Report 100\% Renewable Energy by 2050; WWF: Washington, DC, USA, 2011; ISBN 978-2-940443-26-0.

33. Deng, Y.Y.; Blok, K.; van der Leun, K. Transition to a fully sustainable global energy system. Energy Strateg. Rev. 2012, 1, 109-121. [CrossRef]

34. Achieving the Paris Climate Agreement Goals. Teske, S., Ed.; Springer International Publishing: Cham, Switerland, 2019; ISBN 978-3-030-05842-5.

35. Bogdanov, D.; Ram, M.; Aghahosseini, A.; Gulagi, A.; Oyewo, A.S.; Child, M.; Caldera, U.; Sadovskaia, K.; Farfan, J.; De Souza Noel Simas Barbosa, L.; et al. Low-cost renewable electricity as the key driver of the global energy transition towards sustainability. Energy 2021, 227, 120467. [CrossRef]

36. Ram, M.; Bogdanov, D.; Aghahosseini, A.; Gulagi, A.; Oyewo, A.; Child, M.; Caldera, U.; Sadovskaia, K.; Farfan, J.; Barbosa, L.; et al. Global Energy System based on 100\% Renewable Energy-Power, Heat, Transport and Desalination Sectors. Lappeenranta University of Technology and Energy Watch Group: Lappeenranta, Finland; Berlin, Germany, 2019; ISBN 978-952-335-339-8.

37. Toktarova, A.; Gruber, L.; Hlusiak, M.; Bogdanov, D.; Breyer, C. Long term load projection in high resolution for all countries globally. Int. J. Electr. Power Energy Syst. 2019, 111, 160-181. [CrossRef]

38. United Nations Department of Economic and Social Affairs World Population Prospects 2019; Washington, DC, USA. 2019. Available online: https:/ / population.un.org/wpp/Download/Standard/Population/ (accessed on 23 June 2020).

39. Bogdanov, D.; Farfan, J.; Sadovskaia, K.; Aghahosseini, A.; Child, M.; Gulagi, A.; Oyewo, A.S.; de Souza Noel Simas Barbosa, L.; Breyer, C. Radical transformation pathway towards sustainable electricity via evolutionary steps. Nat. Commun. 2019, 10, 1077. [CrossRef] [PubMed]

40. Naegler, T.; Simon, S.; Klein, M.; Gils, H.C. Quantification of the European industrial heat demand by branch and temperature level. Int. J. Energy Res. 2015, 39, 2019-2030. [CrossRef]

41. Fuentes, E.; Arce, L.; Salom, J. A review of domestic hot water consumption profiles for application in systems and buildings energy performance analysis. Renew. Sustain. Energy Rev. 2018, 81, 1530-1547. [CrossRef]

42. Xue, P.; Hong, T.; Dong, B.; Mak, C. A preliminary investigation of water usage behavior in single-family homes. Build. Simul. 2017, 10, 949-962. [CrossRef]

43. Bich-Ngoc, N.; Teller, J. A Review of Residential Water Consumption Determinants. In Proceedings of the Computational Science and Its Applications-ICCSA 2018; Gervasi, O., Murgante, B., Misra, S., Stankova, E., Torre, C.M., Rocha, A.M.A.C., Taniar, D., Apduhan, B.O., Tarantino, E., Ryu, Y., Eds.; Springer International Publishing: Cham, Switerland, 2018; pp. 685-696.

44. Ürge-Vorsatz, D.; Cabeza, L.F.; Serrano, S.; Barreneche, C.; Petrichenko, K. Heating and cooling energy trends and drivers in buildings. Renew. Sustain. Energy Rev. 2015, 41, 85-98. [CrossRef]

45. International Institute for Applied Systems Analysis MESSAGE Model Regions; Laxenburg. 2013. Available online: https: / / iiasa.ac.at/web/home/research/researchPrograms/Energy/MESSAGE-model-regions.en.html (accessed on 15 January 2021).

46. United Nations Statistics Division Occupied Housing Units by Type of Housing Unit, Number of Rooms and Urban/Rural Location; Washington, DC, USA. 2020. Available online: http:/ / data.un.org/Data.aspx?d=POP\&f=tableCode\%3A278 (accessed on 15 January 2021). 
47. Alioth Finance "Inflation Calculator." U.S. Official Inflation Data. Available online: https:/ / www.officialdata.org/ (accessed on 28 January 2021).

48. Dagnachew, A.G.; Hof, A.F.; Lucas, P.L.; van Vuuren, D.P. Scenario analysis for promoting clean cooking in Sub-Saharan Africa: Costs and benefits. Energy 2020, 192, 116641. [CrossRef]

49. Overend, R.P. Biomass Energy Heat Provision for Cooking and Heating in Developing Countries. In Energy from Organic Materials (Biomass): A Volume in the Encyclopedia of Sustainability Science and Technology, 2nd ed.; Kaltschmitt, M., Ed.; Springer: New York, NY, USA, 2019; pp. 513-531. ISBN 978-1-4939-7813-7.

50. Galimova, T.; Ram, M.; Breyer, C. Air Pollution Mitigation during the Global Energy Transition towards 100\% Renewable Energy Systems by 2050. 2021. Submitted.

51. Rosillo-Calle, F. A review of biomass energy-Shortcomings and concerns. J. Chem. Technol. Biotechnol. 2016, 91, 1933-1945. [CrossRef]

52. Food and Agriculture Organization of the United Nations (FAO). Guidelines on Data Collection for National Statistics on Forest Products; FAO: Rome, Italy, 2018.

53. United Nations Statistic Division-Department of Economic and Social Affairs. Energy Balances 2012; United Nations Statistic Division-Department of Economic and Social Affairs: New York, NY, USA, 2015; ISBN 9789210613705.

54. United Nations Statistic Division-Department of Economic and Social Affairs. Energy Balances 2013; United Nations Statistic Division—Department of Economic and Social Affairs: New York, NY, USA, 2015; ISBN 9789211616071.

55. NITI Aayong. India Energy Security Scenarios 2047; Government of India: New Delhi, India, 2015.

56. Mainali, B.; Pachauri, S.; Nagai, Y. Analyzing cooking fuel and stove choices in China till 2030. J. Renew. Sustain. Energy 2012, 4 , 031805. [CrossRef]

57. FS-UNEP Collaborating Centre; UNEP Finance Initiative. Financing Household Clean Energy Energy Solutions-Mongolia; UNEP: Frankfurt, Germany; Geneva, Switzerland, 2018.

58. Forest Research Typical Caloric Values of Fuels. Available online: https://www.forestresearch.gov.uk/tools-and-resources/ biomass-energy-resources/reference-biomass/facts-figures/typical-calorific-values-of-fuels/ (accessed on 10 March 2021).

59. Kim, I.-S.; Lee, J.-Y.; Kim, Y.-P. Energy Usage and Emissions of Air Pollutants in North Korea. J. Korean Soc. Atmos. Environ. 2011 27, 303-312. [CrossRef]

60. Pachauri, S.; Rao, N.D.; Cameron, C. Outlook for modern cooking energy access in Central America. PLoS ONE 2018, 13, e0197974. [CrossRef] [PubMed]

61. Serrano-Medrano, M.; García-Bustamante, C.; Berrueta, V.M.; Martínez-Bravo, R.; Ruiz-García, V.M.; Ghilardi, A.; Masera, O. Promoting LPG, clean woodburning cookstoves or both? Climate change mitigation implications of integrated household energy transition scenarios in rural Mexico. Environ. Res. Lett. 2018, 13, 115004. [CrossRef]

62. International Renewable Energy Agency (IRENA). Renewable Energy Prospects: Mexico, REmap 2030 Analysis; IRENA: Abu Dhabi, United Arab Emirates, 2015.

63. Lopez, G.; Aghahosseini, A.; Bogdanov, D.; Mensah, T.N.O.; Ghorbani, N.; Caldera, U.; Prada Rivero, A.; Kissel, J.; Breyer, C. Pathway to a fully sustainable energy system for Bolivia across power, heat, and transport sectors by 2050. J. Clean. Prod. 2021, 293, 126195. [CrossRef]

64. Coelho, S.; Lecocq, F.; Cortez, C.; Barbier, C.; Tudeschini, L.G. Fuel Wood Consumption in Brazilian Residential Sector, Energy Consumption in Households and Carbon Footprint of Development in Selected Brazilian Regions, Comparing Brazil and France. In Proceedings of the 22nd European Biomass Conference and Exhibition, Hamburg, Germany, 23-26 June 2014; pp. 1475-1479.

65. Osorio-Aravena, J.C.; Aghahosseini, A.; Bogdanov, D.; Caldera, U.; Ghorbani, N.; Mensah, T.N.O.; Khalili, S.; Muñoz-Cerón, E.; Breyer, $\mathrm{C}$. The impact of renewable energy and sector coupling on the pathway towards a sustainable ener-gy system in Chile. 2021. Submitted.

66. Wood, S.; Rowena, C. National Energy Efficiency Monitoring Report of Guyana, Project Documents, (LC/TS.2020/27); UN: Santiago, CA, USA, 2020.

67. Gonzalez-Salazar, M.A.; Venturini, M.; Poganietz, W.-R.; Finkenrath, M.; Kirsten, T.; Acevedo, H. Bioenergy Technology Roadmap for Colombia; Universitá degli Studi di Ferrara: Ferrara, Italy, 2014; ISBN 9289401702.

68. Organización Latinoamericana de Energía sieLAC-Energy Information System of Latin America and the Caribbean; San Carlos, CA, USA. 2020. Available online: http:/ / sier.olade.org/default.aspx (accessed on 5 March 2021).

69. Wang, X.; Franco, J.; Masera, O.R.; Troncoso, K.; Rivera, M.X. What Have We Learned about Household Biomass Cooking in Central America? World Bank: Washington, DC, USA, 2013.

70. SE4ALL Rapid Assessment Gap Analysis Uruguay. Available online: https://www.seforall.org/sites/default/files/Uruguay_ RAGA_EN_Released.pdf (accessed on 5 March 2021).

71. Lapillone, B. Interpretation of household indicators. Reunión Técnica de Trabajo del Proyecto BIEE. 2014. Available online: https: / / www.slideserve.com/chin/interpretation-of-household-indicators (accessed on 15 March 2021).

72. Hof, A.; Dagnachew, A.G.; Lucas, P.L.; van Vuuren, D.P. Towards Universal Access to Clean Cooking Solutions in Sub-Saharan Africa; PBL Netherlands Environmental Assessment Agency: The Hague, The Netherlands, 2019.

73. World Bioenergy Association. Clean and Efficient Bioenergy Cookstoves; WBA Fact Sheet: Stockholm, Sweden, 2016; Available online: http:/ / www.worldbioenergy.org/uploads/Factsheet\%20-\%20Cookstoves.pdf (accessed on 25 March 2021). 
74. Stackhouse, P.W.; Whitlock, C.H. Surface Meteorology and Solar Energy (SSE) Release 6.0, NASA SSE 6.0; Langley. 2008. Available online: https: / / searchworks.stanford.edu/catalog?q=\%22NASA+Langley+Atmospheric+Sciences+Data+Center\%22\&search_ field=search_author (accessed on 24 May 2021).

75. Stackhouse, P.W.; Whitlock, C.H. Surface Meteorology and Solar Energy (SSE) Release 6.0 Methodology, NASA SSE 6.0; Langley. 2009. Available online: https:/ / power.larc.nasa.gov/docs/methodology/ (accessed on 24 May 2021).

76. WorldPop (School of Geography and Environmental Science-University of Southampton; Department of Geography and Geosciences-University of Louisville; Departement de Geographie-Universite de Namur; Center for International Earth Science Information Ne Population Counts; Southampton. 2018. Available online: https:/ /dx.doi.org/10.5258/SOTON/WP00647 (accessed on 23 April 2021).

77. The World Bank Industry (Including Construction), Value Added (\% of GDP); Washington, DC, USA, 2021. Available online: https:/ / data.worldbank.org/indicator/NV.IND.TOTL.ZS (accessed on 31 March 2021).

78. Elfring, T. The Main Features and Underlying Causes of the Shift to Services. Serv. Ind. J. 1989, 9, 337-356. [CrossRef]

79. European Environment Agency Progress on Energy Efficiency in Europe; Copenhagen. 2021. Available online: https://www.eea. europa.eu/data-and-maps/indicators/progress-on-energy-efficiency-in-europe-3/assessment (accessed on 23 April 2021).

80. International Energy Agency (IEA) SDG7: Data and Projections; Energy Intensity; Paris. 2021. Available online: https://www.iea. org/reports/sdg7-data-and-projections/energy-intensity (accessed on 6 April 2021).

81. Zhang, X.-P.; Cheng, X.-M.; Yuan, J.-H.; Gao, X.-J. Total-factor energy efficiency in developing countries. Energy Policy 2011, 39, 644-650. [CrossRef]

82. Malla, S.; Timilsina, G.R. Household Cooking Fuel Choice and Adoption of Improved Cookstoves in Developing Countries A Review; Policy Research Working Paper; The World Bank: Washington, DC, USA, 2014.

83. Goldemberg, J.; Martinez-Gomez, J.; Sagar, A.; Smith, K.R. Household air pollution, health, and climate change: Cleaning the air. Environ. Res. Lett. 2018, 13, 030201. [CrossRef]

84. Intergovernmental Panel on Climate Change (IPCC). Climate Change 2007: Synthesis Report. Contribution of Working Groups I, II and III to the Fourth Assessment Report of the Intergovernmental Panel on Climate Change; IPCC: Geneva, Switzerland, 2007.

85. The World Bank Climate Data API. Washington, DC, USA. 2021. Available online: https://datahelpdesk.worldbank.org/ knowledgebase/articles/902061-climate-data-api (accessed on 13 April 2021).

86. Verbeke, S.; Audenaert, A. Thermal inertia in buildings: A review of impacts across climate and building use. Renew. Sustain. Energy Rev. 2018, 82, 2300-2318. [CrossRef]

87. Ahmed, K.; Pylsy, P.; Kurnitski, J. Monthly domestic hot water profiles for energy calculation in Finnish apartment buildings. Energy Build. 2015, 97, 77-85. [CrossRef]

88. Möller, B.; Wiechers, E.; Persson, U.; Grundahl, L.; Lund, R.S.; Mathiesen, B.V. Heat Roadmap Europe: Towards EU-Wide, local heat supply strategies. Energy 2019, 177, 554-564. [CrossRef]

89. Guttikunda, S.K.; Lodoysamba, S.; Bulgansaikhan, B.; Dashdondog, B. Particulate pollution in Ulaanbaatar, Mongolia. Air Qual. Atmos. Health 2013, 6, 589-601. [CrossRef]

90. Zeyen, E.; Hagenmeyer, V.; Brown, T. Mitigating heat demand peaks in buildings in a highly renewable European energy system. Energy 2021, 231, 120784. [CrossRef]

91. Khalili, S.; Rantanen, E.; Bogdanov, D.; Breyer, C. Global Transportation Demand Development with Impacts on the Energy Demand and Greenhouse Gas Emissions in a Climate-Constrained World. Energies 2019, 12, 3870. [CrossRef]

92. Connolly, D. Heat Roadmap Europe: Quantitative comparison between the electricity, heating, and cooling sectors for different European countries. Energy 2017, 139, 580-593. [CrossRef]

93. European Commission (EC). Mapping and Analyses of the Current and Future (2020-2030) Heating/Cooling Fuel Deployment (Fossil/Renewables). EC: Brussels, Belgium, 2016.

94. Rehfeldt, M.; Fleiter, T.; Toro, F. A bottom-up estimation of the heating and cooling demand in European industry. Energy Effic. 2018, 11, 1057-1082. [CrossRef]

95. European Commission (EC). Eurostat Energy Balance Guide; EC: Brussels, Belgium; Luxembourg, 2019.

96. Bogdanov, D.; Gulagi, A.; Fasihi, M.; Breyer, C. Full energy sector transition towards $100 \%$ renewable energy supply: Integrating power, heat, transport and industry sectors including desalination. Appl. Energy 2021, 283, 116273. [CrossRef]

97. Kumar, L.; Hasanuzzaman, M.; Rahim, N.A. Global advancement of solar thermal energy technologies for industrial process heat and its future prospects: A review. Energy Convers. Manag. 2019, 195, 885-908. [CrossRef]

98. Lauterbach, C.; Schmitt, B.; Jordan, U.; Vajen, K. The potential of solar heat for industrial processes in Germany. Renew. Sustain. Energy Rev. 2012, 16, 5121-5130. [CrossRef] 